\title{
Large Coil Test Facility Conceptual Design Report
}

\author{
L. W. Nelms \\ P. B. Thompson \\ T. L. Mann
}




\section{DISCLAIMER}

This report was prepared as an account of work sponsored by an agency of the United States Government. Neither the United States Government nor any agency Thereof, nor any of their employees, makes any warranty, express or implied, or assumes any legal liability or responsibility for the accuracy, completeness, or usefulness of any information, apparatus, product, or process disclosed, or represents that its use would not infringe privately owned rights. Reference herein to any specific commercial product, process, or service by trade name, trademark, manufacturer, or otherwise does not necessarily constitute or imply its endorsement, recommendation, or favoring by the United States Government or any agency thereof. The views and opinions of authors expressed herein do not necessarily state or reflect those of the United States Government or any agency thereof. 


\section{DISCLAIMER}

Portions of this document may be illegible in electronic image products. Images are produced from the best available original document. 
Printed in the United States of America. Available from Natiunal Technical Information Servlce

U.S. Department of Commerce

5285 Port Royal Road, Springfield, Virginia 22161

Price: Printed Copy $\$ 7.25$; Microfiche $\$ 3.00$

This report was prepared as an account of work sponsored by an agency of the United Statos Govornmont. Noithor tho Unitod Statoo Govornment nor any' agenoy thoreof, nor any of their employees, contractors, subcontractors, or their employees, makes any warranty, express or implied, nor assumes any legal liability or responsibility for any third party's use or the results of such use of any information, apparatus, product or process disclosed in this report, nor represents that its use by such third party would not infringe privately owned rights. 
ORNL/TM-6032

Dist Category UC-20, b

Contract No. W-7405-eng-26

FUSION ENERGY DIVISION

\section{LARGE COIL TEST FACILITY \\ CONCEPTUAL DESIGN REPORT}

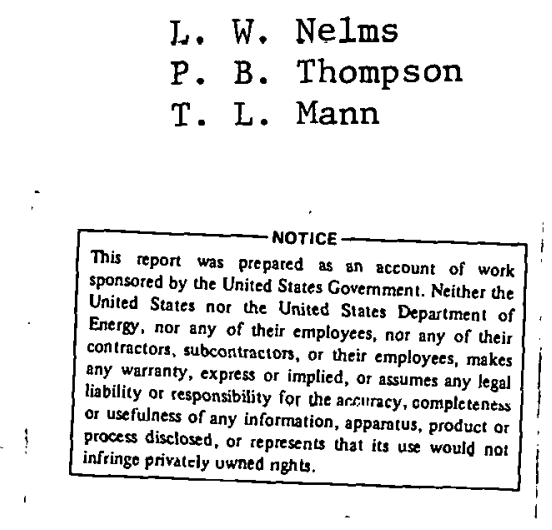

Date Published: February 1978

NOTICE This document contains information of a preliminary nature. it is subject to revision or correction and therefore does not represent a final report.

Prepared by the

OAK RIDGE NATIONAL LABORATORY

Uak Kidge, l'ennessee 37830

operated by

UNION CARBIDE CORPORATION

for the

DEPARTMENT OF ENERGY 


\section{THIS PAGE}

\section{WAS INTENTIONALLY LEFT BLANK}


TABLE OF CONTENTS

Page

ABSTRACT . . . . . . . . . . . . . . . . . . . vi vi

LIST OF FIGURES . . . . . . . . . . . . . . . . . . . vii vi

LIST OF TABLES . . . . . . . . . . . . . . . . . . . . . . ix

ACKNOWLEDGEMENTS . . . . . . . . . . . . . . . . . . . $\mathrm{x}$

1. INTRODUCTION . . . . . . . . . . . . . . . . . . . 1

2. SCIENTIFIC OBJECTIVES, TECHNICAL UNCERTAINTIES,

AND SCOPE OF THE LARGE COIL TEST FACILITY . . . . . . . . . 5

3. CONCEPTUAL DESIGN DESCRIPTION . . . . . . . . . . . . 12

3.1 INTRODUCTION . . . . . . . . . . . . . . . 12

3.2 GENERAL DESCRIPTION . • . . . . . . . . . . . 12

3.3 SIX-COIL TEST STAND . . . . . . . . . . . . 16

3.4 STAGE II FACILITY . . . . . . . . . . . . . . 19

3.4.1 Requirements . . . . . . . . . . . 22

3.4.2 General Description . . . . . . . . . . 23

3.4.3 Uncertainties . . . . . . . . . . . . 27

3.4.4 Structure... . . . . . . . . . . . . . 27

3.4.5 Electrical Power - Primary $\quad$ Distribution Requirements......... 32

3.4.6 Electrical Power - Power Supplies, Heaters, and Secondary Distribution Requirements. . . 37

3.4.7 Instrumentation Requirements. . . . . . . 38

3.4.8 Liquid Helium System. . . . . . . . . . . 45

3.4.9 Liquid Nitrogen System. . . . . . . . . . . 50

3.4.10 Vacuum System ............... . 54

3.4.11 Building Modifications. . . . . . . . . . 57

3.4.12 Dem1neralized Water System. . . . . . . . 58

3.4.13 Instrument Air System............ . 60

3.4.14 Fixtures ................ 60

3.5 STAGE III FACILITY . . . . . . . . . . . . 66

3.5.1 Requirements. . . . . . . . . . . . 66

3.5.2 General Description . . . . . . . . . . 66

3.5.3 Uncertainties . . . . . . . . . . . . 66

3.5 .4 Structure . . . . . . . . . . . . . . 70

3.5.5 Electrlcal Power - Primary Distribution ... 73

3.5.6 Electrical Power - Power Supplies and Secondary Distribution Requlrements. . . . . 75

3.5.7 Tnstrumentation ............. 76

3.5.8 Liquid Helium System. . . . . . . . . . 78 


\section{Table of Contents}

(continued)

Fage

3.5.9 Liquid Nitrogen System. . . . . . . . . 82

3.5.10 Building Modifications . . . . . . . . . . 84

3.6 STAGE IV FACILITY . . . . . . . . . . . . 85

3.6.1 Requirements. . . . . . ...... 85

3.6.2 General Description . . . . . . . . . 85

3.6.3 Pulse Coil System . . . . . . . . . . . . 85

3.6.4 Electrical Power - Primary Distribution.

3.6.5 Electrical Power - Power Supplies and

3.6.6 Instrumentation ................. 999

3.6.7 Liquid Nitrogen System. . . . . . . . . . 99

3.7 STAGE V FACILITY ............... . . . 99

3.7.1 Requirements. .............. 102

3.7.2 General Description ............ 102

3.7.3 Structure................ 102

3.7.4 Electrical Power - Primary Distribution
Requirements................ 106

3.7.5 E1.ertrical. Power - Power Supplies and
Becondary Distibution Requirements. . . . . 108

3.7.6 Instrumentation . . . . . . . . . . . 109

3.7.7 Liquid IIclium Byatcm. . . . . . . . . . 110

3.7.8 Liquid Nitrogen System. . . . . . . . . 115

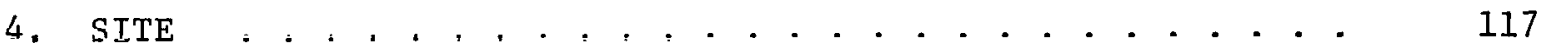

๖. SAFETY, FIRE, AND HEALTH CONSIDERATIONS. . . . . . . . . 118

5.1 SAFETY . . . . . . . . . . . . . . . 118

5.1.1 Safety Programs............. 118

5.1.2 DOE Requirements. . ........... 118

5.1.3 Industrial Safety.............. 119

5.1.4 Radiological Safety . . . . . . . . . . 119

5.1.5 Seismic Considerations. . . . . . . . . 119

5.2 FIRE PROTECTION. . . . . . . . . . . . . . 119

5.3 MEDICAL SERVICES . . . . . . . . . . . . . . 119

6. ENVIRONMENTAL ASSESSMENT ................ . . . 121

6.1 DESCRIPTION. . . . . . . . . . . . . 121

6.1.1 Facility. . . . . . . . . . . . . 121

6.1.2 Characterization of Existing Environment. . . . 121 


\section{Table of Contents}

(continued)

Page

6.2 EVALUATION OF THE ENVIRONMENTAL IMPACT . . . . .

6.2.1 Unavoidable Adverse Effects . . . . . . . .

6.2.2 Cumulative and Long-Term Environmental

6.3 KNOWN OR POTENTIAL CONFLICTS WITH STATE OR LOCAL

PROGRAMS. . . . . . . . . . . . . . . . . .

REFERENCES

DISTRIBUTION

125 
THIS PAGE

\section{WAS INTENTIONALLY \\ LEFT BLANK}


ABSTRACT

In the development of a superconducting toroidal field (TF) magnet for The Next Step (TNS) tokamak reactor, several different TF coils - abnut. half TNS size - will be built and tested to permit selection of a design and fabrication procedure for full-scale TNS coils. A conceptual design has been completed for a facility to test D-shaped TF coils, $2.5 \times 3.5-\mathrm{m}$ bore, operating at 4-6 K, cooled either by boiling helium or by forcedflow supercritical helium. Up to six coils can be accommodated in a toroidal array housed in a single vacuum tank. The chosen site is an existing building at the Y-12 Plant, Oak Ridge.

The principal components and systems in the facility are an 11-m vacuum tank, a test stand providing structural support and service connections for the coils, a liquid nitrogen system, a system providing helium both as saturated liquid and at supercritical pressure, coils to produce a pulsed vertical field at any selected test coil position, coil power supplies, process instrumentation and control, coil diagnostics, and a data acquisition and handling system.

The test stand structure is composed of a central bucking post, a base structure, and two horizontal torque rings. The coils are bolted to the bucking post, which transmits all gravity loads to the base structure. The torque ring structure, consisting of beams between adjacent coils, acts with the bucking structure to react all the magnetic loads that occur when the coils are energized. Liquid helium is used to cool the test stand structure to $5 \mathrm{~K}$ to minimize heat conduction to the coils. Liquid nitrogen is used to precool gaseous helium during system cooldown and to provide therma1 radiation shielding.

The Large Coil Program (LCP) will consist of several stages; in the conceptual design, facility construction was correspondingly broken down into stages, each of which results in augmented testing capability at an identifiable increment in cost. Coils produced and tested in the initial program will be designed for a peak fleld of $8 \mathrm{~T}$, but the facility is adaptable for tests of higher field or larger coils. 
Fig. 3.1. Pictorial facility layout.

Fig. 3.2. Test stand pictorial.

Fig. 3.3. Plan and elevation - complete six-coil array.

Fig. 3.4. Structural mounting arrangement.

Fig. 3.5. Second floor facility plan - Stage II.

Fig. 3.6. First floor facility plan - Stage II.

Fig. 3.7. Facility elevation - end view.

Fig. 3.8. Single-coil test stand.

Fig: 3.9. 15-kA vapnr-cnnle. rurrent. 1eads.

Fig. 3.10. Primary power distribution schematic - Stage 11.

Fig. 3.11. Digital data acquisition system.

Fig. 3.12. Coil diagnostic instrumentation - flow diagram.

Fig. 3.13. Liquid helium flow sheet - Stage II.

Fig. 3.14. Liquid nitrogen flow sheet - Stage II.

Fig. 3.15. Cooldown heat exchanger.

Fig. 3.16. Test tank vacuum system.

F1g. 3.17. S1ze plan.

Fig. 3.18. Demineralized water flow sheet.

Fig. 3.19. Coil lifting fixture.

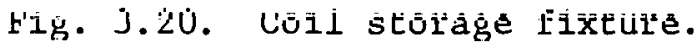

Fig. 3.21. Coil shipping fixture.

Fig. 3.22. Second floor facility plan - Stage III.

Fig. 3.23. First floor facility plan - Stage III.

Fig. 3.24. Three-coil test stand.

Fig. 3.25. Primary power distribution schematic - Stage III.

Fig. 3.26. Liquid helium flow sheet - Stage III.

FIg. 3.27. Liquid nitrogen flow sheet - Stage III.

Fig. 3.28. Second floor facility plan - Stage IV.

Fig. 3.29. First floor facility plan - Stage IV.

Fig. 3.30. Three-coil test stand with pulse coil.

Fig. 3.31. Magnitude of pulse field.

Fig. 3.32. Pulse coil current cycle. 


\section{List of Figures}

(continued)

Fig. 3.33. Pulse coil current waveform.

Fig. 3.34. Pulse coil assembly.

Fig. 3.35. Primary power distribution schematic - Stage IV.

Fig. 3.36. Liquid nitrogen flow sheet - Stage IV.

Fig. 3.37. Second floor facility plan - Stage V.

Fig. 3.38. First floor facility plan - Stage V.

Fig. 3.39. Six-coil test stand with pulse coil.

Fig. 3.40. Primary power distribution schematic - Stage V.

Fig. 3.41. Liquid helium flow sheet - Stage $V$.

F1g. 3.42. Liquid nitrogen flow sheet - Stage $V$. 


\section{LIST OF TABLES}

Table No.

1.1 Large Coil Test Facility equipment requirements by stage

3.1 Test stand requirements

3.2 Large Coil Test Facility elements - Stage II

3.3 Facility electrical loads - Stage TT.

3.4 Test coil signal conditioning

3.5 LHe requirements - six-coll array

3.6 Large Coil Test Facility elements - Stage III

3.7 Facility electrica] Inads - Stage III

3.8 LHe requirements - three-coil array

3.9 Large Coil Test Facility elements - Stage IV

3.10 Facility electrical loads - Stage IV

3.11 Large Coil Test Facility elements - Stage V

3.12 Facility electrical loads - Stage V

3.13 LHe requirements - six-coil array 


\section{ACKNOWLEDGEMENTS}

The authors gratefully acknowledge the contributions of the many people that made this report possible.

During the evolution of the facility design, the staff of the Division of Magnetic Fusion Energy, DOE, provided guidance on goals and scope. Through informal contacts and several reviews they gave encouragement, suggestions, and constructive criticism.

P. N. Haubenreich, in his capacity as Program Manager, had oversight of the planning and design and in particular contributed to the report through careful review, suggestions, and editing.

J. N. Luton, Jr. was especially helpful in delineating technical objectives and in the tailoring of the design of the facility to meet the objectives. He also helped with general review and constructive criticism of both the design and the report.

J. R. May and T. L. Ryan carried the main burden in design and analysis of the cryogenic systems. J. S. Goddard and W. M. Fletcher were primarily responsible for the diagnostic and instrumentation systems.

J. R. Moore was responsible for magnetic analyses for the various test configurations. W.C.T. Stoddart helped with structural analysis, and P. S. Litherland contributed heavily to the design and analysis of the vacuum tank and test stand.

P. B. Burn contributed much to the test stand design, both in concept and analysis. Without his special genius, the quality of the design would surely have suffered.

M. S. Lubell helped with cuncepts and objectlves. His suggestions in the early stages of design meant much.

A. M. Legg was responsible for typing and assembly of many drafts and the final text of the report. Without her cheerful diligence, it would never have been finished on time.

Finally, the authors wish to express their deepest appreciation to the many engineers and draftsmen who labored out of the limelight and whose principal satisfactions are a job well done and the respect of their colleagues. These include K. D. Cook, S. J. Sosnowski, D. R. Norris, W. E. Manrod, and J. P. Kois. 


\section{INTRODUCTION}

One of the essential steps toward the confident use of superconducting coils to produce the toroidal field in The Next Step (TNS) tokamak is testing and demonstration of reliable operation of large coils of relevant design and under conditions at least approximating those in the reactor. The Large Coil Program (LCP) at ORNL has been assigned the responsibility for accomplishing the design, fabrication, and testing of coils that are large enough to prove the design principles, materials, and fabrication techniques now being considered for TNS. The capabilities of U.S. industry are employed in the design and fabrication of test coils to meet guidelines and specifications established by the LCP.

By specification of spatial envelopes, interface dimensions, and certain basic parameters for the test coils, coils of different internal designs can be assembled to generate the magnetic field required for realistic testing. It has been determined that the LCP test coils will have a D-shaped winding bore of $2.5 \times 3.5 \mathrm{~m}$ and will operate with a conductor current of about 10,000 A at a peak field of $8 \mathrm{~T}$. Coils produced by U.S. industrial subcontractors for LCP will be brought together for testing in a facility which provides the essential environment, support systems, and services to meet the demands of the experimental program that has been determined to be necessary. (Foreign coils may also be tested in the same facility under provisions of an international energy agreement for cooperation in fusion magnet development.)

A new facility will be required to provide the framework within which LCP coils can be tested and demonstrated. Such a facility has been conceptually designed and is approved for construction in Building 9204-1, Y-12 Plant, Oak Ridge.

The coil testing program is visualized as consisting of several stages. The first coil to be delivered would be tested alone, the first three coils would be assembled for higher field tests, a pulse coil would be added, and finally six coils would be assembled in a complete torus for the most realistic testing and demonstration. Facility construction can correspondingly be broken down into several stages, each of which 
results in augmented testing capability at a clearly identifiable increment of cost.

Integrated planning of magnet development and coil testing at ORNL has defined five stages of facility construction. The first provides for testing segments of coils, $2 \times 3-\mathrm{m}$ size, that would be wound at 0 ak Ridge using various $10-\mathrm{kA}, 8-\mathrm{T}$ conductors procured on a developmental basis from industrial superconductor manufacturers. Subsequent stages of the facility, which provide for testing one, three, or six $2.5 \times 3.5-\mathrm{m}$ coils, use some of the equipment items employed in the segment tests. The stages are briefly identified as follows.

I. LCS lairge cuil seymellls, ulle aí a rlme, using existing $\mathrm{NL}_{3} 3 n$ (IlPP) culls for background flèld, in relocated ORMAK tank.

II. LCF-1 - a slingle Large coll Program coil, tested in seltfield.

III. LCP-3 - a cluster (or torus) of three LCP coils.

IV. LCP-3/F - a cluster (or torus) of three LCP coils with spparate pulse coil to provide vertical field at test coil location.

V. LCP $-6 / P$ - a torus of six LCP coils with pulse coil movable to any test coil location.

A sixth stage, which has been considered in sizing the facility vacuum vessel but has not been fully conceptualized, is a provision for testing higher field coils or up to two full-size TNS coils (twice the LCP coil size).

The first stage (segment tests) uses mostly existing equipment (the ORMAK vacuum tank and IMP coils for background fields) and items procured for the superconducting magnet base $R \delta_{i} D$ program (power supplies, helium refrigerator-1iquefier, and computer for data acquisition and control). In the second stage a vacuum tank large enough to house all subsequent tests is constructed, and additional equipment sufficient for a single coil test is procured. More equipment is added for each successive stage, as indicated in Table 1.1. 
Table 1.1. Large Coil Test Facility equipment requirements by stage

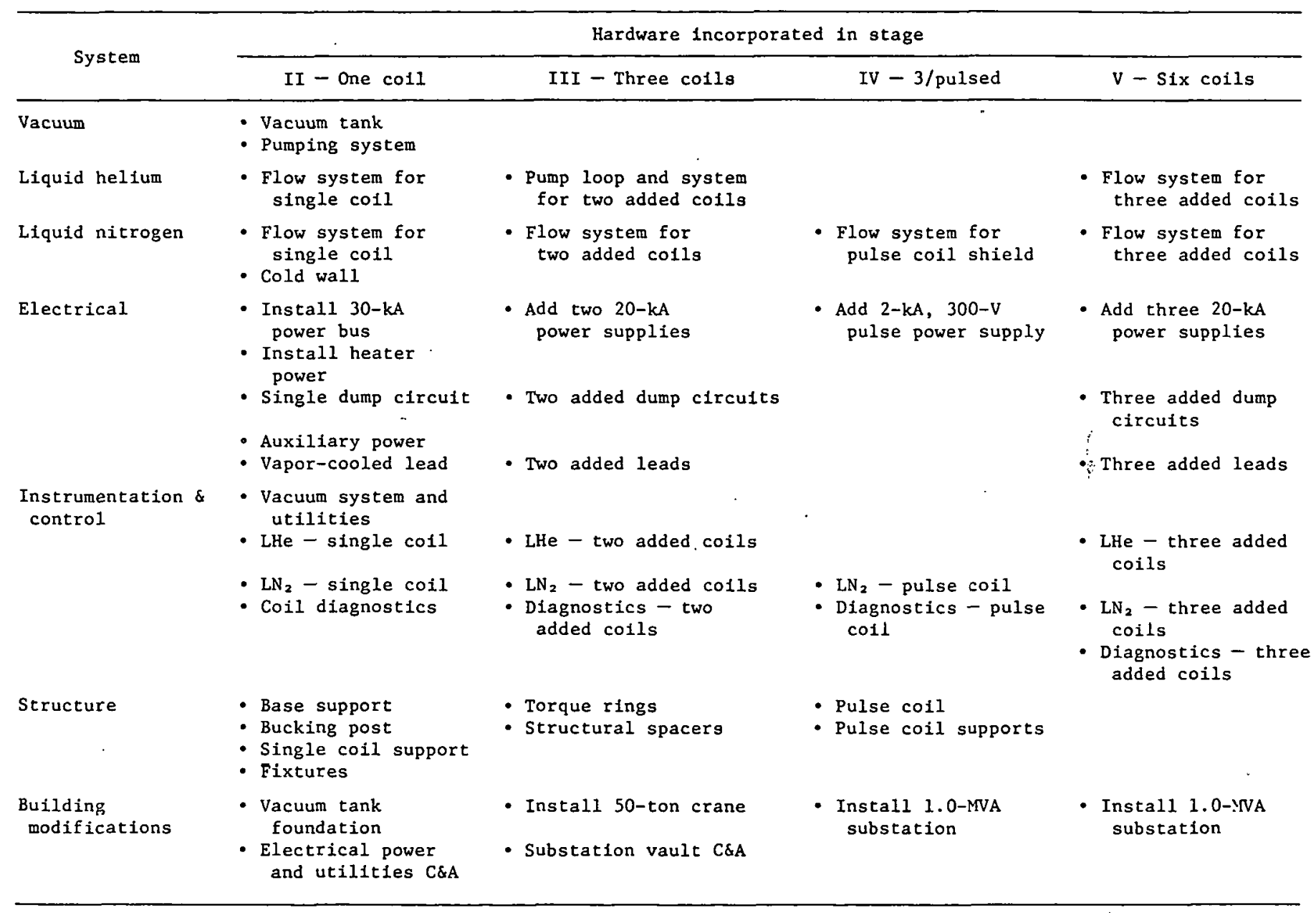


Section 2 of this document briefly summarizes the justification for the testing program and requirements which appear in more detail in the LCP Plan. ${ }^{1}$ Section 3 is an engineering description, in considerable detail, of the conceptual design of each stage of the facility. The remaining sections provide information on the site; on the safety, fire and health provisions; and on the very minor environmental impact. 
2. SCIENTIFIC OBJECTIVES, TECHNICAL UNCERTAINTIES, AND SCOPE OF THE LARGE COIL TEST FACILITY

Commercial tokamak power reactors will require confining fields of such large volume, field strength, and duration that superconducting magnets appear to be the only economic means of their production. Furthermore, conceptual studies presently in progress for TNS (The Next Step in the U.S. fusion program) indicate that probably the coils producing the toroidal confining field for that machine will also be superconducting. The toroidal field (TF) magnets in current reference designs of TNS at General Atomic and at ORNL consist of 16 to 20 coils, each having an oval or D-shaped bore of about $5 \times 7 \mathrm{~m}$, with a peak field at the windings of 8-12 $\mathrm{T}$ and a pulsed component (due to poloidal windings) of $0.05-0.2 \mathrm{~T}$.

Although both small, high field coils and large, low field superconducting coils have been successfully operated, the operating conditions and performance requirements for TNS and subsequent tokamak coils are different from - and in many ways far beyond - anything that has been accomplished so far. The history of superconducting magnets shows that when large extrapolations in size or complexity are attempted, even though they may seem straightforward, previously negligible phenomena often interfere with successful operation until the new problems are recognized and solved. The primary purpose of the U.S. Large Coil Program, therefore, is the fabrication, testing, and demonstration of reliable operation of superconducting coila that are large enough to prove the design principles, materials, and fabrication techniques proposed for the toroidal magnet of a tokamak fusion reactor and are extrapolable to TNS with a high degree of confidence. The function of the Large Coil Test Facility is to provide, in an economic and timely fashion, a framework within which such coils can be tested and reliable nperation demonstrated.

A wide variety of design concepts has been considered for tokamak reactor toroidal field coils. They employ different combinations of coolant conditions (forced and natural convection, boiling and singlephase), conductor configurations (laminated, open or snlider-fi.11e. 
cable, or braid), superconductor material ( $\mathrm{NbTi}$ or $\mathrm{Nb}_{3} \mathrm{Sn}$ ), methods of winding or installation of conductor, and ways of incorporating structural materials (holding individual turns separately, structure distributed through the winding or lumped on the outside, welded, or bolted). Because there is presently insufficient experimental or theoretical basis for choosing the best concept for reactor coils and concentrating all efforts on it, the U.S. program will carry leading candidate designs through fabrication and testing to an appropriate decision point.

The testing program will commence with coils of large conductor, moderate bore, but relatively small winding section (coil segments); progress to half-size, full-current, full-field coils; and finally lead to a single full-size TNS prototype coil. Thus, problems will be addressed early and the most appropriate design determined with minimum overall risk and cost. The first stage, the Large Coil Segments (LCS), is a part of the Superconducting Magnet Development Program (SCMDP) at ORNL and is primarily for conductor testing and development of the diagnostic and testing techniques required for later stages. The following discussion concerns the stages in which subsize $(2.5 \times 3.5 \mathrm{~m})$ coils will be tested and system operation demonstrated to such levels of confidence that the full-size TNS coils can then be designed and a prototype fabricated.

Chapter 5 of the LCP Plan ${ }^{1}$ contains a detailed treatment of the size of test coil the facility should accommodate, general requirements on coll designs, and the environment that should be produced in order to test the coil. It was concluded that the test coil requirements should bc as follows.

(1) The conductor-coolant configuration and the design heat fluxes should be the same as in the TNS coil.

(2) The design rurrent density over the winding chould be cqual to that of the full-size coil.

(3) Full-size conductor should be used.

(4) Helium pressure, pressure drop, and quality should duplicate conditions in the full-size coil. The helium temperature should be controllable from below to above the value for the full-size coil. 
(5) Radiation heating in the TNS coil should be simulated.

(6) Local heat inputs should be provided to test the coil's electrical, thermal, and mechanical responses and to measure stability margins, recovery currents, and velocities of propagation and contraction of the normal front.

(7) For test coils with cooling by forced flow down the conductor, the flow path length must be the greatest anticipated for a full-size coil, with at least two adjacent parallel paths to check their interaction.

(8) For test coils cooled by boiling a fraction of the helium, whether the circulation is entirely natural or is slightly forced to aid in bubble removal, provision must be made to simulate the effects of a full-size winding by varying the overall pressure, introducing helium of controllable quality, and energizing properly located heaters.

These test coil requirements are made specific and are treated in detail in the coil specifications that are incorporated in the subcontracts with U.S. industrial organizations for design and fabrication of coils for LCP. The complete cost specification is described by Ref. 2. The LCP Plan also concluded that the test facility should:

(1) accept test coils of $2.5 \times 3.5-\mathrm{m}$ winding bore,

(2) provide design peak field in the test coil winding when the test coil current is at design value,

(3) produce a pattern of stresses and strains in the test coil similar to that in a full-size coil of TNS,

(4) produce maximum strains in the conductor of the test coil the same as in the full-size coil,

(5) provide pulsed fields in the test coil winding equal in magnitude and ramp rate and similar in orientation to those in TNS application,

(6) provide specific stored energy of $6 \mathrm{~J} / \mathrm{g}$ in the test coil, and

(7) accommodate the test coll in a vertical plane with its longer axis vertical, as is the case for a tokamak coil. 
In short, the test facility and instrumentation within the coil will prove test coil operation and delineate design margins for relevant and extrapolable coil designs while the test coil is simultaneously exposed to all of the influences of TNS operation with the exception of neutron irradiation damage and possible effects of plasma disruption.

The test stand and ancillary systems must accommodate coils designed to produce a peak field of $8 \mathrm{~T}$. The facility must also be practically adaptable to accept $12-\mathrm{T}$ coils with moderate additional cost if the U.S. fusion program should require development of higher field superconducting toroidal magnets.

The above discussion, the LCP Program Plan, and this document all refer to the program to be carried out with the $2.5 \times 3.5-\mathrm{m}$ "Large Coils," which is encompassed by Stages II-V. Stage VI, the TNS prototype, has been considered in the conceptual design to ensure that the vacuum tank is large enough to accept (with some vertical extension) either one or two coils presently considered suitable for TNS. Further consideration of Stage VI must await resolution of questions being addressed in TNS studies.

The schedule for TNS design and construction is not yet firm, but $1 t$ is clear that experimental data from LCP coil tests will be desired at the earliest practicable date. Because the delivery dates for different coils from different manufacturers may be several months apart, we expect that there will be an incentive to test the first coil to be delivered without waiting for others. Subsequently we would expect to test three coils, and finally to test six coils in a compact toroidal array. In view of the staged manner in which test data is expected, it is appropriate to break down the facility construction into stages for approval and budgetary purposes also.

During Stage II, also called LCP-1, the facility will accept a single LCP coil cooled by pool-boiling helium and will rcstrain it against magnetic loads produced at full design current. Stage II operation will verify and shake down the basic facility (except forced-flow loop and multicoil structure), will permit full investigation of coil cooldown and warmup, and will give limited data on coil stability. In the test of an isolated coil having a D-shape selected for minimum bending when used in a toroidal array, the pattern of in-plane magnetic loads and the location of 
limiting stresses will be quite different from the toroidal case. The location of the peak field in a single D-shaped coil will be $20 \%$ in halfcircumference from the equatorial plane. For coils which prove capable. of operation at design current with the mechanical constraints provided in Stage II, the peak field will be $6 \mathrm{~T}$.

In Stage III, LCP-3, the facility will accept three coils at spacings of either $60^{\circ}$ ("cluster") or $120^{\circ}$ ("torus") and will be capable of testing them to full current either individually or as a group. In this stage a helium pump loop will be added so that one coil can be cooled with forced flow. The influence on the facility design of the decision for cluster or torus operation is only on the selection of the stations at which coil cooling is provided with a slight saving in plumbing runs in Stage III for the cluster configuration. Torus operation would test the coils symmetrically, and therefore equally, without the necessity of changing coils from one location to another. The maximum field in this case with all coils at design current would be $6.6 \mathrm{~T}$. A higher field at one coil might be achieved in the cluster arrangement, provided the out-of-plane forces which are developed in the outer coils are not limiting. If the two outer coils can be run at $80 \%$ of design current while the center coil is at full current, then the center coil will see $7.4 \mathrm{~T}$ and the end coils $5.7 \mathrm{~T}$. The cluster arrangement has been chosen for the reference conceptual design and planning purposes. The program schedule probably will not allow time for moving a coil for testing in another location in the cluster. Thus, by the end of Stages II and III, three coils of different designs will have been tested separately to full design current and $6 \mathrm{~T}$, two of these will have been tested to $5.7 \mathrm{~T}$ with severe out-of-plane loads, and one will have been tested to $7.4 \mathrm{~T}$ with no out-of-plane loading. In Stage IV, or LCP $-3 / P$, a coil pair with vertical axis is suspended inside the bore of the central toroidal field coil to provide a pulsed vertical field. The center coil would then be tested in a pulse field to determine the pulse losses and to see the effects of the internal conductor heating and the large overturning moment produced by the pulse field on coil performance and stability. 
In Stage V, called LCP-6/P, the six-coil compact torus will be completed and the pulse coil moved to other coils of interest for pulse testing. Successful operation of LCP $-6 / P$ would be a demonstration and a systems test of torus operation at full current, field $(8 \mathrm{~T})$, and stored energy $(615 \mathrm{MJ})$. For the first time, the location of the peak field will have moved to near the torus equatorial plane, and TNS field distribution, coil shape, and stress magnitude and pattern will be simultaneously approximated. Coil and system stability and protection will be thoroughly investigated in tests at this stage. LCP-6/P will also be capable of "extended tests"; if all coils should prove capable of simultaneous operation at design current, each could be exposed to a peak field of 8.6 ' 1 '. 'lesting with $L C F-6 / P$ should be flexible and conventent: all test parameters except the selection of the coil to be exposed to the pulse tield can be varied at wili ejectricically without warming the cest stand. In this stage there is less dependence on successful operation of all test coils, since the torus design permits five of the coils to operate at only $80 \%$ of their design current while only the coil being tested at the moment is operated at full current. Furthermore, if one coll is not delivered on schedule, or fails completely, the test coil field is reduced by only 0.2 to $1.0 \mathrm{~T}$ (depending on coil position). Fatigue and endurance testing can be carried out on a routine bosio. Succcooful teoting of coils in LCP-6/P would give full confidence that larger coils of the same design would be suitable for operation in an 8-T TNS and would delineate the environmental limits within which they could perform.

As indicated in Ref. 3, the stage VI facility could accommodate various scenarios of high field coils without disturbing the remaining 8-T coils. Ref. 3 includes a tabulation indicating the 11- and 12-T arrangements which can be fitted inside the selected 11-m tank; in none of these cases is the current-field requirement on the 8-T coils inconsistent with their predicted capabilities. Testing of high field coils would require modification of the torque rings of the structure and an improvised hoisting fixture. Eight-T coils with $\mathrm{Nb}_{3} \mathrm{Sn}$ conductor could be utilized at any stage of the facility. 
It would also be feasible to test TNS coils in Stage VI. Again, as shown in Ref. 3, if we assume that the presently envisaged TNS coil dimensions do not change drastically, then there exist at least two test arrangements, using only LCP and TNS coils, which will test the TNS coils to full field. A new support structure and a vertical extension to the tank are required, but the use of the then-existing coils, power supplies, vacuum system, and $11-\mathrm{m}$ tank would give a much simpler and less expensive test than if the Stage $V$ facility were not available. One of the two preferred test arrangements will test a single TNS coil and should be useful for tests on a prototype coil. The other arrangement will test two coils at once and, particularly if the refrigerator is upgraded, should be suitable for testing of the production coils before they are installed in TNS.

In contrast to the test coils, there appears to be no major technical uncertainty in the design, fabrication, and operation of the test facility. The only advanced technology equipment required is in the refrigeration system (primarily the liquid helium pump loop for forcing coolant through those coils which are designed to be cooled with supercritical helium); the vapor-cooled leads, and selected coil diagnostic instrumentation. Commercial equipment with the required capability for this loop is being procured for use in fusion development at Oak Ridge and will be proven by the time it is needed for the Large Coil Test Facility. Nevertheless, the facility is unusual in comparison with other facilities of similar nature and size in that a quite minimal amount of redundancy has been provided. 


\section{CONCEPTUAL DESIGN DESCRIPTION}

\subsection{INTRODUCTION}

The conceptual design of the test facility described in this section is based on the fundamental requirements, Identified in Sect. 2, for testing large superconducting coils under conditions anticipated in an ignition tokamak environment. A general description of the ultimate six-coil facility is given first. Subsequent sections give detailed descriptions of the facility elements required for each stage and the modifications that are incorporated at each succeeding stage.

The Large Cuil Test Failily ls Lu be lucaled lin Bullding 9204-1, Y-12 Plant, Oak Ridge, adjacent to the existing Superconducting Magnet Development Program Laboratories. It will include the vacuum, electrical power, cryogenics, cooling water, and data handling systems and the specialized support equipment integral to the coil tests. (This last category includes items such as the support structure, pulse coils, and vaporcooled leads.) The facility is designed to be capable of:

- testing combinations of pool-builing and forced-flow cooled coils,

- selecting any coil within a particular array as a specified full-current test coll (warmup of the oyotem and interchange of hardware are required for testing different coils in a pulse field), and

- practical modification to test higher field (up to 12-T) coils.

\subsection{GENERAL̇ DESCRIPTION}

The following summary description covers the total test facility as it would appear at the final testing stage with a complete six-coil array.

The complete facility is depicted in Fig. 3.1. A new 11-m-diam bv 12-m-high cylindrical vacuum chamber, located in an existing building, houses the coil test stand, which is coupled to appropriate cryogenic, electrical, vacuum, instrumentation, and diagnostic systems. Adequate assembly/disassembly areas, shop space, test control center, offices, and test support laboratories are provided in the same building. Assembly and installation operations are accomplished with a 50-ton overhead crane. 


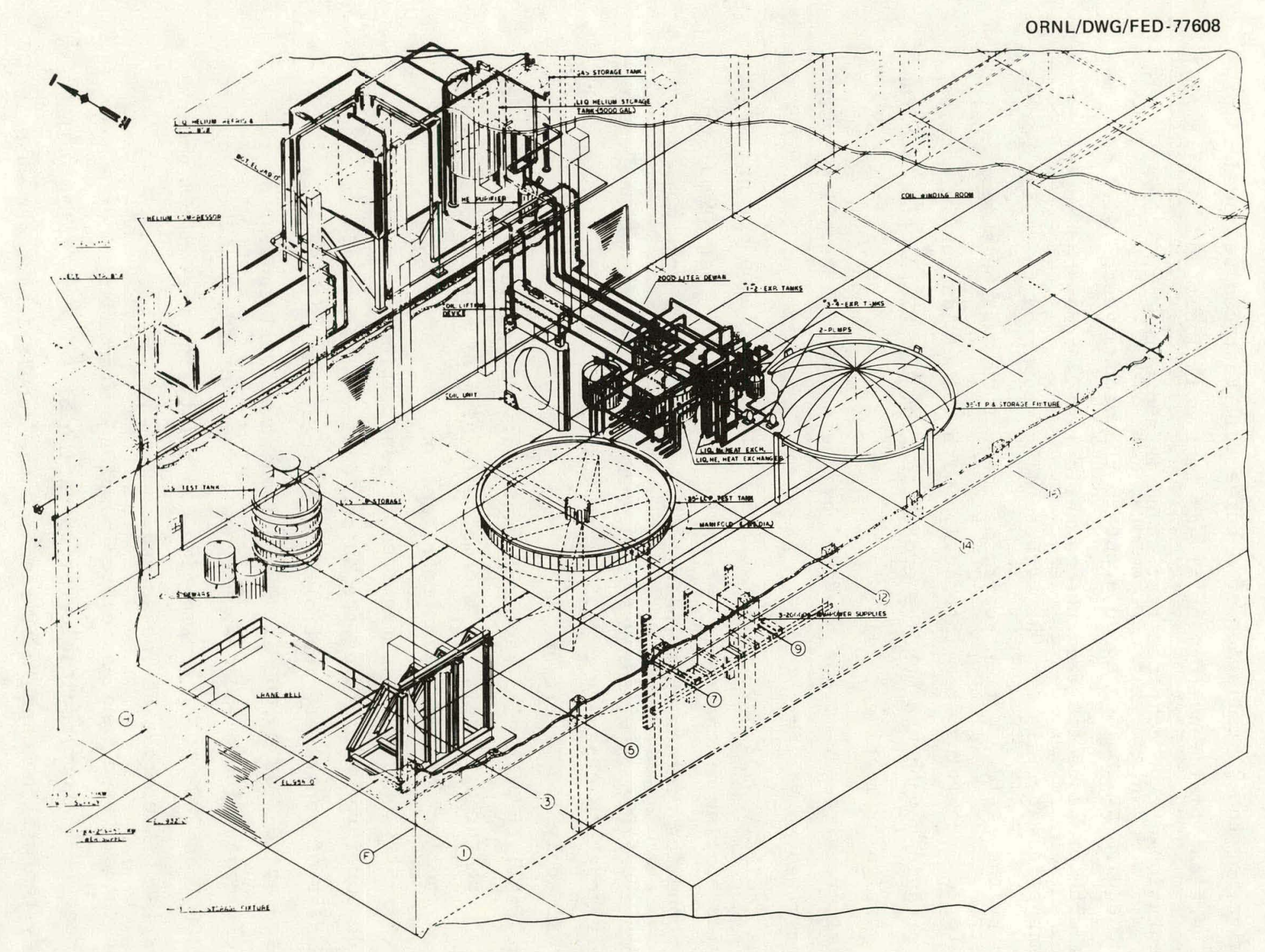

Fig. 3.1. Pictorial facility layout. 
The test stand structure within the vacuum tank is designed to support a toroidal array of six $8-T$ test coils. Provisions are included in its design for the installation of a pulse coil that can be moved to provide a vertical field environment at any test coil location. A pictorial representation of the complete test stand is shown in Fig. 3.2.

The equipment inside and adjacent to the vacuum vessel will be compatible with or protected from the magnetic fields generated during testing. Magnetic materials must be structurally supported to resist forces exerted by the fields, current-carrying conductors must be supported to resist forces resulting from interaction with the fields, and electrical and electronic components must be protecter from the field effects either through design or local shielding.

Basic requirements to be provided by the supporting facility systems are summarized as follows.

The facility will have helium refrigeration and liquefaction capacity to provide cooling of the coils, electrical leads, and test stand structure. Economics dictate that the helium system be of a closed-loop, recirculating type. The liquid helium supply will have a nominal equivalent refrigeration capacity of $1.5 \mathrm{~kW}$ at $4.2 \mathrm{~K}$ and liquefaction capacity of approximately 120 liters/hr.

The facility will also have the capability of providing liquid nitrogen on a once-through basis for thermal shielding of helium-cooled surfaces and cooling for the helium refrigerator.

Steady-state dc power is required for energizing the test coils and pulsed dc power for energizing the pulsed coils. The steady-state power will consist of separately controllable sources, including one existing unit rated at $20 \mathrm{~V}$ at $30,000 \mathrm{~A}$. The pulsed power will consist of two separately controllable sources, one new and one existing unit, each providing $300 \mathrm{~V}$ at $2000 \mathrm{~A}$. 'l'he ramp-time capability for the pulsed power supplies is on the order of one second.

The vacuum vessel and associated pumping system must provide an environment ( $10^{-4}$ torr) suitable for operation of the test coils. The vacuum system will be capable of reaching the required base pressure in less than eight hours. At the base pressure of $10^{-4}$ torr, the vacuum 
ORNL/DWG/FED - 77601

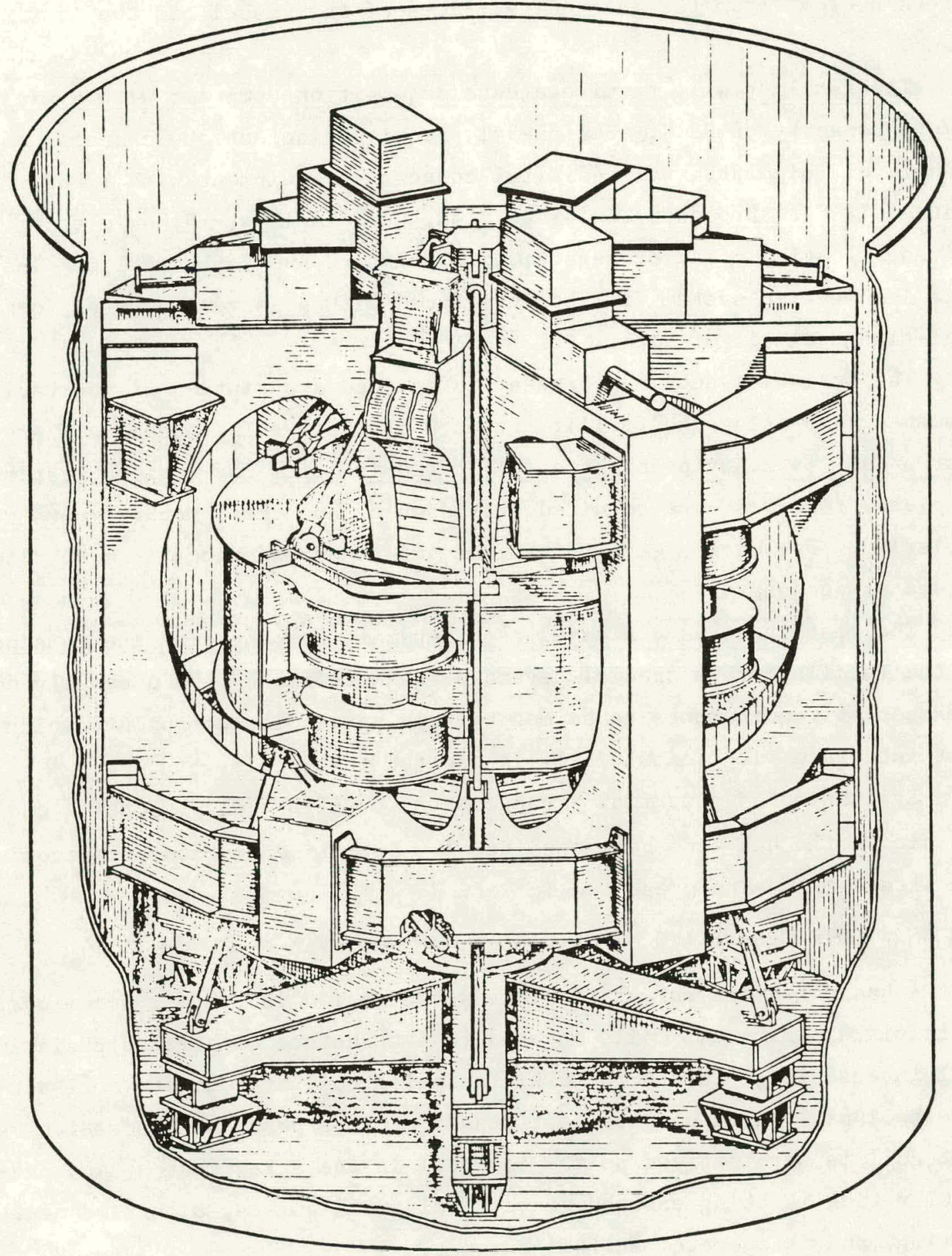

Fig. 3.2. Test stand pictorial. 
system will be capable of pumping an expected outgassing rate of $10^{-7}$ torr liters $/ \mathrm{sec} / \mathrm{cm}^{2}$ from the internal surfaces of the vessel and the test stand.

The facility will require a data acquisition computer with a minimum memory capacity of $32 \mathrm{~K}$. Peripherals required include 500 channels of high level, bipolar, analog-digital conversion equipment with $1 \mathrm{kHz} /$ channel 12-bit throughput, storage disk, CRT displays, magnetic tape drives, floating point processor, line printer, and keyboard I/O. The data acquisition system will be interfaced with a larger computer for real-time analysis of data.

The following sectiong present a detailed descilpliun of Lhe various elements comprising the facility at each of the testing stages. Where appropriate, a description of specific requirements for a given system is given, followed by a detailed breakdown of how these requirements were satisfied. Evaluation of alternatives and recommendations is also discussed as necessary.

The test stand is discussed as a separate element from the remainder of the facility; this special coverage is justified by the unusually complex set of requirements to be met by this particular component, which must interface with industrially fabricated test coils.

Evaluation of potential arrangements for high field LCP coils and TNS size coils has also been considered. Details on various trade-offs and alternatives are presented in Ref. 3.

\subsection{SIX-CULL 'I'E'S'I' S"I'AND}

A basic requirement of the test stand design is that it accommodate up to six experimental coils mounted to a structure capable of resisting coil interaction. This structure, the pulse coil system, and coil service hookups, constitute the test stand. For purposes of discussion, a test coil is here defined as the one coil in the array that at any particular time is being exposed to vertical field pulses, simulated neutron heating, and is operated at full current.

Specific requirements used in defining the test stand array and the test $\operatorname{coil}^{2}$ were determined from current TNS studies. Both pool-boiling 
and force-cooled toroidal field coils must be accommodated simultaneously. The tests must duplicate, approximate, or simulate important conditions anticipated in an ignition tokamak.

To be duplicated:

- maximum toroidal field of $8.0 \mathrm{~T}$,

- coolant conditions required for stability under specified operating conditions, and

- design heat flux generated by the thermal and magnetic environment.

To be approximated:

- pulsed fields imposed by poloidal windings and plasma,

- elastic support boundary of support structure elements,

- operating modes anticipated in a reactor, and

- failure events anticipated in actual operation.

To be simulated:

- thermal surroundings of a tokamak,

- radiation heating, and

- pulsed cycles anticipated in reactor operation.

In addition to the above conditions based on TNS criteria, the testing must minimize the direct influence between coils of different design concepts and between the facility and test coils.

The initial planning for the Large Coil Program produced a set of basic criteria for the test coils, test stand, and facility. A series of parametric studies resulted in a decision to test at least three different coil designs in a toroidal array. The most significant tests would require a complete torus of six coils, so the stand has been conceived as a six-coil array with the requirements listed in Table 3.1 .

The test stand will sit on the floor of the 11-m-diam, flat-bottom cylindrical vacuum vessel. Between the vessel floor and test stand there will be a roller pedestal, maintained at a temperature of $80 \mathrm{~K}$, to limit heat transfer and allow for displacements. The entire vessel will be lined with a liquid nitrogen-cooled thermal shroud to limit the radiation heat transfer to the equipment at $4 \mathrm{~K}$ to less than $25 \mathrm{~W}$. The instrument conduits, supply and return lines, and gravity supports will be designed 
Table 3.1. Test stand requirements

\begin{tabular}{ll} 
Number of TF coils & 6 \\
Major radius & $2.27 \mathrm{~m}$ \\
Coil bore (clear opening) & $2.35 \mathrm{~m} \times 3.35 \mathrm{~m}$ \\
Maximum toroidal field & $8 \mathrm{~T}^{\mathrm{a}}$ \\
Peak pulsed field & $0.2 \mathrm{~T}$ \\
Number of coils exposed to pulsed field & $1 \mathrm{~min}$. \\
Number of colls heated & $1 \mathrm{max}$. \\
Number of coils at full design current & $1 \mathrm{~min}$. \\
Number of coils at $80 \%$ design current & $5 \mathrm{max}$. \\
Design current & $10-1.5 \mathrm{kA}$ \\
Number of pool-boiling coils & $4 \mathrm{max}, 2 \mathrm{~min}$. \\
Number of force-cooled coils & $4 \mathrm{max}, 2 \mathrm{~min}$. \\
\hline
\end{tabular}

$a_{\text {There }}$ is also a requirement for $12-\mathrm{T}$ peak field testing. The 12-T mode of operation is discussed in Ref. 3.

with high thermal resistance paths to liquid helium and liquid nitrogen interfaces to minimize conductive heat transfer to the TF coils. Heat transfer across these interfaces will be approximately $100 \mathrm{~W}$ at steadystate conditions. The bucking post will have its own pool-boiling liquid helium circuit to dissipate conductive heat transferred from the pulse coil supports as well as a small amount of eddy current heating induced in the structure during testing.

As the test stand must accommodate from one to six coils that are as structurally independent as possible, a set of structural spacers was defined to provide a full complement of structural pieces regard1ess nf the number of actual coils.

Several structural concepts were evaluated to meet the requirement for isolating each coil while minimizing heat leaks to the helium system and accommodating the out-of-plane forces produced by the pulsed field. These alternatives are discussed in Ref. 4 . 
The pulsed field is produced by a pair of coil windings suspended in the bore of the test coil, as shown in Fig. 3.3; both sections together constitute one pulse coil. The concept illustrated shows a forced-flow, water-cooled coil suspended from the bucking post by two-force members and also supported off the base structure with another two-force member. The criterion for design of pulse windings was to approximate the TNS pulsed environment. A detailed discussion of the pulse coil design and alternatives is presented in Ref. 5 .

The structural interfaces consist of the attachment points for the coil support structure. The support structure will consist of a bucking structure in the center of the coil array, a base structure, and two segmented torque rings around the outside of the toroidal coil array, as described by Fig. 3.4. A more detailed description of each of these elements is presented in the section pertaining to use of a particular item as part of a specific test stage.

\subsection{STAGE II FACILITY}

The following sections present a detailed description of the systems comprising the test facility required to support testing in Stage II of the program. Each system has been developed to be consistent with the defined requirements, keeping in mind the needs of subsequent stages. Special attention has been paid to design approaches which are essentially modular to allow for the planned augmentation of facility capabilities as the program develops. A summary of the test facility hardware elements required to support Stage II is presented in Table 3.2.

The problems and permutations associated with providing for power, coolant, instrumentation, and data handling for a test coil array consisting of an unknown combination of different coils are reflected in the seeming complexity of these supporting systems. Design concepts which satisfied the defined requirements were derived from detailed flow sheets which identified each function as a specific hardware requirement. Analyses to size lines and operational sequences to define valving and controls received particular emphasis. Again, attention was given to the development of modular concepts which could be modified and evaluated relative to cost impact and programmatic changes. 


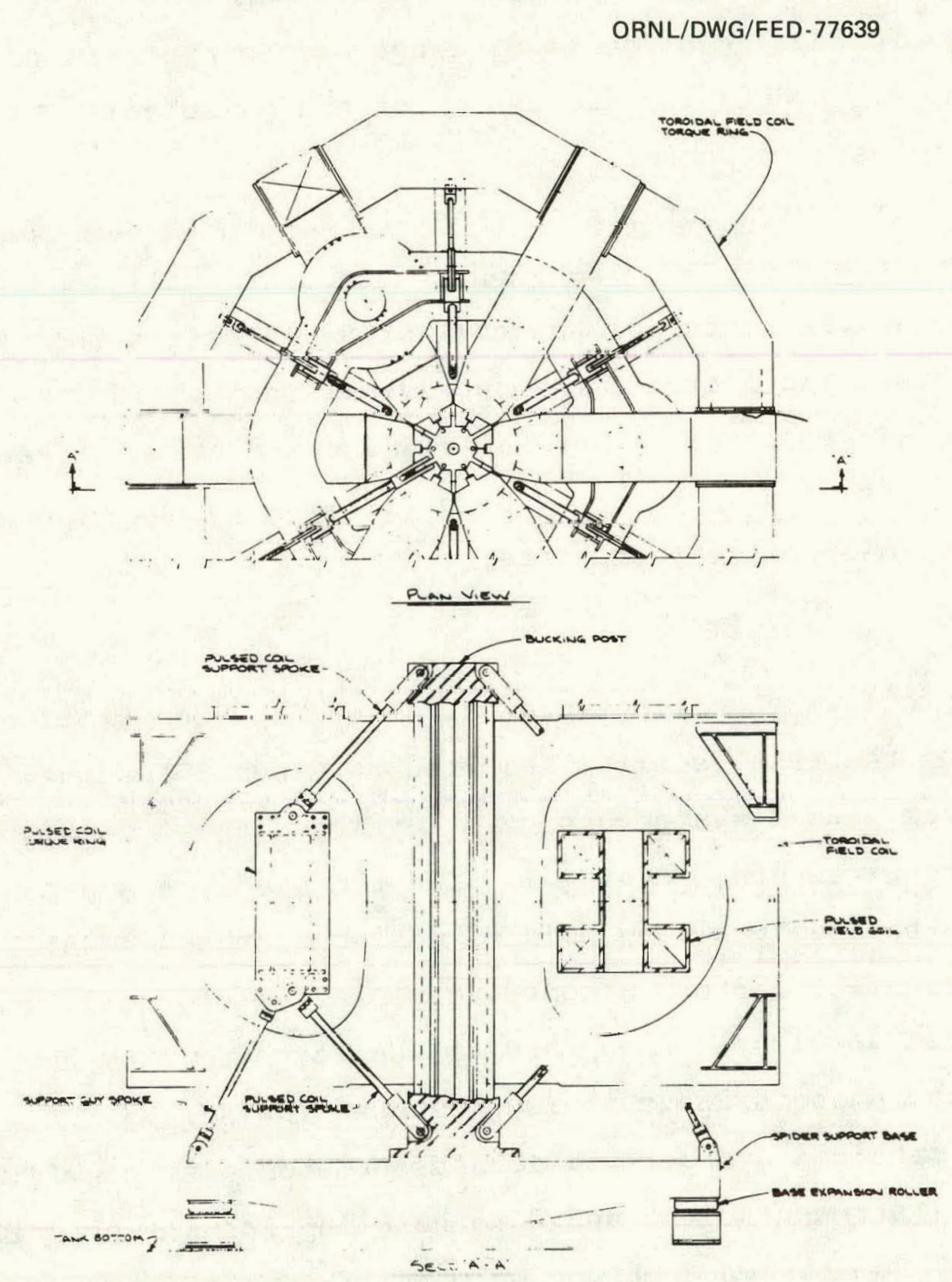

Fig. 3.3. L'lan and elevation complete six-coil array. 

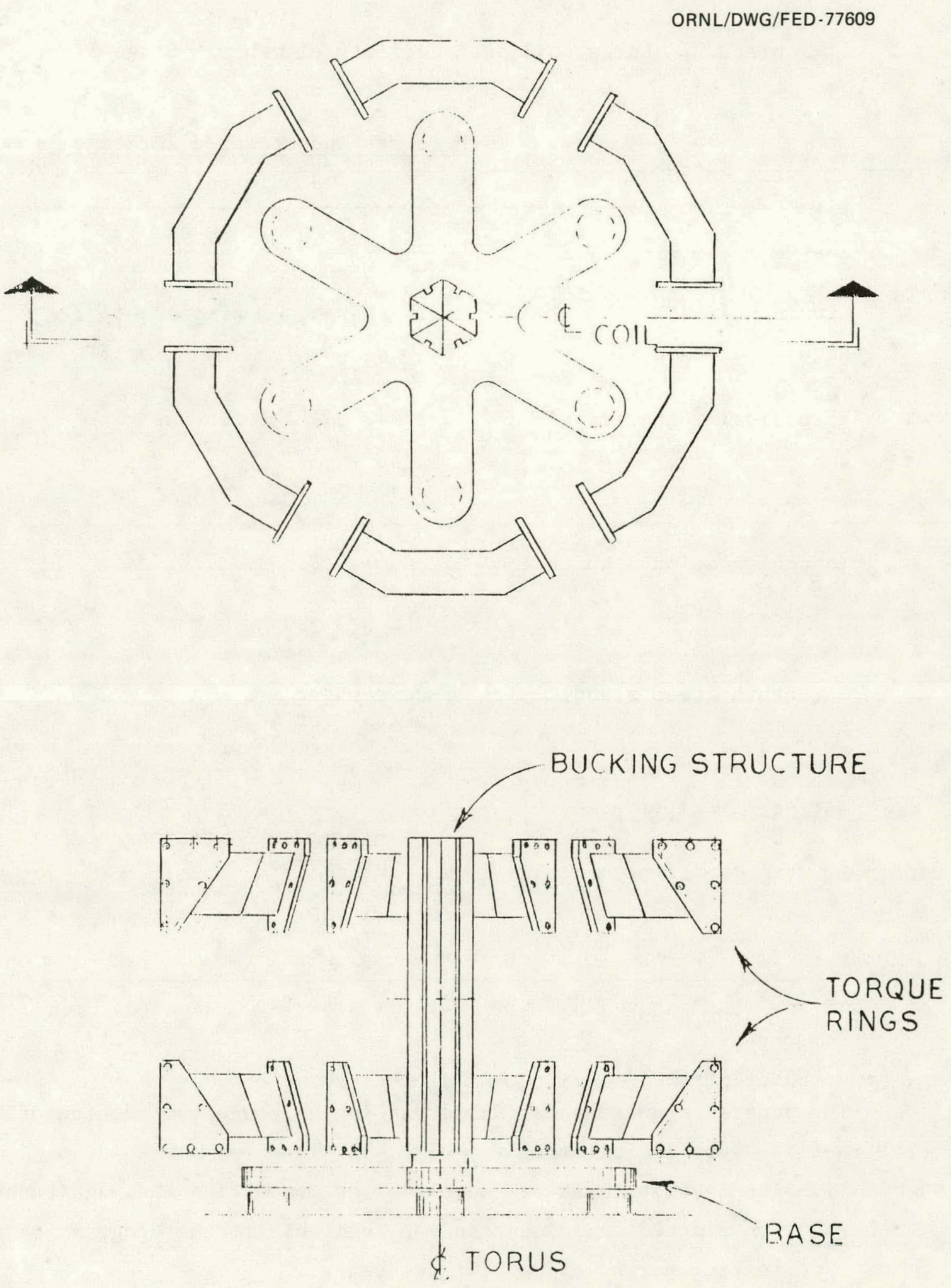

Fig. 3.4. Structural mounting arrangement. 
Table 3.2. Large Coil Test Facility elements - Stage II

Hardware incorporated in Stage II

System

Single coil

\begin{tabular}{|c|c|}
\hline Vacuum & $\begin{array}{l}\text { Vacuum tank } \\
\text { Pumping system }\end{array}$ \\
\hline Liquid helium & Flow system for single coil \\
\hline Liquid nitrogen & $\begin{array}{l}\text { Flow system for single coil } \\
\text { Cold wall }\end{array}$ \\
\hline Electrical (experiment) & $\begin{array}{l}\text { Install 30-kA Power bus } \\
\text { Install heater power } \\
\text { Single dump circuit } \\
\text { Auxiliary power } \\
\text { Vapor-cooled lead }\end{array}$ \\
\hline \multirow[t]{2}{*}{ Instrumentation \& control } & $\begin{array}{l}\text { Vacuum system \& ulizities } \\
\text { LHe - single coil }\end{array}$ \\
\hline & $\begin{array}{l}\mathrm{LN}_{2} \text { - single coil } \\
\text { Coil diagnostics }\end{array}$ \\
\hline Structure (test stand) & $\begin{array}{l}\text { Base support } \\
\text { Bucking post } \\
\text { Single-coil support } \\
\text { Pixtures }\end{array}$ \\
\hline Building modifications & $\begin{array}{l}\text { Vacuum tank foundation } \\
\text { Electric power \& utilities C\&A } \\
\text { Fire protection } \\
\text { Upgrade 13.8-kV tie Iine } \\
\text { Install 1.5-MVA substation } \\
\text { Utilities }\end{array}$ \\
\hline
\end{tabular}

\subsubsection{Requirements}

The general requirements considered in the conceptual design of the LCP facility were as follows.

1. The facility must be capable of accommodating the magnitude of the planned experiment and be available to the program for a testing period of up to three years. 
2. The facility design is to support the test program for the first coil procured by UCC-ND under specification TS-14700-01, Rev. A (Ref. 2).

3. The facility design is to include the option for eventual installation of one or more high field (12 $\mathrm{T})$ coils in the final six-coil array and up to two TNS size coils in an independent structural array.

\subsubsection{Description - General}

The site selected for this facility, Building 9204-1, in the Y-12 plant, meets the first requirement above. Plan and elevation views of the proposed installation are shown in Figs. 3.5, 3.6, and 3.7. The west half of the building, which is assigned to the Fusion Energy Division, ORNL, is large enough for all the required structures and systems and is available for the period that includes the projected construction phase and test program. Two of the necessary subsystems for the Large Coil Program are currently in the design and procurement phase. These two subsystems are:

1. procurement and installation of a liquid helium refrigerator, and

2. installation of the major portion of a demineralized water system.

Other aspects of the building must be upgraded and modified to support the Large Coil Program. These areas are discussed in the following paragraphs.

In order to satisfy the second requirement, all of the conceptual system designs and building modifications identified in the detailed discussions are based on criteria derived from the coil specification. The facility will provide all the necessary support functions and interfaces for the coil. These systems are discussed in the following sections.

The third requirement (high field option) has been addressed by the selection of a 11-m-diam vacuum vessel. This size vessel allows room for the eventual installation of high field coils and TNS size coils as discussed in Ref. 3. 


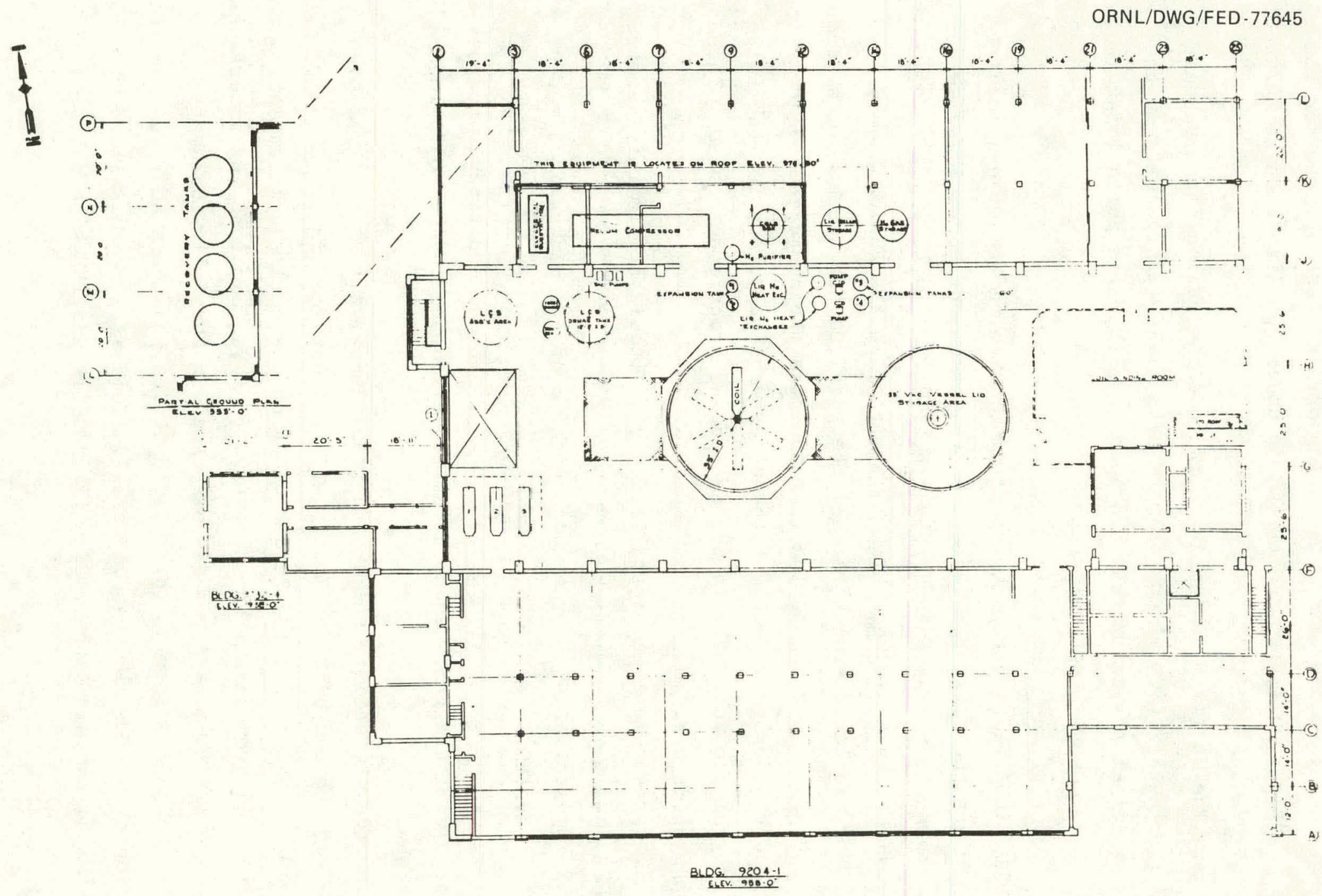

Fig. 3.5. Second floor facility plan - Stage II. 


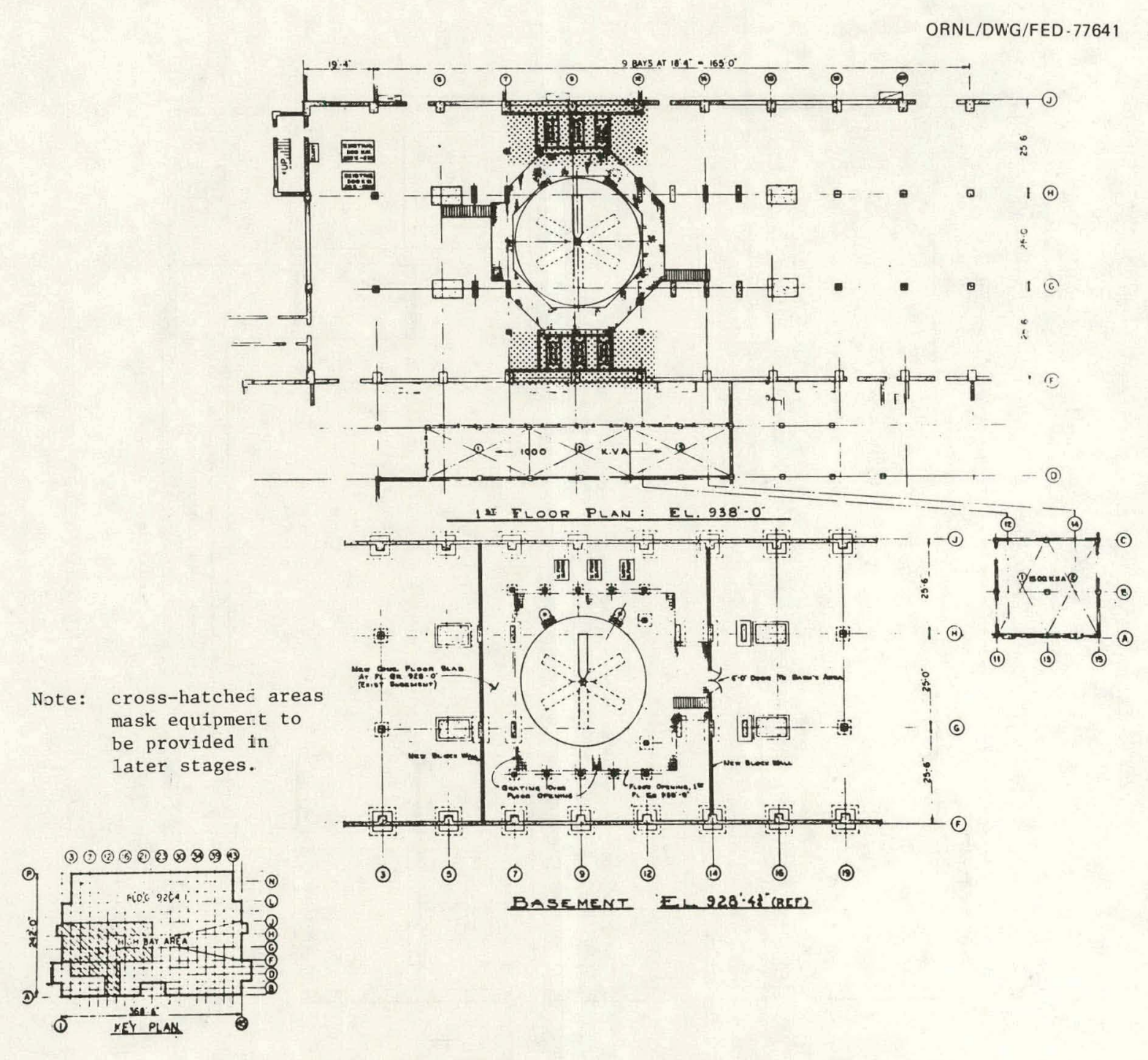

Fig. 3.6. First floor facility plan - Stage II. 
ORNL/DWG/FED-77610

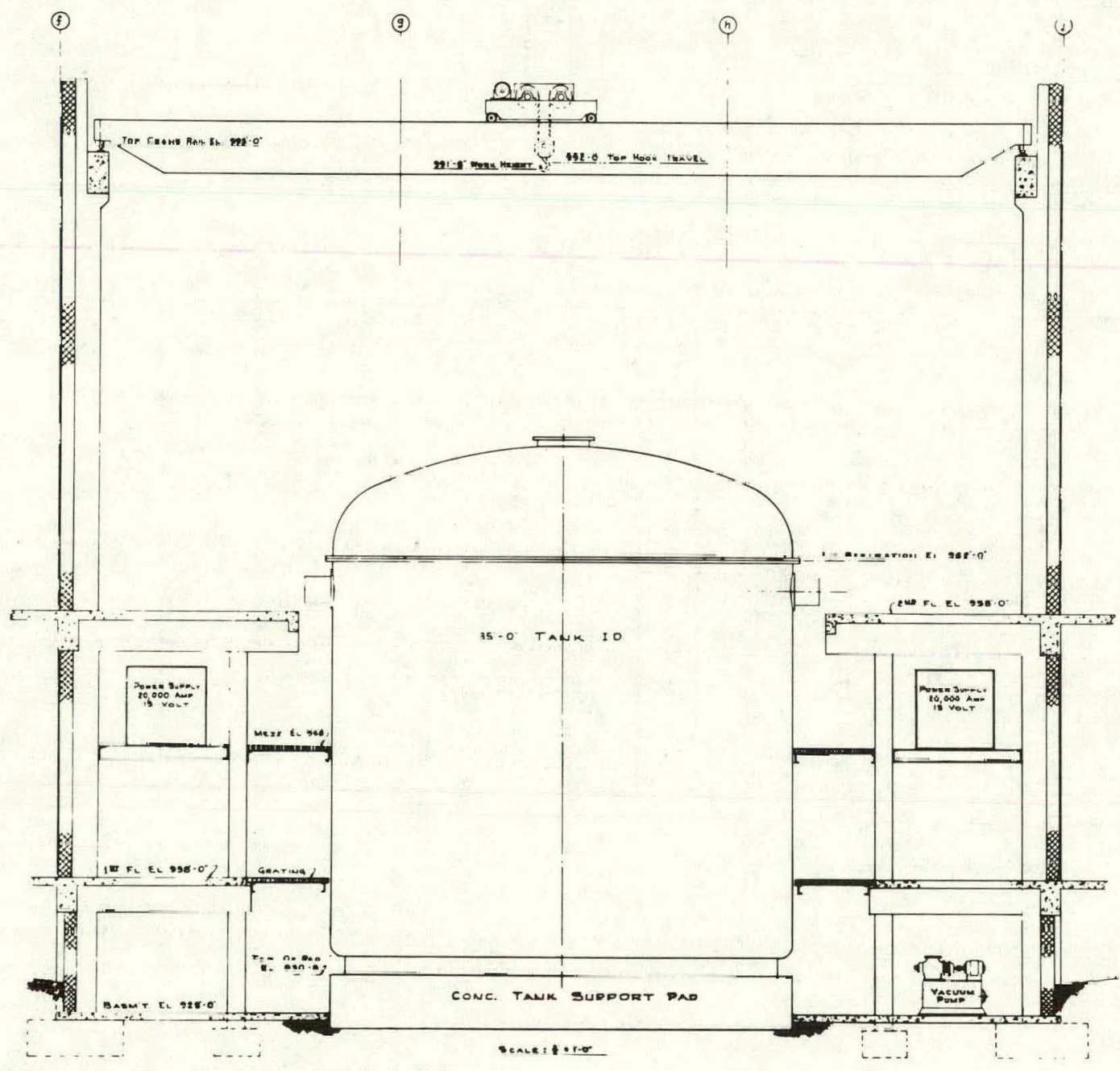

Tig. 3.7. Facility elevation - end view. 
The facility cryogenic systems designs have not considered the high field options, since sufficient information is not available about thermal performance associated with these units to make meaningful evaluations. It is recognized that additional liquid helium capability will probably be required to support a high field option. This determination is based on the now marginal ability of the current refrigerator installation to support the maximum six-coil array of 8-T units.

\subsubsection{Uncertainties}

There are three major aspects associated with the Large Coil Program that qualify as development areas. These development areas are:

(1) Vapor-cooled-leads - It is planned that the interface between the superconductor and the room temperature bus will be bridged by a helium vapor-cooled lead. This design has been specified as part of the facility to reduce the scope of the coil designs and provide a single design point. These leads also provide a common interface with the facility which can be properly planned for and separate coolant supply provided without affecting the facility's ability to provide the required cryogens to the coils themselves.

(2) Liquid helium refrigerator - There is little experience available on the operation of liquid helium refrigerator systems comparable to the one envisioned for use with the LCP facility. It is recognized that it will take substantial effort to make this helium system work reliably over lengthy testing periods.

(3) Instrumentation - Several of the sensors required for installation and usc at high magnelic fields and cryogenic temperatures are currently unavailable. The LCTF will use equipment for this service which is being developed under the SCMDP at ORNL. It is also expected that software required for the LCTF instrumentation data acquisition system will be developed by the program in the course of testing large coil segments. 3.4 .4 Structure

Requirements

Stage II testing requires a support structure to hold a single coil with sufficient structural restraints to permit operation at full design current. 


\section{Description}

A conceptual design for a single-coil test stand support structure is shown in Fig. 3.8. Bolted attachments at both ends of the nose section and full bearing support along the length of the nose closely duplicate the restraints of the bucking post in the toroidal array.

For the single-coil test facility to be workable from a stress point of view, either the current level must be kept below $60 \%$ or the singlecoil support structure must provide restraint at the torque ring interface. Adding restraint at the torque ring interface can be accomplished with an arrangement as shown. This structural arrangement will require further analysis before it can be shown to be fully effectivc.

The interfaces for the single-coil test stand cunsist of the attachment points for the coil support structure, coolant ports, and electrical leads.

The support structure will consist of a bucking structure in the center of the coil array, a base structure, and tie-rods with adapter structure to simulate reactions normally provided by the torque rings around the outside of the toroidal coil array.

The coolant interface will provide connections for both coil condurtor and coil structure coolant. For the pool-boiling coil, a coolant reservoir will be attached at the appropriatc coil interface alnng with a low point fill line (or optional inlet).

The electrical interface consists of a coil current lead connection, instrumentation connections, and coil heating element connections.

The coil current will be supplied through a hclium vapor-cooled current lead assembly (Fig. 3.9) attached to the vacuum vesse1. Superconductor will be used from the coil interface to the current lead assemb1y. The current lead assembly will be universal in the sense that this Interface is compatible for use with both the pool-boiling and subsequent forced-flow coils. The lead assembly will have a helium reservoir separate from the coil coolant, and the vapor-cooled section will be matched with the coil design current to minimize the helium boiloff.

The current leads will be of the thermal inertia type to allow a safe discharge of the coil if the lead coolant is lost. 
ORNL/DWG/FED-77611

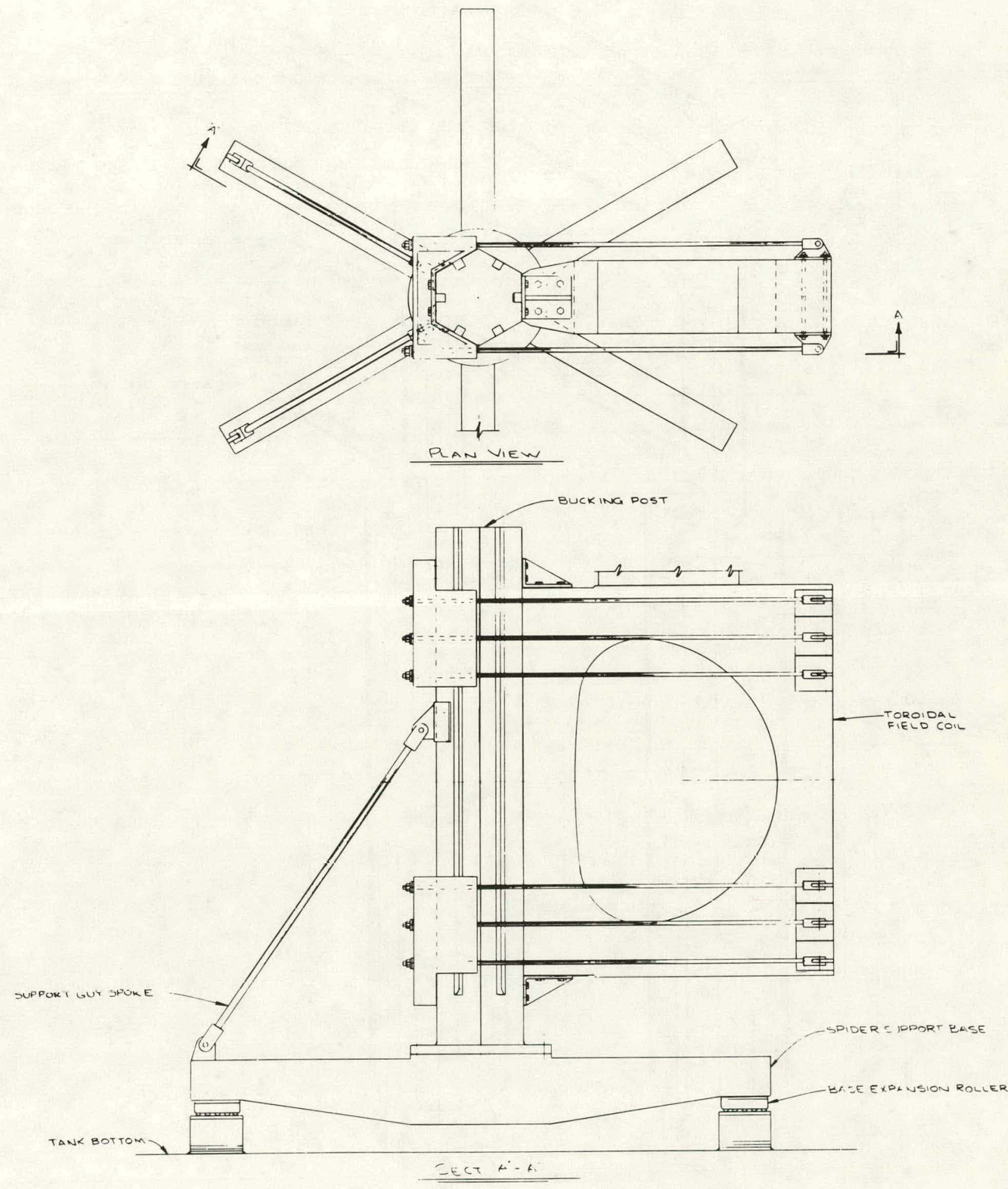

Fig. 3.8. Single-coil test stand. 


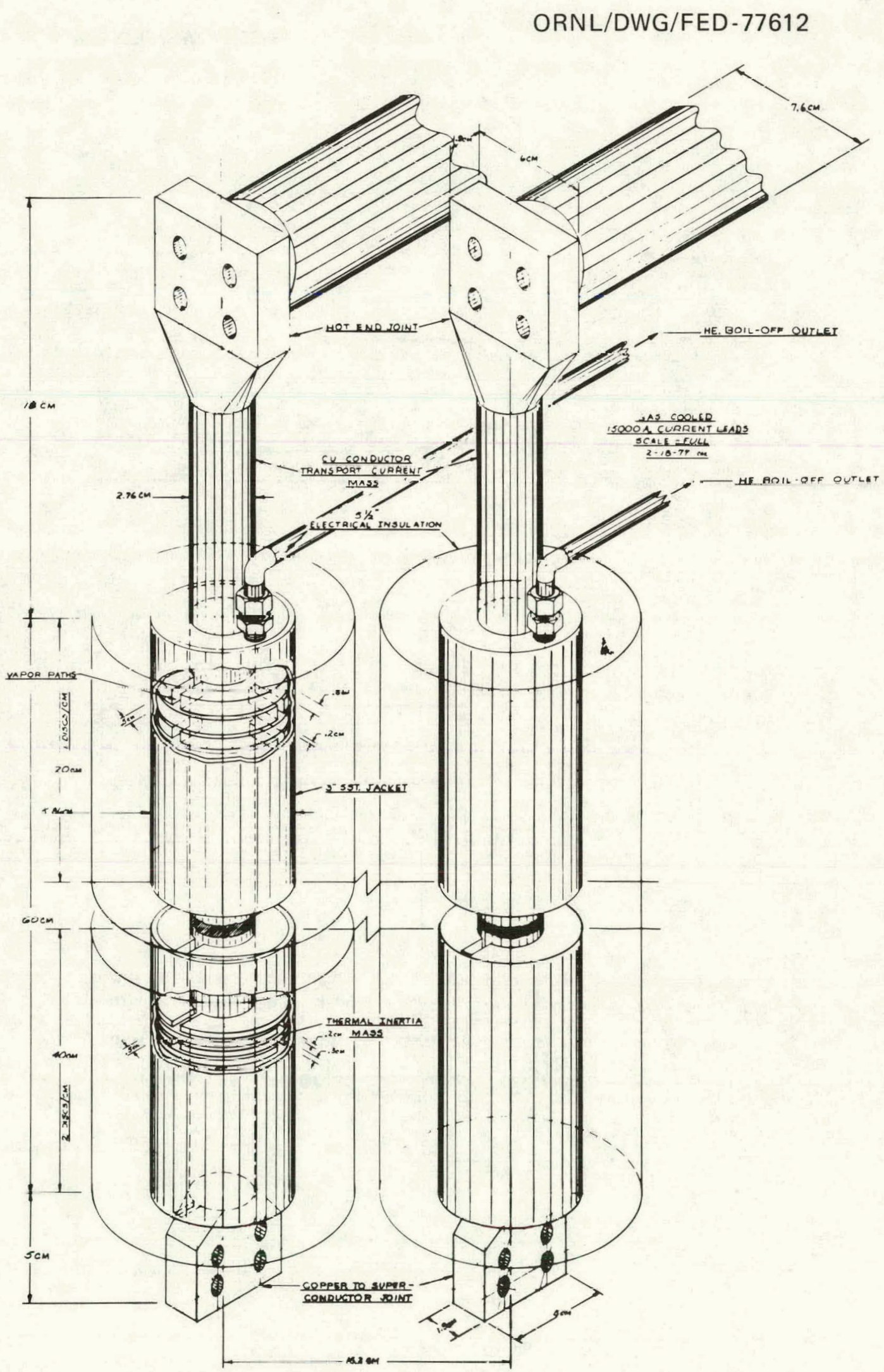

Fig. 3.9. 15-kA vapor-cooled current leads. 
Instrumentation and coil heating element connections will also be located on the coil interface envelope. The facility will have provisions for connection of leads to each coil as necessary.

The coil support structure is designed to support the gravity loads and magnetic loads on the toroidal field coil being tested. Specific details on the major structural items are discussed below.

\section{Bucking post}

The bucking post is designed for the full torus and is constructed from a forging of 304 series stainless steel. The post has a hexagonal cross section over its entire length. Each toroidal field coil bears against one of these six faces and transmits the centering force of the coil to the post. A portion of the out-of-plane forces is carried by a groove which runs the full length of each of the six faces. A matching tongue running the full length of each coil nose fits into the post groove and provides support against the out-of-plane forces. The toroidal field (TF) coils are rigldly attached to the top and bottom of the post with a bolted connection.

The post will be cooled with liquid helium which runs through coolant holes in the interior of the post. These holes run the full length of the post and will be drilled after forging.

\section{Base structure}

The entire weight of the toroidal coil system is supported by a sixlegged base. The base contains a central socket and flange into which the bucking post is attached. The base legs serve as long thermal paths wh1ch aid in isolating the helium-cooled bucking post from the $80 \mathrm{~K}$ pads on the vacuum enclosure floor. Each leg is a box type section which provides its own coolant passage. The end of each leg rests on an expansion roller, which in turn rests on the vacuum enclosure floor. Under the full load of a six TF coil and pulse coil experimental assembly, the frame has a maximum combined stress of $172 \mathrm{MPa}$ and deflects $0.8 \mathrm{~cm}$ downward at its center.

Tie-rod support assembly

The tie-rods and adapter structure assembly are provided to allow the coil to be operated at...full design current without exceeding allowable 
stress levels. This is accomplished by an arrangement which simulates the restraint normally provided by the complete torque ring structure which would be present in a more complete coil array. A structural assembly fits in the bucking post groove on the face opposite that to which the test coil is attached. Tie-rods are then installed from this structure to the torque ring attachment face of the coil.

Energizing the coil tends to force the conductor into a circular geometry. The tie-rods resist this circularizing trend and transmit the forces into the bucking post structure.

\section{Support structure assembly procedure}

'l'he assembly of the structural support system bejgins by leveling the base onto the tloor of the vacuum enclosure. 'lihe base bears on the enclosure floor through six expansion rollers and should not require further adjustments or removal.

The bucking post is lowered into a socket in the center of the base frame. A flange on the lower end of the post is shimmed snug and bolted to the mating surface on the top of the base. To provide for stability of the post during further assembly of the experiment, temporary guy wires are attached between the top of the post and the legs of the base.

The structure is now ready to accept the TF coil. A TF coil is lowered into place by overhead crane and set on temporary jacks on the enclosure floor. These jacks will support and adjust the coil while it is being aligned.

The coil nose tongue is shimmed into the bucking post vertical groove to provide full bearing along the sides of the tongue and groove joint. The coil is then rigidly attached to the bucking post with bolted angle brackets at the top and bottom of the post, and the tie-rod assembly is bolted in place and adiusted.

Use of the base and bucking post for testing a single coil eliminates the need for a separate structure; the coil can remain in place for the next stage of testing, thus reducing downtime between stages.

\subsubsection{Electrical Power - Primary Distribution}

\section{Requirements}

The electrical loads for Stage II of the LCTF will consist of cryogenic pumps and compressors, vacuum pumps, cooling water pumps, 
ventilation and air conditioning devices, lighting, and other normal building services. The estimated loads are broken down in Table 3.3. A schematic of the proposed distribution system is given in Fig. 3.10.

Table 3.3. Facility electrical loads - Stage II

\begin{tabular}{lr}
\hline \multicolumn{1}{c}{ System } & $\begin{array}{c}\text { Connected } \\
\text { load (kVA) }\end{array}$ \\
\hline Helium refrigerator & 1000 \\
Cooling water & 500 \\
Toroidal field power supplies & 300 \\
Pulsed coil power supplies & 0 \\
Vacuum systems & 200 \\
Dump resistor ventilation (intermittent) & 50 \\
HVAC & 100 \\
Clean power & 7 \\
Lighting and convenience receptacles & 150 \\
\end{tabular}

Primary electrical power for Building 9204-1 is obtained from Building 9204-3 via an overhead $13.8-\mathrm{kV}$ feeder which is currently rated at 5.5 MVA. 'The present power demand in 9204-1 is about 1 MVA; however, this is expected to increase in the near future by approximately 3 MVA. The additional anticipated power requirements for the LCTF are estimated to be on the order of 6 MVA. In order to meet the additional power requirements and to handle the incremental load requirements for Stage II testing, the following modifications to the primary power source and the building distribution system will be required.

\section{Description}

Upgrade 13.8-kV overhead tie line. The 13.0-kV Lie 1lue will be upgraded to a capacity of 16 MVA by removing the existing overhead wire/ pole line hardware and $15-\mathrm{kV}$. cable. Five hundred-MCM wire will be installed overhead on the existing poles from the bus entrance at 9204-1 to the existing tie line entrance at. 92.04-3. Single-conductor, 350-MCM, 


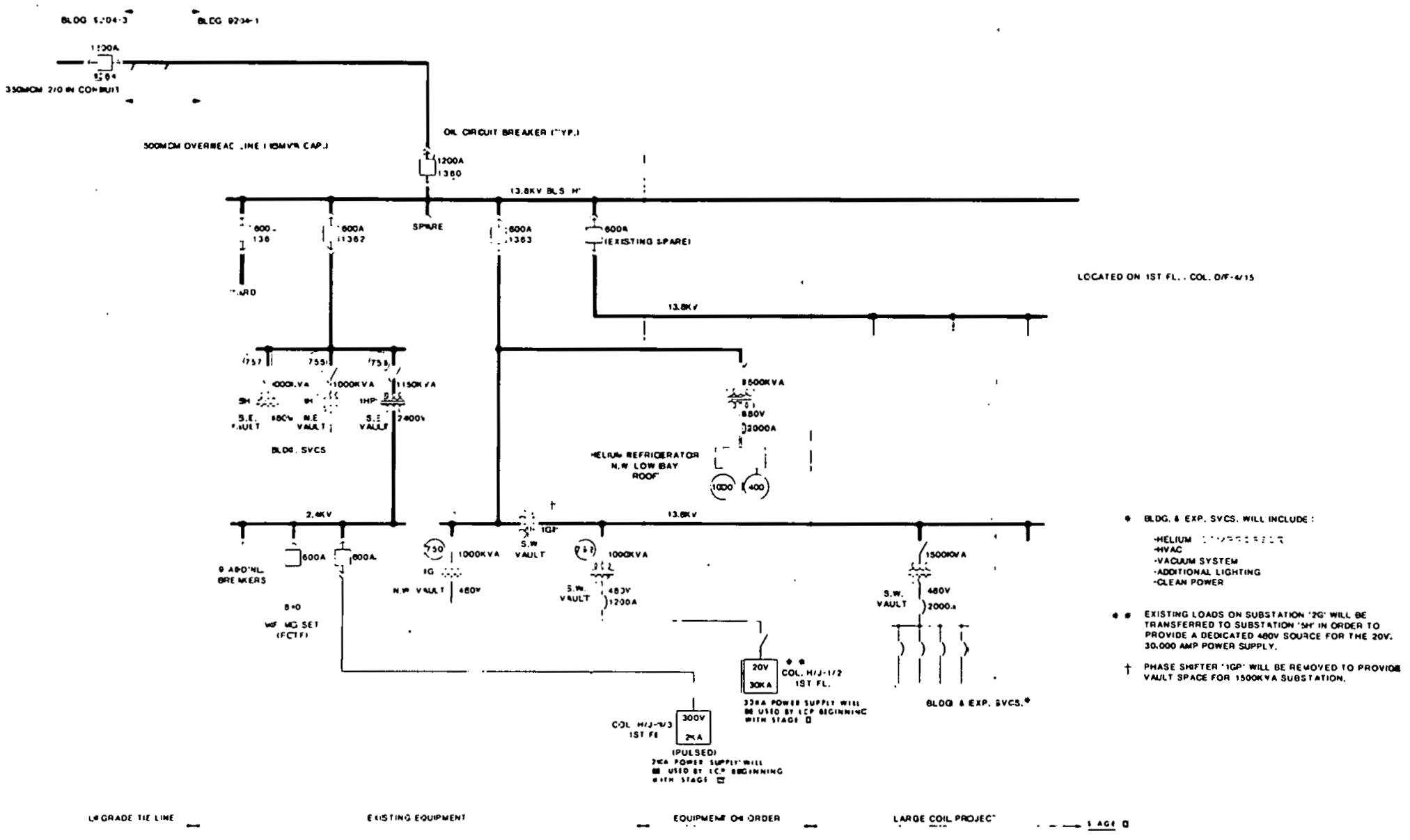

Fig. 3.10. Erimary power distribution schematic - Stagə II. 
$15-\mathrm{kV}$, cross-1inked polyethylene cable (two per phase) will be installed in existing conduit in 9204-3 from the tie line entrance to a metal-clad switchgear unit.

13.8-kV metal-clad switchgear modification. Additional metal-clad switchgear units or other major modifications to the $13.8-\mathrm{kV}$ bus arrangement in Building 9204-1 will not be required to maintain an adequate and reliable power source for the LCTF. One of the two existing spare feeder breaker units will be utilized to provide input power to new unit substations which, in turn, supply both the pulsed and steady-state dc power supplies required in later testing stages. This spare breaker unit was formerly used as a motor-generator (MG) feeder breaker. Modifications to the spare unit will include installation of new current transformers, new overcurrent relays, a new ammeter, a watt meter, connection of breaker auxiliary contacts to the Emergency Monitoring System, and other miscellaneous wiring changes to the breaker control system.

New unit substations, building services. The LCTF will require low voltage building and experiment power in excess of existing transformer capacity. A new 1500-kVA, 13.8-0.48-kV indoor unit substation will be installed in the southwest transformer vault to provide the additional power. Floor space in the southwest vault for the new unit substation will be obtained by the removal of the phaseshifting transformer and the removal of one set of low voltage switchgear which had previously supported a transformer. All 15-kV PILC cable feeding the southwest vault will be replaced with shielded, cross-linked polyethylene cable. Existing 480-V luads will be transferred to the new unit substations as required.

Vacuum system. The major electrical loads for the LCTF vacuum system will include one 10-hp mechanical pump, three 17.5-hp mechanical pump/ blowers, and two 35-in. diffusion pumps rated at $24 \mathrm{~kW}$ each. A motor control center (MCC), centrally located, will be used to distribute power to these loads. A panel with push-button controls will be installed to provide reilule control of the vacuum system.

Miscellaneous building and experimental loads. The LCTF will require power for various building and experimental loads which are not well defined at this time. 'The loads may include heating and ventilating units, additional lighting, and various controls and Instrumentation. 
A $1000-k V A$ continuous load is identified in the tabulation for the liquid helium refrigerator. A special load is represented by the 50-hp motor driving the blower to cool the dump resistor. This motor will be started after the load represented by the TF power supply has been dropped of $f$ the system. The blower only functions when the TF coil is being discharged in an emergency situation.

Motor control centers located at several points throughout the facility will be installed to provide centralized points for control and protection of these various loads. All wiring will be done with 600-V cable in rigid conduit.

A motor generator set rated at $15 \mathrm{~kW}$ will be installed to provide clean power for the data acquisition system.

Fluorescent lighting, convenience receptacles, emergency exit lighting, a public address system, and a fire alarm system will be provided for the control room and other areas as required.

UCC-ND General Design Criteria, Y-EF-538, shall be used in the design of all electrical systems for LCTF.

Other LCP facilities

Following are desrriptinns of equipment which will be a part of LCTF, but which are currently on order for use in other portions of the Superconducting Magnet Development Program.

(1) Helium refrigerator - A new 1500-kVA, 13.8-0.48-kV indoor unit substation will be installed on the low bay roof to provide power for the 1000-hp and 400-hp motors in the compressor section of the helium refrigerator. Primary power will be provided by an extension of the $13.8-\mathrm{kV}$ feeder in the northwest vault to the new unit substation. The 480-V feeder to the compressor will be via 600-V, 2000-A feeder busway.

(2) Cooling water system - The cooling water pumps, two 300-hp units, will be locaced west of Bulldluy 9731. Power for these pumps will be supplied from an existing 2400-V substation in Building 9736. A $5-\mathrm{kV}$ cable in rigid conduit will. be run from 9736 to Building 9404-6, where two metal-clad switchgear units will be installed. These switchgear units are existing spare units and will be relocated from Building 9404-11. Feeders to the water pumps will be run in underground ducts from Building 9404-6. 
(3) $600-\mathrm{kW}$ power supply - The Title II design has been completed for a $2400-\mathrm{V}$ feeder to a 300-V, 2000-A dc power supply to be located on the first floor of Building 9204-1, at Column $\mathrm{H} / \mathrm{V}-1 / 3$. The feeder is extended from the $2400-V$ substation in the southeast corner of the building. It is anticipated that this power supply will be used as one of the pulsed power supplies for LCTF which is provided in Stage IV.

\subsubsection{Electrical Power - Power Supplies, Heaters, and}

Secondary Distribution Requirements

It will be necessary to provide the following:

1. independently controlled dc power to the test coil location, and

2. ac power for the operation of auxillary equipment including vacuum pumps, diffusion pumps, and dump resistor ventilation fan.

\section{Description}

An existing $30-\mathrm{kA}, 20-\mathrm{V}$ dc power supply will be used to supply the coil power for testing a single coil in the vacuum tank. Switches will be installed in the supply output bus so that the power can be routed to three locations: that is, its present location (serving a laboratory), the single test coil, and a future laboratory test site. These switches will be remotely operated from a panel to be installed near the power supply. Six 1/2-in. $x$ 6-in. copper bus per leg will be installed from the new switch to the test tank for the power conductors. A new control panel for the existing power supply, complete with interconnecting cables, will be purchased and installed in a rack in the LCTF control room.

A dump circuit (for emergency use) that limits the voltage to $1000 \mathrm{~V}$ and will discharge the coil in $50 \mathrm{sec}$ will be installed. A fan to cool the dump resistor to room temperature in one hour will also be supplied.

The 16 heaters in the coil will each be powered from a dc power supply rated at $0-20 \mathrm{~V}, 50 \mathrm{~A}$. The heaters in the coil will be connected by a cable and a shell-type MS plug to a switch panel, and the panel will be connected to the power supplies. Interlocks will be arranged so that all the heaters to any single coil must be switched on before the power supplies can be energized. This will permit proper expansion to later testing 
stages involving multiple coils. The power supplies will have remote panels in the LCTF control room and can be computer controlled.

Auxiliary systems

A motor control center sized to supply all existing equipment and with $20 \%$ spare units will be installed. The motor control center will be supplied from a spare $600-\mathrm{A}$ breaker in the $480-\mathrm{V}$ unit switchgear. This center will supply the vacuum pumping units, diffusion pumps, and any other auxiliary equipment. All of the equipment will be controlled from stations located in the LCTF control room. The control circuits will be interlocked with the necessary instruments and valves to prevent a misoperation of the equipment. A 75-kVA, 3- $\phi, 480-208 / 120-V$ transformer and 2-36 circuit panels will be installed to provide the necessary control power at the test site and in the control room.

A 2-kVA uninterruptible power supply wi,l be installed to provide control power to the dump circuit and other selected instruments.

\subsubsection{Instrumentation Requirements}

It will be necessary to provide;

(1) instrumentation and control of the facility services including the cryogenic, cooling water, and vacuum systems;

(2) data acquisition on the operating characteristics of the test stand, support structure, and vacuum vcoscl cold walls; and

(3) coil diagnostic instrumentation to monitor the sensors inside and on each test coil.

Deseription

Instrumentation and controls for the LCTF facility can be broken down into various subsystems to be instrumented. These include the liquid helium system, liquid nitrogen system, vacuum system, demineralized water system, and coil diagnostic system. Each of these areas is discussed in greater detail below. In general the facility controls are manually operated, while most facility and diagnostic variables are monitored by computer. However, fault detection and response are automatic and are redundant in critical areas. The needs of the total system required for all testing stages have been considered, and designs compatible with a phased 
testing program are proposed. Each system's operation and specific component requirements have been derived froin detailed flow sheets and instrumentation diagrams.

Liquid helium system. The liquid helium transfer system will be monitored and controlled by a combination manual and automatic control system, The transfer of helium to the individual pool-boiling or forced-flow coil manifolds will be controlled by an operator, but with the transfer monitored by the transducers necessary to ensure correct and orderly operation. It is proposed that liquid helium flow from the coil manifold through each coil be automatically controlled by individual flow valves. The flow valves would be operated in a cascade control loop with both pressure and temperature being monitored to control the valve. The controls would utilize transducers for measurements at liquid helium temperatures with signal conditioning to convert their outputs into signals compatible with standard off-the-shelf process control equipment. The present concept calls for the process control equipment to be an electronic series such as the Taylor 1300 or Mod. III or the Leeds and Northrup 400 Century Line. The choice of instrumentation is not limited to these two vendors, but these are examples of the type of preferred equipment. One specific advantage of this type of control is single loop continuous ana-. log control, but with the option of later modifying the control loop for either direct digital or supervisory control by a digital computer. Additional advantages include standard packing, standard cabling, well defined interconnection and installation details, interchangeability of components, complete documentation, and familiarity with the systems by UCC-ND Maintenance personnel. In addition to the flow control loops provided for each coil path, each path will have temperature, pressure, and flow monitored by an instrumentation manifold whose outputs are linked to the facility digital computer. The details of the manifold are yet to be developed. The helium gas returned will have its flow monitored and totalized to provide an indication of liquid helium usage.

Liquid nitrogen system. The $\mathrm{LN}_{2}$ system will be monitored and controlled by the same type of process controls as the liquid helium. The transducers involved will be for liquid nitrogen temperatures, but the 
controls will be configured similar to those defined for the LHe. The valving to each item included in the $\mathrm{LN}_{2}$ distribution system will be manually operated. The flow and pressure will be monitored and alarmed in each liquid nitrogen line going to the colls. In addition to the $\mathrm{LN}_{2}$ flow to the coils, liquid nitrogen will be utilized in the necessary heat exchangers. The pressure and temperature across each heat exchanger will be monitored and recorded to permit heat balance calculations across the exchangers.

Data acquisition. The support structures and cold walls are to be instrumented with a variety of thermocouples, thermistors, and strain gages. These transducers will require a very low scanning rate and are external to the magnetic field. A digital data acquisition system has been proposed to $\log$ these data points and alarm if preset limits are exceeded. The system will basically be a low level, slow speed multiplexer, analog-to-digital convertor, and PDP-8E digital computer. The computer will act as the system controller and provide the capability of linearizing signals from thermistors and other cryogenic transducers. The basic elements comprising this system are depicted in Fig. 3.11. Fundamental to the system design is the capability to modify components as necessary to support subsequent testing stages.

vacuum syscem. The vacuum sȳsem instrumentation and control measurements include pressure inside the vacuum vesse1, pressure at the inlet to each of the diffusion pumps, foreline pressure to the diffusion pumps. line pressure at various points, and inlet pressure to the mechanical roughing pumps. All valves are to be remotely operated pneumatic valves with electrical contact closures for on-off position indication. The remaining monitoring points include diffusion pump baffle temperature and a gas analyzer for the vacuum tank. The analyzer is to detect vacuum lcaks from any of three sources - outside air, liquid nitrogen system, and liquid helium system.

During normal operation, the system is brought down to vacuum from atmosphere under manual control. An interlock circuit ensures proper operation of the vacuum pumps. If a fault occurs, an alarm for the affected parameters is indicated, and action is taken automatically to shut 
ORNL/DWG/FED-77614

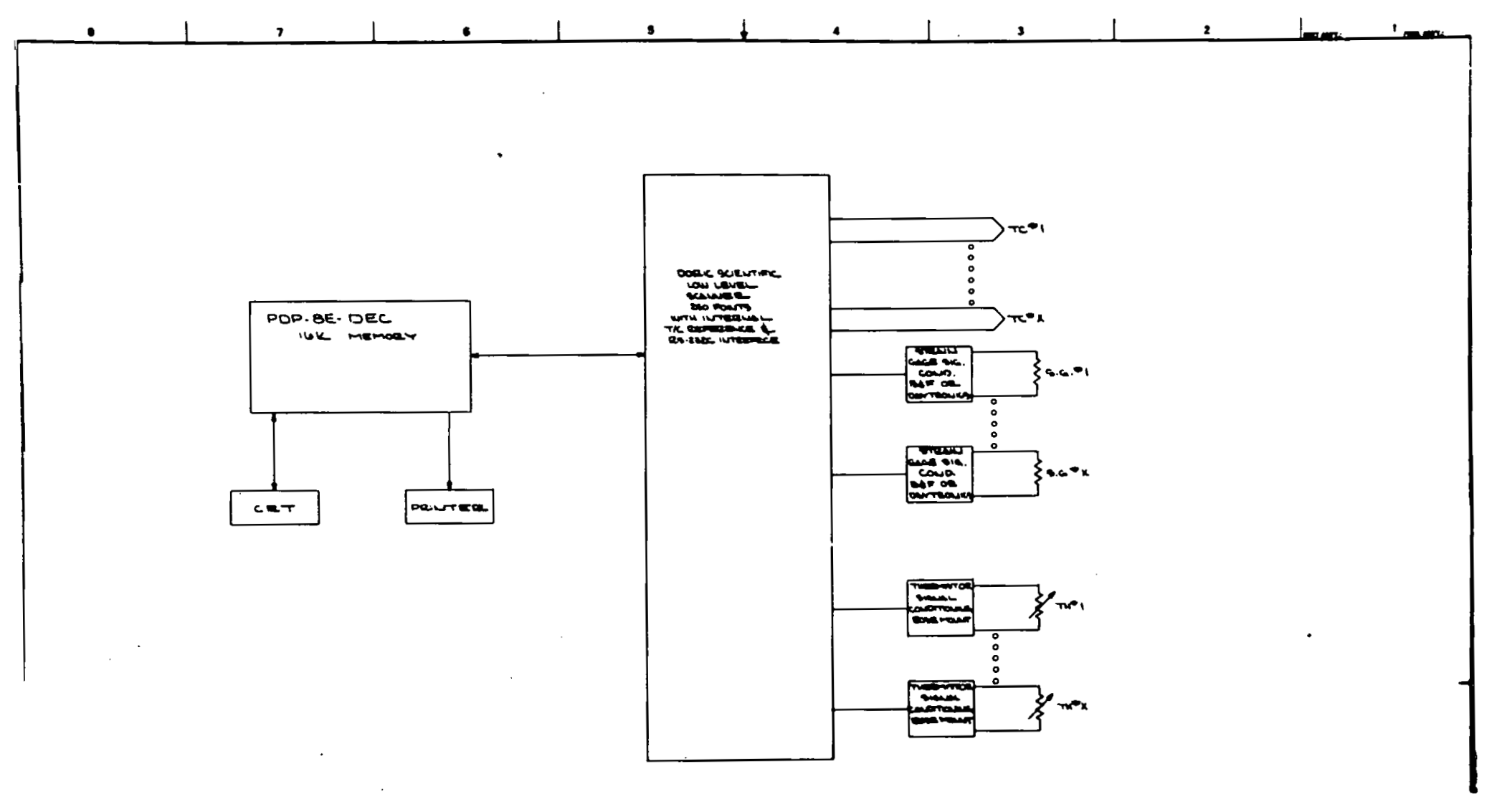

Fig. 3.11. Digital data acquisition system. 
down the faulty equipment and protect the rest of the facility. Status information on fault conditions, as well as parameters such as tank pressure, are fed back to the control computer system for backup monitoring and recording purposes.

Demineralized water system. The demineralized water system instrumentation and controls monitor the water flow throughout the various subsystems in the facility. Flow switches indicate the flow to the diffusion pumps, the mechanical vacuum pumps, the liquid helium system, the liquid nitrogen system, test coil power supplies, pulse coil power supplies, and dummy loads. In addition, as another indicator of proper or improper operation. differential temperature transducers are placed across the inlets and outlets of the power supplies, the water-couled leads, and the dummy loads. Remotely operated valves are placed on the inlet and outlet to the main water supply lines. Flowmeters show the amount of water flow both in and out. Interlock and alarm circuits monitor the flow switches, temperature sensors, and flowmeters for improper flow or temperature. Alarm signals are fed to each subsystem's protection circuit to initiate the proper response to the fault.

Co1l dagnostic inotrumentation. The coil diagnostic instrumentation consists of the slgnal conditioning and analug-to-digital conversion equipment required to monitor the various types of sensors located inside and on each test coil. Figure 3.12 shows the outline of the proposed monitoring. Due to the extreme environment of high noise and very low temperatures, an amplifier per channel approach is used for analog signal conditioning on all but the cooldown and warmup temperature sensors. In the case of strain, field, and displacement measurements, ac carrier amplifiers are required to reduce errors to acceptable levels. In Table 3.4, the number and sampling rates of the different types of signals for one test coil are given. In a full six-coil tescing arrangement, only one test coil would have this number of signals monitored. The other five would have about half this number from each coil fed through the signal conditioning.

While the temperature, strain, field, and displacement measurements are primarily diagnostic variables, the voltage taps serve a dual 
ORNL/DWG/FED-7761E

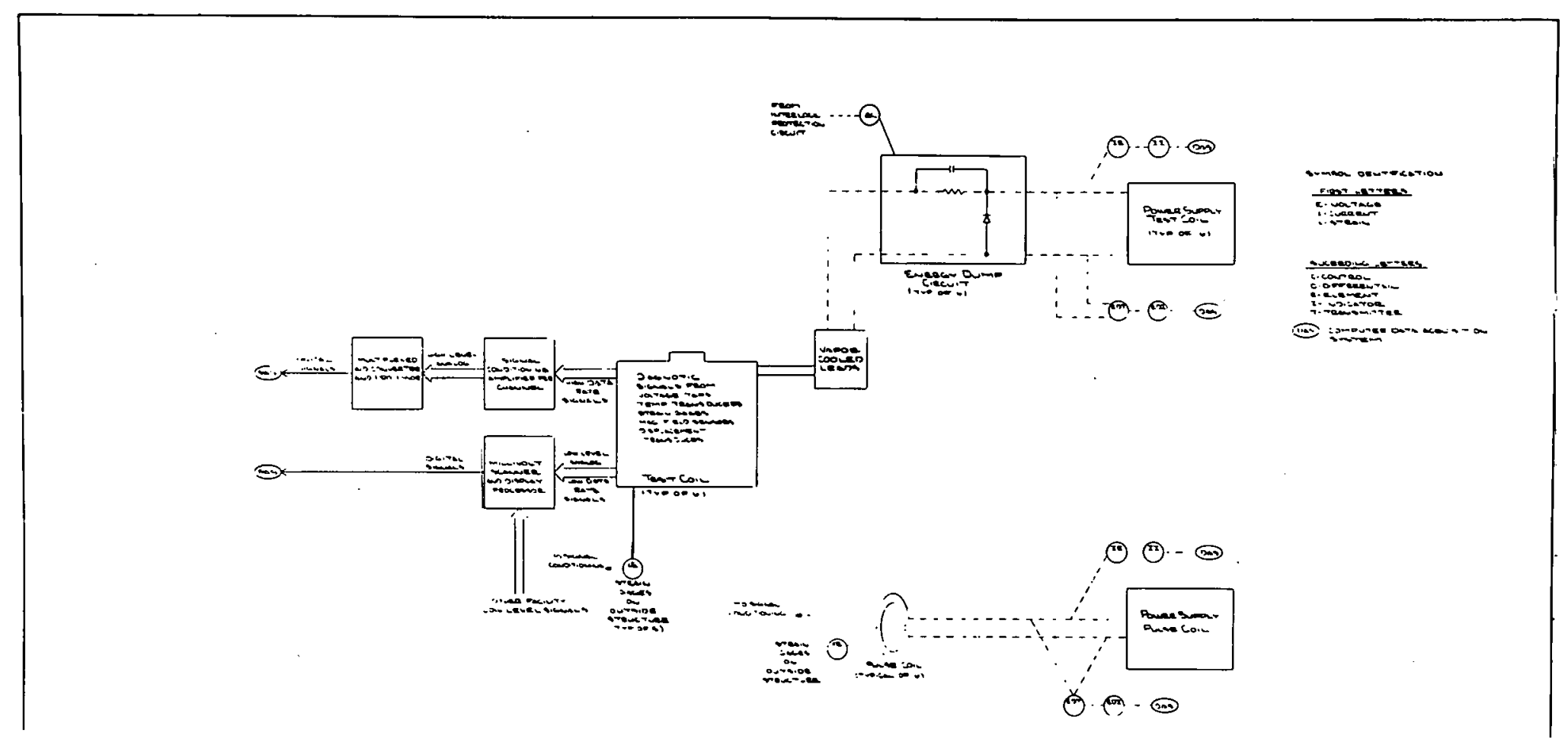

Fig. 3.12. Coil diagnostic instrumentation - flow diagram. 
Table 3.4. Test coll signal conditioning

\begin{tabular}{|c|c|c|c|}
\hline $\begin{array}{l}\text { Variable } \\
\text { monitored }\end{array}$ & $\begin{array}{c}\text { Number of } \\
\text { fast channels } \\
\text { (1 kHz rate) }\end{array}$ & $\begin{array}{c}\text { Number of } \\
\text { medium channels } \\
(100 \mathrm{~Hz})\end{array}$ & $\begin{array}{c}\text { Number of } \\
\text { slow channels } \\
(1 \mathrm{~Hz})\end{array}$ \\
\hline Voltage tap & 20 & & \\
\hline Temperature & $36(16)^{a}$ & & 39 \\
\hline Strain & 10 & 25 & 15 \\
\hline Displacement & & 8 & \\
\hline Field & 8 & & \\
\hline Pressure & & 2 & \\
\hline Flow & & $20(a)^{a}$ & \\
\hline Other & 5 & & \\
\hline Total & $79(59)^{a}$ & $55(35)^{a}$ & 54 \\
\hline
\end{tabular}

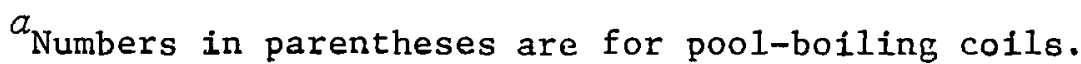

purpose. Not only do they serve as indicators of voltage across the coil windings but also as a primary means of detecting the start of a quench. By subtracting inductively induced voltages from the value measured across the voltage tap and then dividing this signal by the current through the coil, a quantity which represents the resistance of the coil is obtained. A resistive zone in a coil which is either very large or which exceeds some level for a certain length of time will signal the protection system to operate the energy dump circuit for that coil.

The outputs of the signal conditioning equipment are high level analog signals which are fed into a number of multiplexing analog-to-digital converters, each controlled by a small processor. Data are continuously taken and stored at high speed in buffer memory while a test is under way. Samples of the data are also sent to the diagnostic computer for processing and display. When a quench occurs or the pulse coils are energized, 
the data acquisition is stopped, and the buffer memory will contain a large amount of data both before and after the triggering event. The data can then be sent to the diagnostic computer for analysis.

The cooldown temperature signals are connected to the scanner and facility processor. These can then be displayed locally without having to go through the diagnostic computer. In addition to these signals, a number of other facility variables are monitored by the facility processor. Capabilities include not only display but also limit checking and some control functions.

\subsubsection{Liquid Helium System}

\section{Requirements}

The design of the cryogenic system has considered the total range of requirements for all stages of testing in order to provide a concept permitting phased design, construction, and installation. A discussion of the overall requirements is included here with specific data on Stage II. Subsequent sections relative to future testing stages indicate how the system is modified for each testing requirement.

The specifications given to industrial suppliers of the large coils to be tested have given the cryogenic conditions to be used in the design; these conditions are therefore constraints on the facility design. An option was given to the designer to use either pool-boiling of 4.2-K, 1-atm helium or forced convection cooling using supercritical helium at $4 \mathrm{~K}$ minimum and $6 \mathrm{~atm}$ maximum pressure. The return fluid was to be no hotter than $6 \mathrm{~K}$ and at a minimum pressure of $2.5 \mathrm{~atm}$. The initial procurement of three coils will include at least one of each type, so both forms of cooling must be provided in the facility design. Subsequent procurement of an additional three coils to provide a simulated full torus configuration may also have a mixture of coolant modes. Combinations were then postulated of the various arrangements that might be expected for both three- and six-coil tests to establish the range of cooling requirements to be provided. These are summarized in Table 3.5.

In addition to the cooling required for the coils and their associated structure, cooling for the electrical leads feeding energy to the coils will be necessary. A transition from the nominal $4 \mathrm{~K}$ of the coils 
Table 3.5. LHe requirements - six-coil array

\begin{tabular}{|c|c|c|c|c|c|c|c|}
\hline Configuration & $\begin{array}{l}\text { Total } \\
\text { coils }\end{array}$ & $\begin{array}{l}\text { PB } \\
\text { coils }\end{array}$ & $\begin{array}{l}\text { FF } \\
\text { coils }\end{array}$ & $\begin{array}{l}\text { Test } \\
\text { Coil } \\
\text { type }\end{array}$ & $\begin{array}{c}\mathrm{W} \\
\text { (a) } 3.5 \mathrm{~K}\end{array}$ & $\begin{array}{c}W \\
\text { (a) } 4.2 \mathrm{~K}\end{array}$ & $\begin{array}{l}\text { 1iters } / \mathrm{hr} \\
\text { for leads }\end{array}$ \\
\hline A & 3 & 2 & 1 & $\mathrm{FF}$ & 550 & 400 & 170 \\
\hline B & 3 & 2 & 1 & PB & 100 & 600 & 170 \\
\hline c & 3 & 1 & 2 & $H^{\prime} H^{\prime}$ & 650 & 350 & 170 \\
\hline $\mathrm{D}$ & 3 & 1 & 2 & $\mathrm{~PB}$ & 200 & 550 & 170 \\
\hline E & 6 & $?$ & 4 & $\mathrm{EF}$ & 250 & $40 n$ & 330 \\
\hline$\overline{\mathrm{F}}$ & 6 & 2 & 4 & $\mathrm{~PB}$ & 400 & 600 & 330 \\
\hline G & 6 & 4 & 2 & $\mathrm{~PB}$ & 200 & 700 & 330 \\
\hline $\mathrm{H}$ & 6 & 4 & 2 & $\mathbf{F E}$ & 650 & 500 & 330 \\
\hline
\end{tabular}

to room temperature at the power supply must be made, with helium cooling at the coil-lead interface being the first step in the provision of this gradient. The helium requirements for these leads are also indicated in the above table.

Some of the cooling, e.g., in the pool-boiling coils, will occur with the helium at essentially isothermal conditions with the return flow to the refrigerator as a saturated vapor. Cooling of this vapor can be considered as a refrigeration load, since the cold vapor is available to return through the various regenerative heat exchangers of the refrigerator system. Other cooling, such as that required for the leads, will have discharge conditions at a higher temperature, which makes it impractical to return in the same manner and hence is considered a purely liquefaction requirement. Each imposes somewhat different constraints on the operation of the refrigerator system, since a limited range of combinations of refrigeration and liquefaction can be provided at a given time. This leads to the requirement for storage capacity for previously liquefied cryogen to be used during a test period. 


\section{Description}

Refrigeration capacity. A helium refrigerator is currently being procured which can provide helium at more than one condition. The procurement specification for this refrigerator describes the following operating conditions to be provided:

(1) a full refrigeration condition (i.e., no liquid draw-off) of $969 \mathrm{~W}$,

(2) a maximum liquefaction condition providing $12.2 \mathrm{~g} / \mathrm{sec}$ of liquid at $4.42 \mathrm{~K}$ with a minimal refrigeration load of $23 \mathrm{~W}$ to balance the system, and

(3) a combination operation of $4.5 \mathrm{~g} / \mathrm{sec}$ of liquid at $3.56 \mathrm{~K}$ and a refrigeration load of $866 \mathrm{~W}$.

Other combinations should be possible, and the vendor is being requested to supply additional information in this regard.

It is currently planned to operate the refrigerator during a test period to supply the needed refrigeration at $3.56 \mathrm{~K}$ to satisfy the $4 \mathrm{~K}$ refrigeration requirements with a $4.2 \mathrm{~K}$ liquefaction the third priority if additional capacity is available. During nontest periods, e.g., nights and weekends, operation would be changed to provide just enough refrigeration to maintain the entire structure at the appropriate temperature and to use the liquefaction capability to replenish the storage dewars with 4.2-K helium. In this manner, it is felt that the greatest operational flexibility can be maintained to satisfy the test operations to be performed.

LIle test facllity descripelon. A conceptual design has been made of the LHe portion of the test facility, based on the requirements described above along with the constraints imposed by the refrigerator capabilities. $\Lambda$ schematic flow diagram of the system required fot stage II is shown in Fig. 3.13. Testing of the coil will be done primarily in a large evacuated vessel capable of containing up to six coils simultaneously. Since various cumblnations of coolant mode are possible, it is necessary to provide, through suitable manifolding, a specified coolant condition to a particular coil station. The conductors and associated structure will be cooled in a similar manner. This accounts, in part, for the multiplicity of lines and valves indicated. 
ORNL/DWG/FED 77616

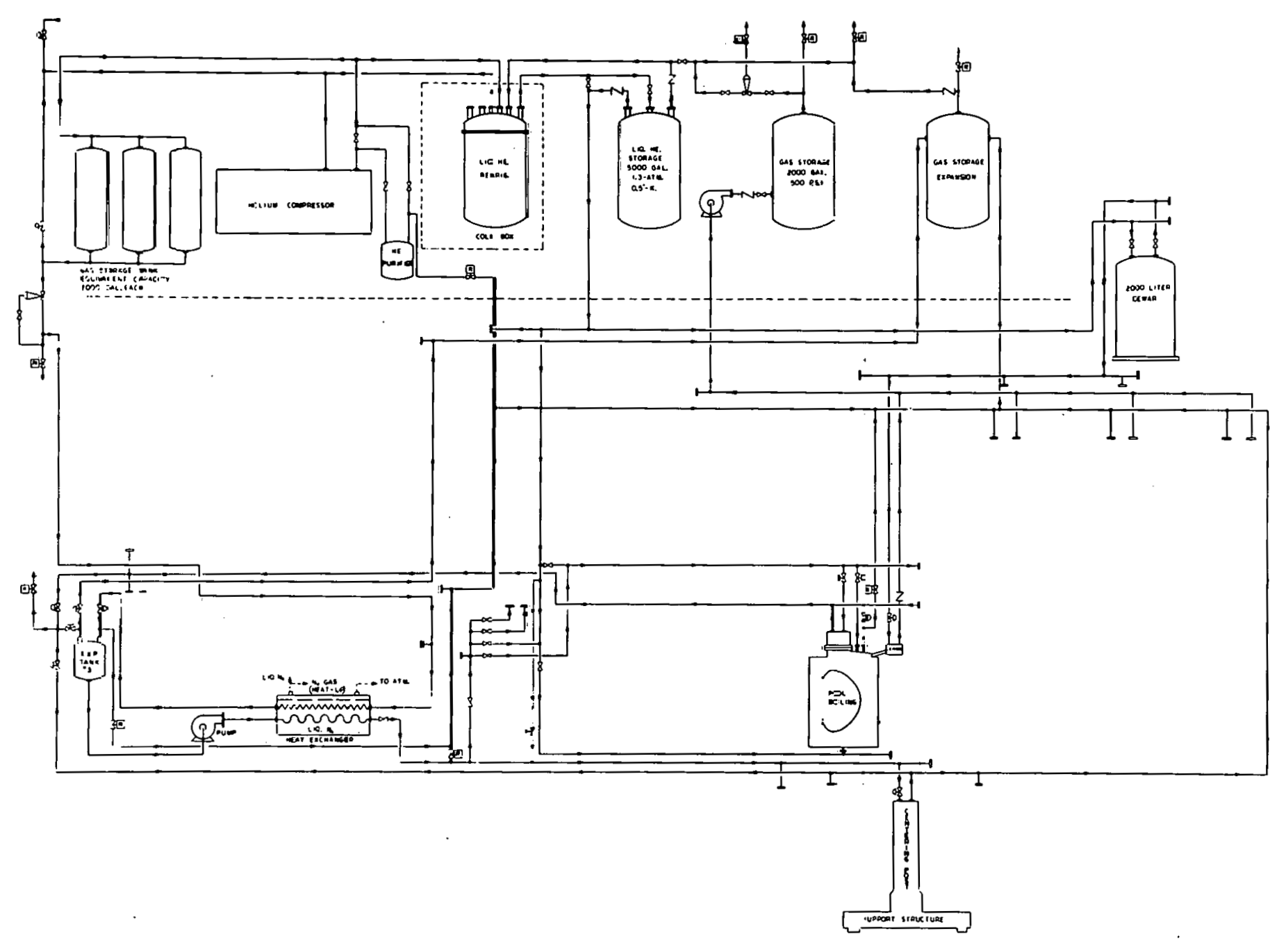

Fig. 3.13. Liquid helium flow sheet - Stage II. 
Three basic subsystems are required for Stage II and, along with the refrigerator, make up the helium system. The three are: (1) saturated liquid distribution and vapor return for pool boiling, (2) lead cooling, and (3) the cooldown loop.

Pool-boiling loop. In the pool-boiling loop, liquid helium from the refrigerator at $1.3 \mathrm{~atm}, 4.5 \mathrm{~K}$ is stored in a 5000-gal dewar. From here it flows to the manifold for the pool-boiling-cooled test coil in the test vessel. A feed tank will be supplied for the coil to provide a vapor disengaging space to help ensure that only liquid will be fed to the coil coolant passages. This feed tank will be at the top of the coil to provide sufficient static head for flow into the coil. Provision is made to supply this liquid either at the top or at the bottom of the test coil.

Vapor generated in the boiling-cooling process will pass out the top of the coil and flow to a compressor for return to the refrigerator. The compressor is provided with an expansion surge tank to help provide a smooth feed without significant pulsations. This return flow, essentially saturated vapor at $4.2 \mathrm{~K}$, will return to the refrigerator through its heat exchange system and hence represents a refrigeration load as opposed to a liquefaction load. The distinction between these was described in connection with the refrigerator.

Power leads. The electrical leads supplying current to the coil must have a temperature gradient because they pass from the coil interface at nominally $4 \mathrm{~K}$ to the power supply at room temperature. The cold end of the leads will be cooled with 4.2-K helium from storage dewars separate from that supplying the pool-boiling feed for tluse colls. One 2000-1iter dewar will be provided for each two colls to provide redundancy and facilitate plumbing and operation with varying numbers of coils installed in the test vessel in later testing stages. This dewar will be filled from the 5000-gal dewar as required during periods between tests.

Cooldown loop. The chird subsystem module is the equipment required to assist in cooling the entire test veosel and contents from room temperature down to operating conditions. The entire assembly represents a mass on the order of $3780 \mathrm{kN}$ requiring the removal of about $5.9 \times 10^{10} \mathrm{~J}$ to cool down to a nominal $4 \mathrm{~K}$. While in thcory this could be done by operating 
the refrigerator and cooling systems just described, the time required for cooldown would be excessively long. For this reason as well as for energy conservation, it was decided to perform as much of the cooldown as possible using $\mathrm{LN}_{2}$ as the heat sink. Direct introduction of nitrogen into the various cooling passages is not desirable, however, since subsequent use of cryogenic helium could freeze traces of nitrogen which might still remain in the system, thus causing potential problems with flow maldistribution or even blockage. It was therefore decided to use helium as the heat transfer medium and reject the heat in a GHe-LN 2 heat exchanger. Two parallel systems are to be used, one primarily for the coils and the other for associated support structure. This was done to permit more uniform control of the rnnldnwn, to minimlze undesirable temperature gradienta, and to use reasonable pipe sizes for the increased helium flow used during cooldown.

Gaseous helium at supercritical pressure will be pumped through the $\mathrm{LN}_{2}$ heat exchanger and then to the test assembly, i.e., coils and structure. When the temperature has been brought down to near $\mathrm{LN}_{2}$ temperature, 80-90 K, cooling will be switched to the helium refrigerator loops for the final couling.

\subsection{9 İiquid Nitrogen Systèm}

Requirements

The $\mathrm{LN}_{2}$ system must satisfy the following requirements:

(1) provide a low temperature environmental shield to reduce the Lhe system thermal loads,

(2) provide cooling to vacuum diffusion pump baffles to prevent back streaming and thermal radiation into the vacuum vessel, and

(3) provide secondary cooling for GHe during cooldown of the test stand and coils from amblent to $85 \mathrm{~K}$.

Liquid nitrogen requirements for the LHe refrigerator are befing handled separately under a specific procurement and installation package. 


\section{Description}

The thermal loads analysis for the system established that approximately $3 \times 10^{5}$ liters of $\mathrm{LN}_{2}$ will be required during cooldown of the experiment. The steady-state cooling load is determined to be approximately 550 liters/hr. A schematic flow diagram of the system required for Stage II is shown in Fig. 3.14.

The low temperature environmental shield for the experiment will be provided by a 77-K liquid nitrogen cold wall with $4 \mathrm{~cm}$ of super insulation between the cold wall and the vacuum vessel. The surface of the cold wall facing the test stand will be electropolished to reduce its emissivity to 0.1 . The total area of the cold wall will be approximately $400 \mathrm{~m}^{2}$ including the bottom, cylindrical sides, and inside the ellipsoidal closure head.

Liquid nitrogen will be supplied to the vacuum diffuston pump baffles and coil support structure to reduce the thermal load on the liquid helium system. Common supply and return manifolds will deliver the liquid nitrogen to these areas. Remote shutoff valves will allow independent control of the flow to each diffusion pump baffle, the support structure, and the cold wall. The return manifold from these areas includes a relief valve sized to handle a loss of vacuum. flow rate from the vacuum vessel system.

Cooldown loop. A liquid nitrogen-to-gaseous helium tube and shell heat exchanger provides secondary cooling for the Stage II test equipment during the cooldown from $300 \mathrm{~K}$ to $85 \mathrm{~K}$. The heat exchanger (Fig. 3.15) is sized to handle the full cooling load; however, some of this load will be taken out directly by the liquid nitrogen cold wall and the liquid nitrogen loops at Lle structural support base.

The heat exchanger contains $2.8 \times 10^{6} \mathrm{~cm}^{2}$ of heat transfer surface area. This will handle approximately $100 \mathrm{~g} / \mathrm{sec}$ of helium at 5-atm pressure over a temperature range from $300 \mathrm{~K}$ to $85 \mathrm{~K}$. This capacity will result in a cooldown of the experiment from $300 \mathrm{~K}$ to $85 \mathrm{~K}$ in $60 \mathrm{hr}$. The second-stage cooling from $85 \mathrm{~K}$ to $4.5 \mathrm{~K}$ is handled by the liquid helium system and will réquire an additional 60 hours.

The tube and shell heat exchanger wi.1.1. also be used to raise the experiment equipment to ambient temperature after shutdown of an experiment. Hot nitrogen gas will be supplied to the shell side of the heat 
ORNL/DWG/FED-77617

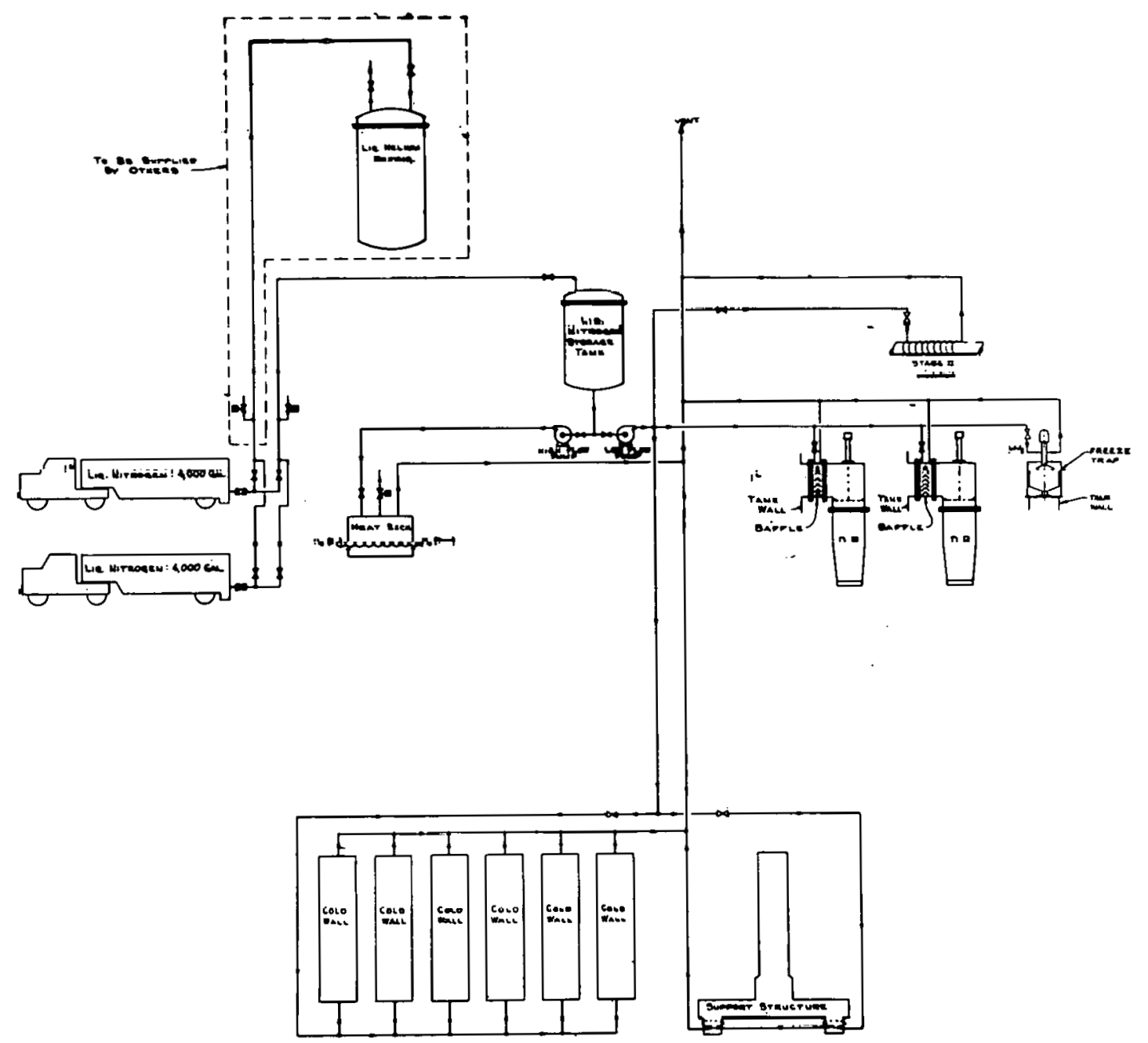

Fig. 3.14. Liquid nitrogen flow sheet - Stage II. 


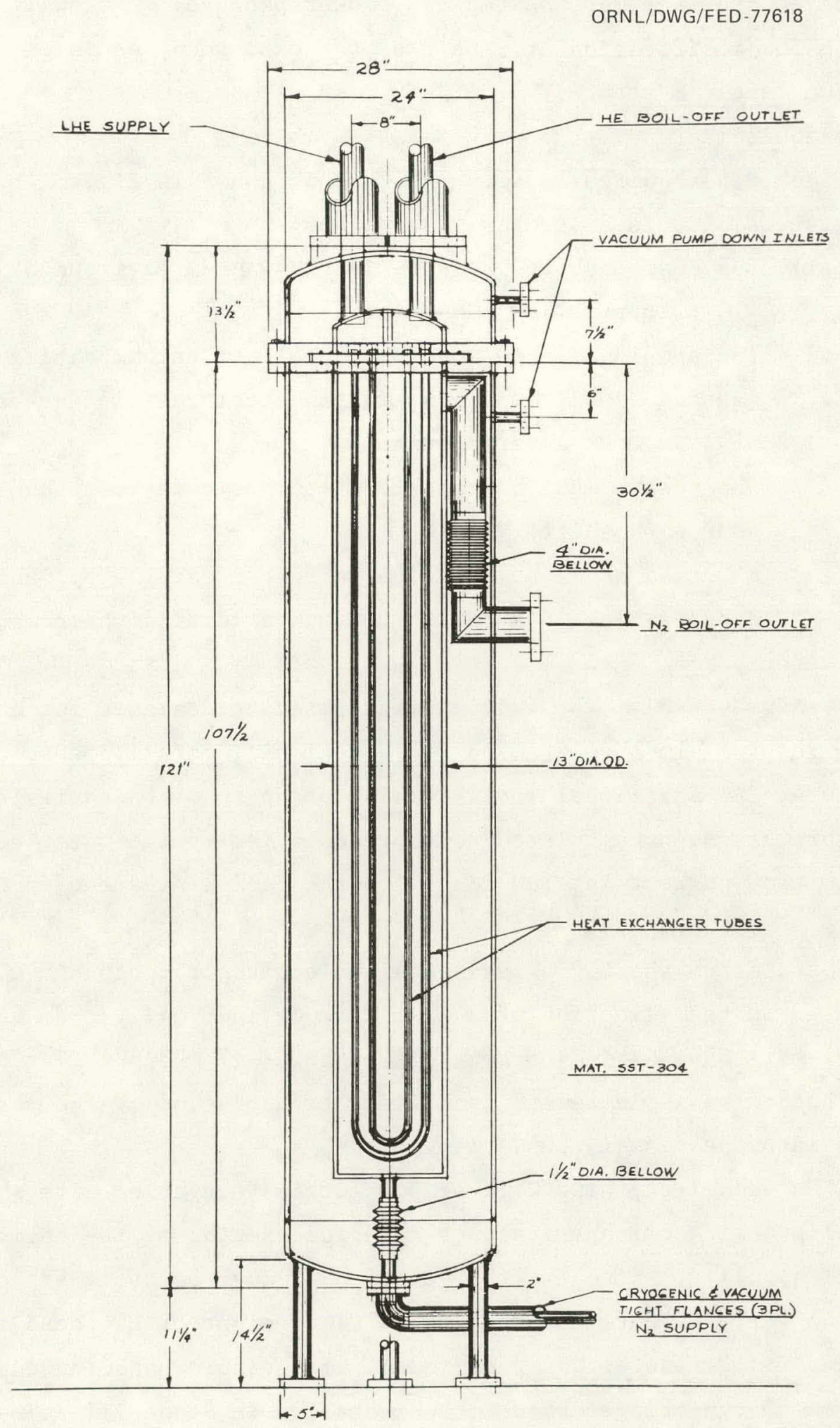

Fig. 3.15. Cooldown heat exchanger. 
exchanger from a remote heater and blower package. This will allow quick warmup for modification or repair of the experiment equipment.

\subsubsection{Vacuum System}

\section{Requirements}

The LCTF requires a vacuum system, as shown in Fig. 3.16. The characteristics of this system are as follows:

(1) The desired base pressure in the vacuum environment is $\leq 10^{-4}$ torr.

(2) The pumping system must be capable of accommodating an outgassing rate from the stainless steel vessel and test equipment of $10^{-7}$ torr liters $/ \mathrm{sec} / \mathrm{cm}^{2}$.

(3) The vessel must be capable of pumpdown in 1ess than nne eighthour work shift.

(4) A method shall be provided to remove water vapor and other noncondensibles in a controlled manner during the pumpdown cycle.

\section{Description}

Vacuum vessel. The vacuum vessel will be designed for an external pressure of 1 atm absolute and for a maximum internal pressure of $2 \mathrm{~atm}$ absolute. An additional local loading of up to $7 \mathrm{kPa}$ equivalent external pressure has been calculated as representative of the worst case condition due to eddy current interactions with the fields produced in testing stages of the program.

Studies of the LCP experimental objectives through Stage VI (Ref. 3) resulted in the selection of a $11-m-d i a m$ cylindrical vacuum vessel. The vessel will have an inside central height of $12 \mathrm{~m}$ and a flat bottom. The flat bottom was selected to facilitate transmission of the test stand loads into the vessel foundation.

The veosel top head will be completely removable. Tts shape may he an elliptical, torispherical, or spherical sector at the option of the vessel supplier. However, the vessel head must be designed to meet a maximum vertical envelope of $2.67 \mathrm{~m}$. The weight of the head is to be limited to 40 tons. This requirement will ensure handling capability by the new 50-ton bridge crane to be installed in Stage III. The approximate weight of the entire vessel is 100 tons. 


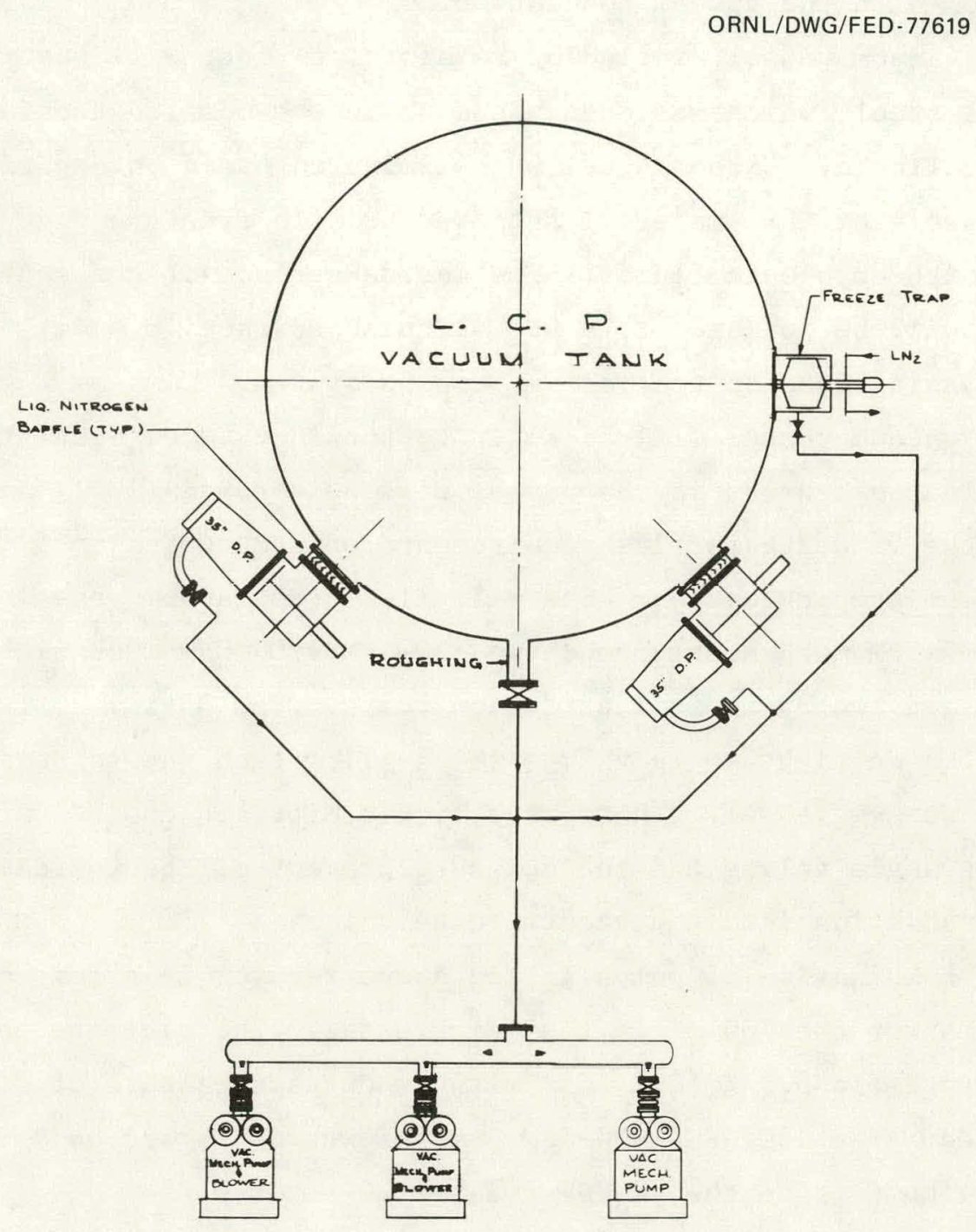

Fig. 3.16. Test tank vacuum system. 
Based on the pressure requirements, the vessel will have a wall thickness of $\sim 2 \mathrm{~cm}$ in the cylindrical section and up to $3 \mathrm{~cm}$ in the head. The vessel is stiffened on all surfaces by external reinforcing ribs. These ribs on the bottom of the vessel also provide the means of connection with the vessel foundation.

The vacuum vesse1, including reinforcing ribs, will be type 304 stainless steel, which was determined to be the most cost-effective material available. Carbon steel was eliminated based on experiences where vessels of that material suffered brittle fracture under accidental contact with cryogenic fluids. The inside surface of the stainless material will be polished to a No. 4 finish surface in order to reduce the outgassing load on the vacuum pumping system.

The vacuum vessel will be built to the ASME Code, Sect. VIII, Div. 2. In addition, all welds in the vessel will be $\mathrm{x}$-rayed $(100 \%)$ and required to meet the $5 \%$ delta ferrite requirements of ASME Code, Sect. III.

Vacuum pumping system. The main $11-m-d i a m$ vacuum vessel is serviced by one 300-CFM mechanical pump, two 130-CFM/1100-CFM mechanical pump/ blowers, and two 35-in. oil diffusion pumps. The 35-in. diffusion pumps are mounted on right angle valves which allow each one to be isolated trom the vacuum vessel. 'l'here is a liquid nitrogen-cooled baffle between the right angle valves and the pumps to prevent oil backstreaming and thermal radiation into the vacuum vessel.

The combination of pumps listed above results in a pumpdown time of five hours for the $700 \mathrm{~m}^{3}$ in the main vessel. The ultimate base pressure of the system is $5.2 \times 10^{-5}$ torr with an outgassing rate of 2.6 torr liters/sec. The 130-CFM/1100-CFM pump/blower units are used to back the diffusion pumps once the vessel reaches $10^{-2}$ torr.

In order to remove condensibles during the pumpdown cycle, a liquid nitrogen freeze trap has been included in the main vesse $\perp$ design. 'I'his trap will be filled and extended into the vessel during the pumpdown cycle. No cryogens will be introduced into the cold wall, support structure, or coils until the bulk of the condensibles is removed and the cold trap retracted. 
It is possible for leaks to develop from several sources during the operation of this vessel. These include the liquid helium system, liquid nitrogen system, and air leakage. To reduce the leak hunting necessary to maintain the vacuum integrity of this system, a leak detector that can distinguish between the gases noted above has been specified for installation on the main vessel.

\subsubsection{Building Modifications}

\section{Requirements}

(1) The high bay region at Building 9204-1 must be modified to allow the installation of the 11-m-diam main test vessel.

(2) The west end of Building 9204-1 must be modified to allow access for construction and coil delivery to the experimental area.

\section{Description}

Demolition. The Large Coil Test Facility in Building 9204-1 will require demolition of ten reinforced concrete columns and sufficient concrete slabs to provide a $13.75-\mathrm{m}$ square around the proposed 11-m-diam vessel. A major portion of the demolition to be done in Building 9204-1 will be on structural members contaminated by prior process work in the structure. The existing steel framework and steel grating on the second floor will be removed.

\section{New construction}

Foundation for vessel. The foundation for the vessel will be a reinforced concrete slab placed on bedrock. Foundation preparation will require some earth excavation and "dental work" on the bedrock to ensure minimum settlement of the foundation. The bearing capacity of the bedrock is approximately $15,000 \mathrm{MPa}$.

Structural modifications to 9204-1. The perimeter of the opening around the large vessel will be supported by reinforced concrete beams and columns. A new $5.33 \times 6.10$-m roll-up door will be located in the west wa11 of 9204-1 between column lines $G$ and $H$ on column line 1 .

Vessel access platform. A 2-m-wide aluminum grate will be installed around the 11-m-diam tank at elevation 948. Aluminum handrails meeting OSHA standards will be installed around all floor openings and along the perimeters of all platforms and stairs. 
Site improvements. The area immediately west of 9204-1 will be improved to accommodate 17-m tractor-trailer delivery to the west side of 9204-1. Two 7.32-m-wide gates will be installed in the security fence. The area will be paved with asphalt, and a retaining wall will be constructed to provide a maximum paved area west of 9204-1. A plan view of these areas is shown in Fig. 3.17.

\subsubsection{Demineralized Water System}

Requirements

(1) The LCTF has a steady-state cooling load of bU0 tons. I'he bulk of this load results from cooling the six TF coil power supplics and the two puloc coil power supplies.

(2) Cooling must be provided to the following items of equipment :
(a) 35-in. oil diffusion pumps,
(b) water-cooled baffles between the oil diffusion pumps and the angle valves on the vacuum vessel,
(c) 300-CFM vacuum roughing pump,
(d) 130-CFM/1100-CFM vacuum pump/blowers,
(e) 20-kA, 15-V TF coil power supp1y,
(f) 300-V, 2-kA pulse coil power supply, and
(g) connertions for cooling a portable load bank, which can be used to check out power supplies after instal- lation.

Discussion

The cooling water system for Building 9204-1 was initiated with FY 1976 GPP funds, This effort will provide a distribution system within the building, heat exchangers, two pumps (300-hp motors), and exterior piping connecting the closed building system to an existing cooling tower.

The LCTF must tie into the 10-in. supply and return distribution headers provided by this GPP funding. This tie-in will be accomplished near the intersection of column rows $J$ and 8 on the north side of the bay area. The 10-in. distribution system runs at a centerline elevation of $942 \mathrm{ft}$. The distribution headers to the LCTF are 6-in. lines running north and south across the bay area on column row 8. Flow into and out of this system is controlled by automatically operated 6-in. butterfly 
ORNL/DWG/FED-77620

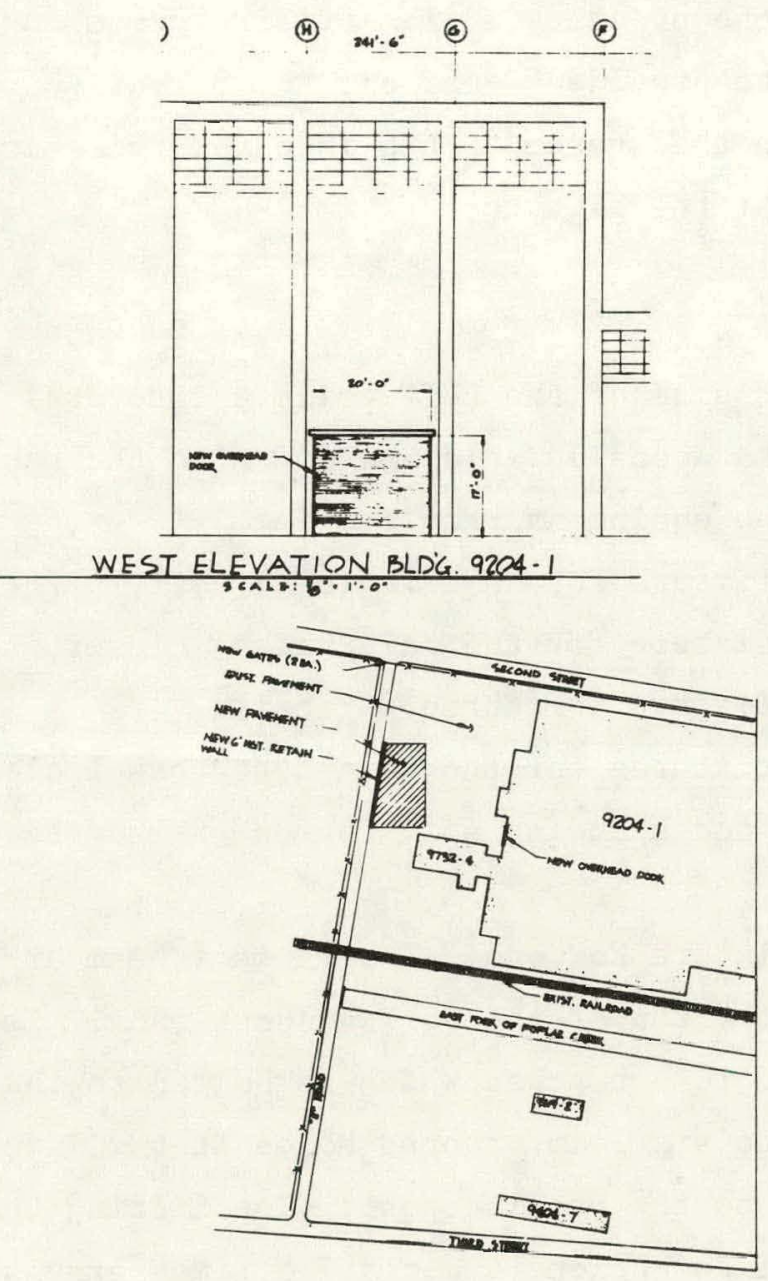

Fig. 3.17. Site plan. 
valves backed by gate valves. This supply header also has an in-line filter just downstream from the butterfly valve. The 6-in. discharge header is protected from backflow by a check valve just before the 6-in. butterfly. A flow sheet of the water system is presented in Fig. 3.18.

\subsubsection{Instrument Air System}

Expansion of the present instrument air system in Building 9204-1 will be necessary to provide 90-psi air to the various water and vacuum valve operations in the system. This involves tying into existing headers on the north side of the high bay.

\subsubsection{Fixtures}

Requirements

The weiglil and size of the T.CTF coils and several components of the facility require that consideration be given to the handling and storage of these items. The equipment required is:

(1) lifting fixture for an LCTF (8-T) coil,

(2) lifting fixture for the main vessel closure head,

(3) storage fixture for three 8-T coils,

(4) storage fixtures for the main test vessel closure head, and

(5) shipping and upeudlng skid for one 8-T coil.

\section{Description}

The lifting fixture for one 8-T coil is a heam arrangement (Fig. 3.19) which attaches to the top of the coil at both ends. The end close to the coil nose is pinned to a bracket which is bolted to the coil. This bracket is bolted to six 3-in. tapped holes that will ultimatcly be used to attach the coil to the bucking post. The lifting bcam will be designed for extremely small defections under a 1.5 times gravity vertical accelcration loading that can be imposed on the coil hy rrane operations. The luy on the top of the lifting beam will be adjustable so that it can be positloned direclly over the center of gravity of the various vendors' coils.

The fixture for lifting the closure head will be a spider arrangement with the cross members at $90^{\circ}$ to each other. This piece of equipment will be designed for the 30-ton load of the 11-m-diam head. The attachment points for the head lift rig will be at four tapped holes on the quadrant lines of the closure head flanges. This fixture will also be designed for the appropriate acceleration loads. 


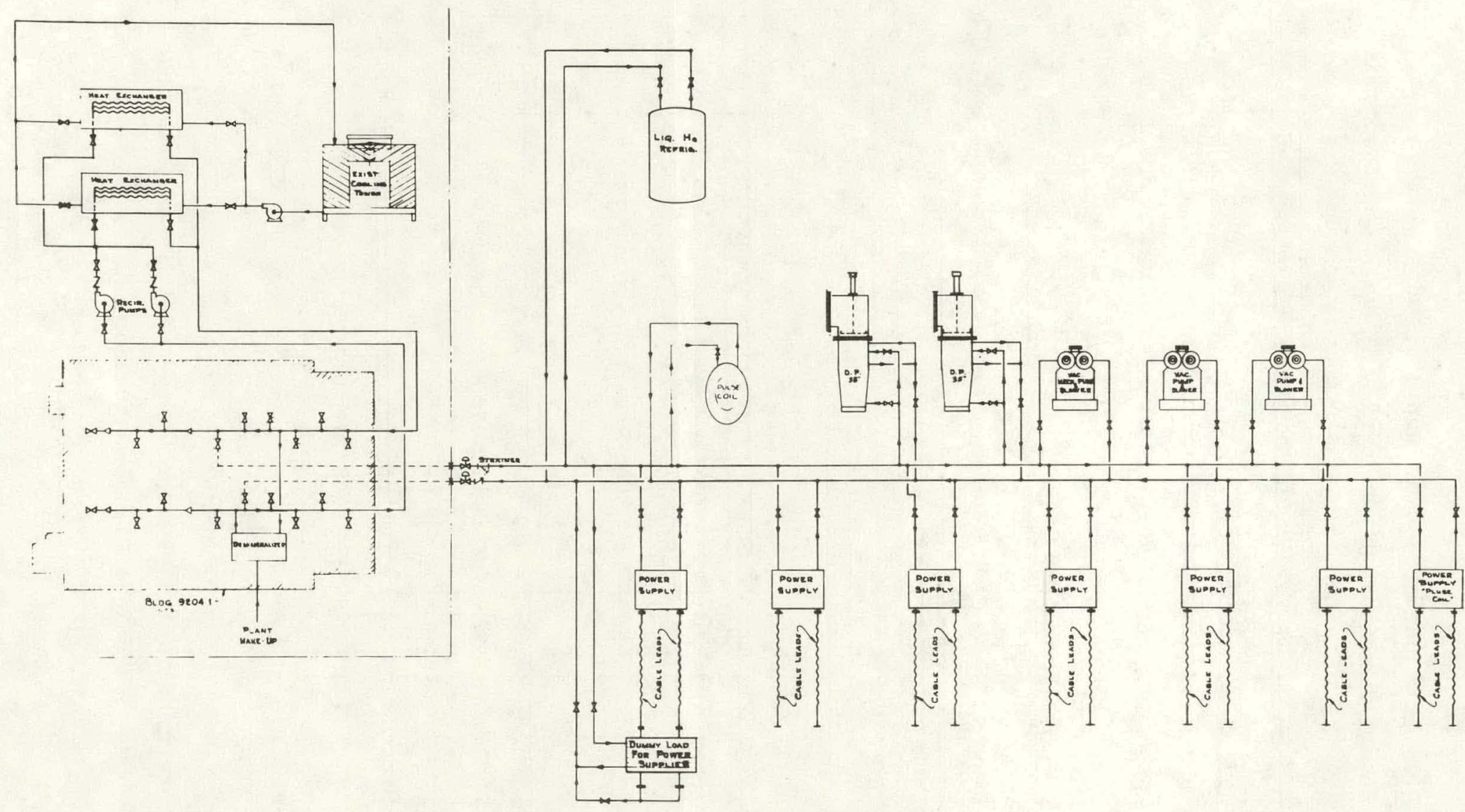

Fig. 3.18. Demineralized water flow sheet. 

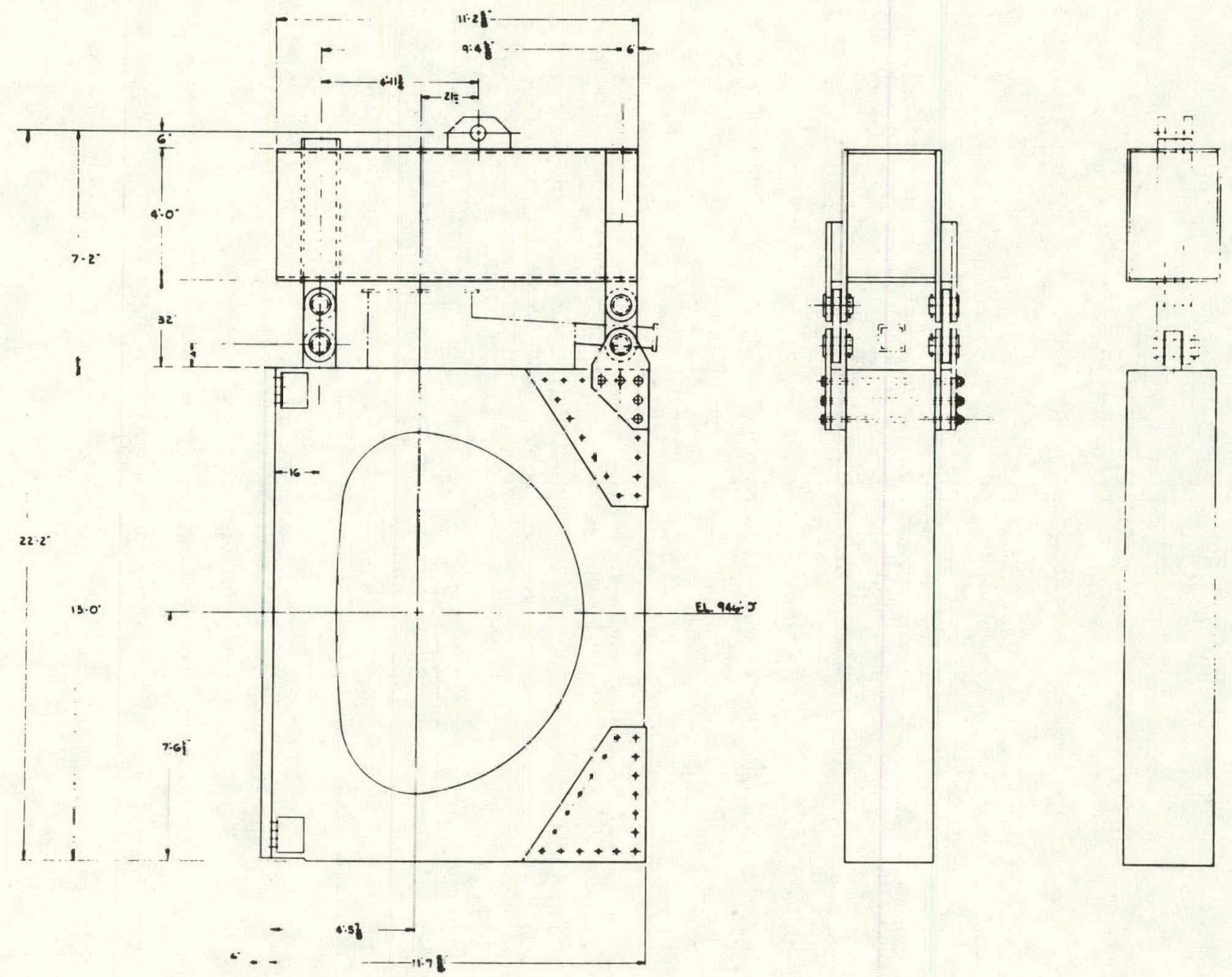

Fig. 3.19. Coil lifting fixture. 
Because the exact arrival of the first three coils and their installation sequence cannot be accurately predicted, a storage rack (Fig. 3.20) for three 8-T coils has been included in the facility conceptual design. This will provide a position to check the coils prior to their installation into the vacuum vessel. It is especially necessary because the allowable floor loading of the 958-ft level in Building 9204-1 is only $300 \mathrm{lb} / \mathrm{ft}^{2}$. Because of this limitation, this storage rack will have to be supported all the way from bedrock under the 938-ft first floor of the building. The storage rack will be considered a part of the building structure and as such will be designed for the Zone 2 seismic loads required for other civil and architectural work in the facility.

A storage rack for the vessel closure head accomplishes several functions.

(1) It protects the machined mating surface of the closure head when it is not in use.

(2) The thickness of the closure head is relatively thin compared to its diameter. If it is temporarily supported from the floor, it may take a permanent deflection which may prevent it from sealing when placed back on the vacuum vessel. This fixture will be designed so that a low pressure nitrogen gas purge can be placed on the inside of the head during storage periods. The fixture will be designed to distribute the load on the $300 \mathrm{lb} / \mathrm{ft}$ rated 958-ft level.

A combination shipping skid and upending skid (Fig. 3.21) has heen included in the facility design because this piece of equipment is relatively expensive and it is cost-effective to use the same fixture for all six shipments. This skid will be designed for acceleration and shock loads developed by the selected method of shipping. The lifting beam will be attached to the coil when it arrives at Building 9204-1. The 1ifting beam will then be used to upend the coil and skid. The skid can then be removed from the coil with the coil hanging from the crane hook. The coil is then placed on the storage rack for checkout. 
ORNL/DWG/FED-77623

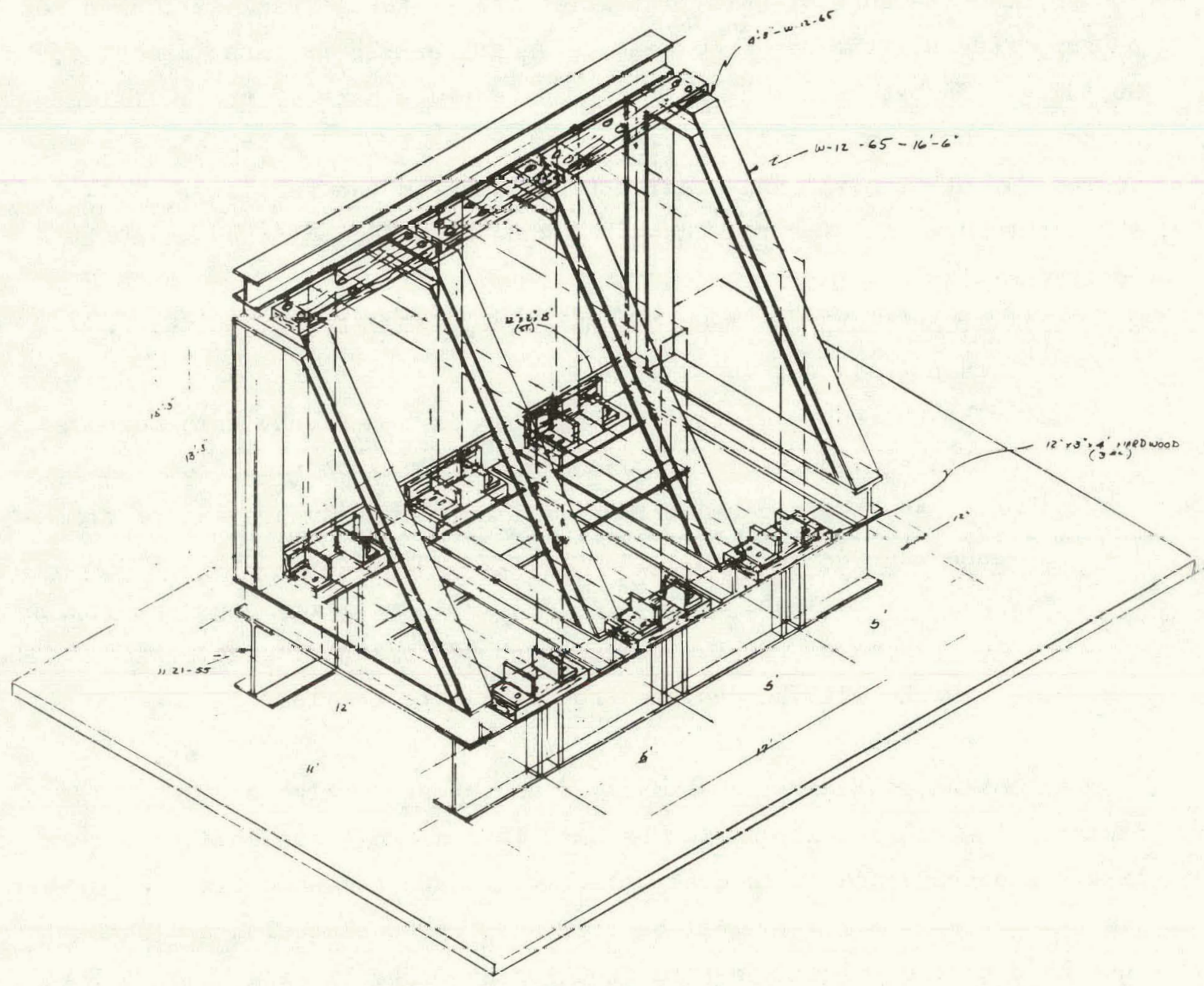

Fig. 3.20. Coil storage fixture. 
ORNL/DWG/FED-77624

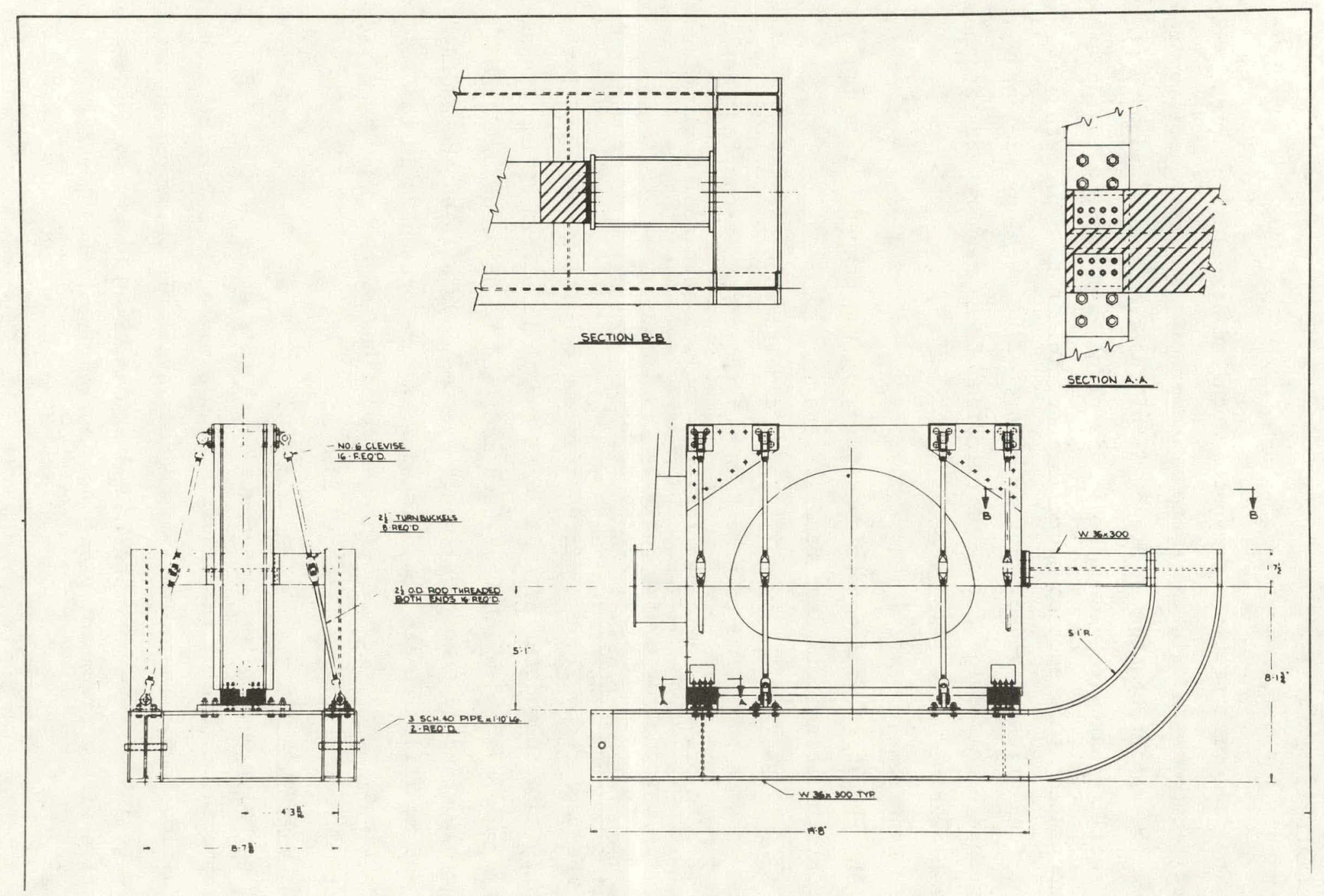

Fig. 3.21. Coil shipping fixture. 


\subsection{STAGE III FACILITY}

The following sections present a detailed description of the systems, or modifications to existing systems, comprising the test facility required to support testing in Stage III of the program. A summary of the test facility hardware elements of this stage is presented in Table 3.6. The content of this section alone is insufficient to depict the full scope of the facilities provided. Review of preceding sections will provide the background required for full comprehension of the requirements and how these are being satisfied.

\subsubsection{Kequirements}

'l'he specitic requirements considered in the conceptual design of this stage of the Large Coil Test Facility are:

(1) to provide the capability for simultaneous testing of three coils with provision to select any of the three as the test coil, and

(2) to provide the capability for cooling both pool-boiling and forced-f1ow conled coils.

\subsubsection{General Description}

The facility will be modified from the condition described for Stage II to accommodate the additional two coils. Primary impacts are in cryogenic systems which have been modificd to provide for forcedflow cooling and in electrical power systems. Details on the added systems and modifications to established items are presented in the following sections. Plan views showing the locations of the major items added are presented in Figs. 3.22 and 3.23 .

\subsubsection{Uncertainties}

The major uncertainty associated with this stage of the LCTF is the developmental nature of the liquid helium pump required for the proposed forced-flow 1oop. There are limited data available on pumps for use in liquid helium service, and heavy reliance is being placed on successful operation with a preprototypical pump currently planned for the LCS program. 
Table 3.6. Large Coil Test Facility Elements - Stage III $^{\alpha}$

\begin{tabular}{|c|c|c|}
\hline \multirow[t]{2}{*}{ System } & \multicolumn{2}{|c|}{ Hardware Incorporated in Stage } \\
\hline & II - Single coil & III - Three coils \\
\hline Vacuum & $\begin{array}{l}\text { - Vacuum tank } \\
\text { - Pumping system }\end{array}$ & \\
\hline Liquid helium & $\begin{array}{l}\text { - Flow system for } \\
\text { single coil }\end{array}$ & $\begin{array}{l}\text { - Pump loop \& system for } \\
\text { two added coils }\end{array}$ \\
\hline Liquid nitrogen & $\begin{array}{l}\text { - Flow system for } \\
\text { single coil }\end{array}$ & $\begin{array}{l}\text { - Flow system for two } \\
\text { added coils }\end{array}$ \\
\hline $\begin{array}{l}\text { Electrical } \\
\quad(\text { experiment })\end{array}$ & $\begin{array}{l}\text { - Install 30-kA power } \\
\text { bus } \\
\text { - Install heater power } \\
\text { - Single dump circuit } \\
\text { - Auxiliary power } \\
\text { - Vapor-cooled lead }\end{array}$ & $\begin{array}{l}\text { - Add two 20-kA power } \\
\text { supplies } \\
\text { - Two added dump circuits } \\
\text { - Two added leads }\end{array}$ \\
\hline $\begin{array}{l}\text { Instrumentation } \& \\
\text { control }\end{array}$ & $\begin{array}{l}\text { - Vacuum system \& } \\
\text { utilities } \\
\text { - LHe } \\
\text { - } \mathrm{LN}_{2} \text { - single coil } \\
\text { - Coil diagnostics }\end{array}$ & $\begin{array}{l}\text { - LHe - two added coils } \\
\text { - } L N_{2} \text { - two added coils } \\
\text { - Diagnostics - two } \\
\text { added coils }\end{array}$ \\
\hline $\begin{array}{l}\text { Structure } \\
\text { (test stand) }\end{array}$ & $\begin{array}{l}\text { - Base support } \\
\text { - Bucking post } \\
\text { - Single-coil support } \\
\text { - Fixtures }\end{array}$ & $\begin{array}{l}\text { - Torque rings } \\
\text { - Structural spacers }\end{array}$ \\
\hline 1ilding modifications & $\begin{array}{l}\text { - Vacul1m tank } \\
\text { foundation } \\
\text { - Electrical power \& } \\
\text { utilities C\&A } \\
\text { - Fire protection } \\
\text { - Upgrade } 13.8-\mathrm{kV} \text { tie } \\
\text { line } \\
\text { - Install 1.5-MVA } \\
\text { substation } \\
\text { - Utilities }\end{array}$ & $\begin{array}{l}\text { - Instalz 50-ton crane } \\
\text { - Substation vault C\&A } \\
\text { - Instalz 1.5-MVA \& } \\
\text { 1.0-MVA substations }\end{array}$ \\
\hline
\end{tabular}

\footnotetext{
$a_{\text {New requirements are in italics. }}$
} 


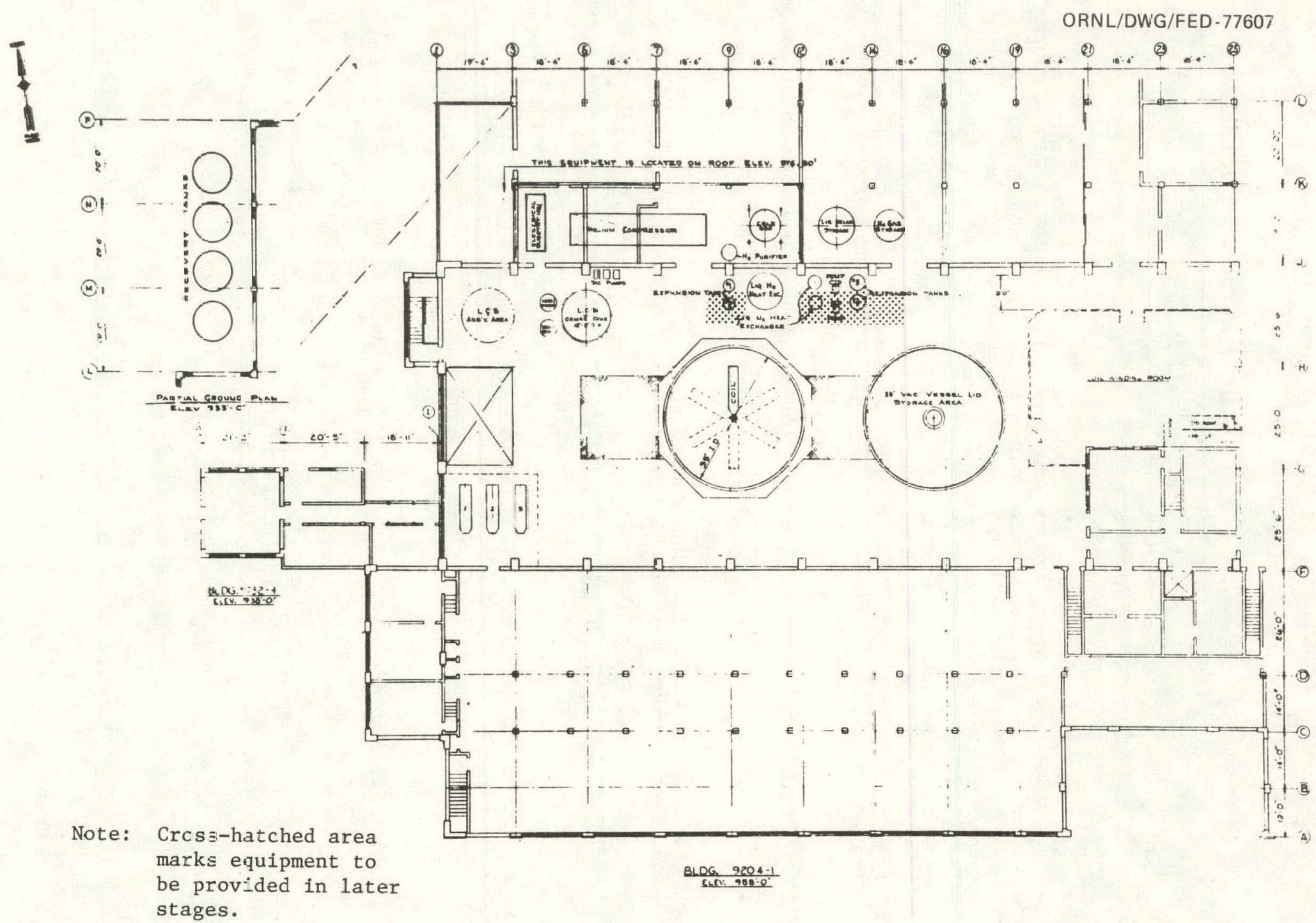

Fig. 3.22. Second floor facility plan - Stage III. 


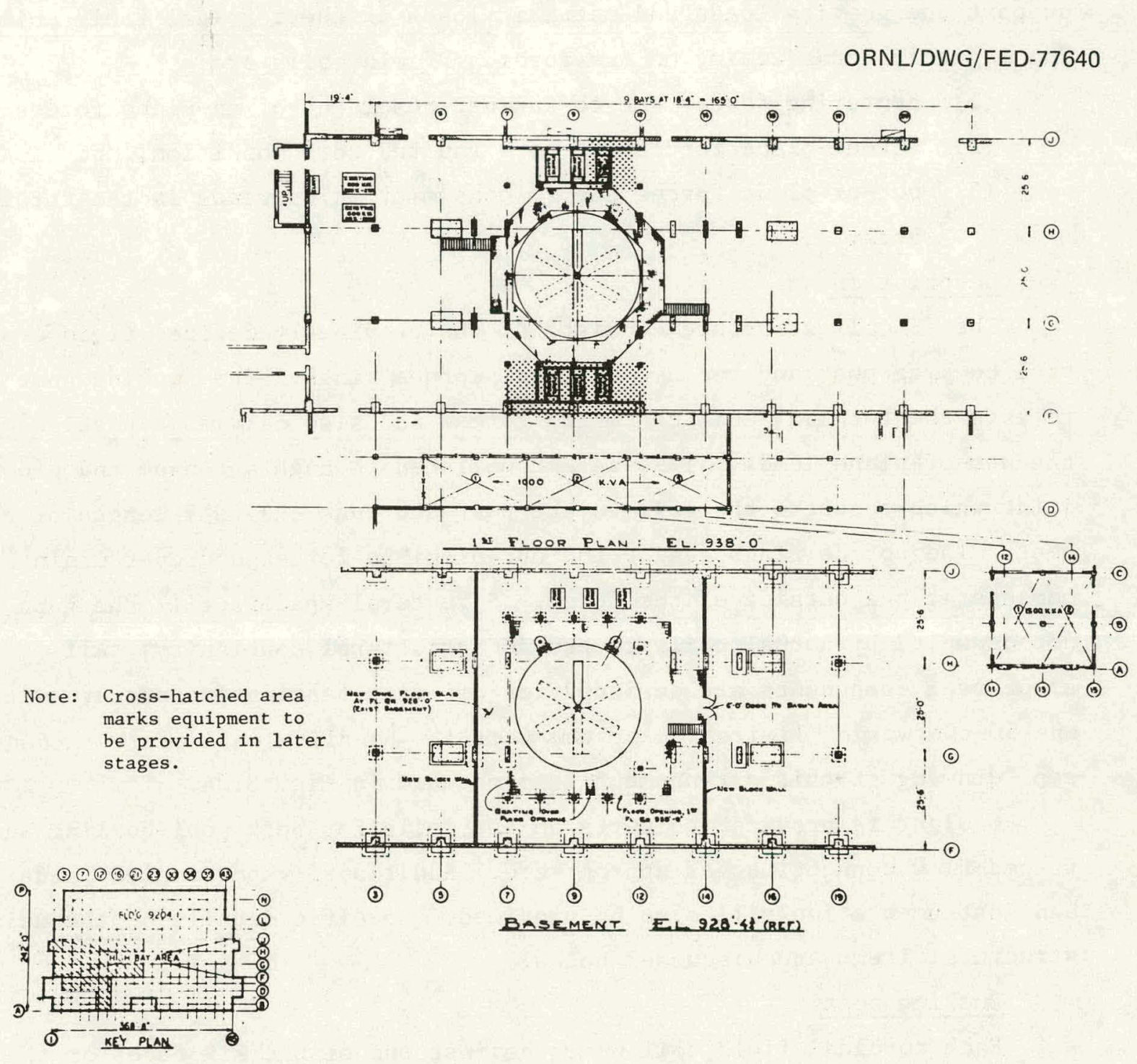

Fig. 3.23. First floor facility plan - Stage III. 


\subsubsection{Structure}

\section{Requirements}

The support structure required for a three-coil array is designed to support the gravity loads and magnetic loads of the toroidal field coils. The magnetic loads acting on the toroidal field coils are:

(1) centering forces due to the net resultant of in-plane forces,

(2) out-of-plane forces due to a faulted coil condition, and

(3) out-of-plane forces due to nonsymmetric currents in the toroidal array.

\section{Description}

The TF coil structure consicts of the previously defined rigid een tral bucking poct and two new external torque rings. The bucking post resists the toroidal coil centering forces and also carries a portion of the out-of-plane loads. This is accomplished through a tongue and groove joint which connects the coil to the post and runs the full length of the post. The torque rings resist the out-of-plane forces and overturning moments at the outside of the torus. Structural spacers fill the gaps not occupied by actual coils to provide structural continuity. All structural components are designed for off-site fabrication and are within the 50-ton weight limitation of the facility, handling equipment. A concept drawing of this arrangement is presented in Fig. 3.24.

Coolant is provided to ports on the coils for both pool-boiling and forced-flow connections as appropriate. Additional vapor-cooled leads and instrumentation will also be provided. Specific details on the major structural items are discussed below.

\section{Bucking post}

Each toroidal field coil bears against one of the six faces of the bucking post and transmits the centering force of the coil to the post. A portion of the out-of-plane forces is carried by a groove which runs the full length of each of the six faces. A matching tongue running the full length of each coil nose fits into the post groove and provides support against the out-of-plane forces. The $\mathrm{TF}$ coils are rigidly attached to the top and bottom of the post with a bolted connection. 


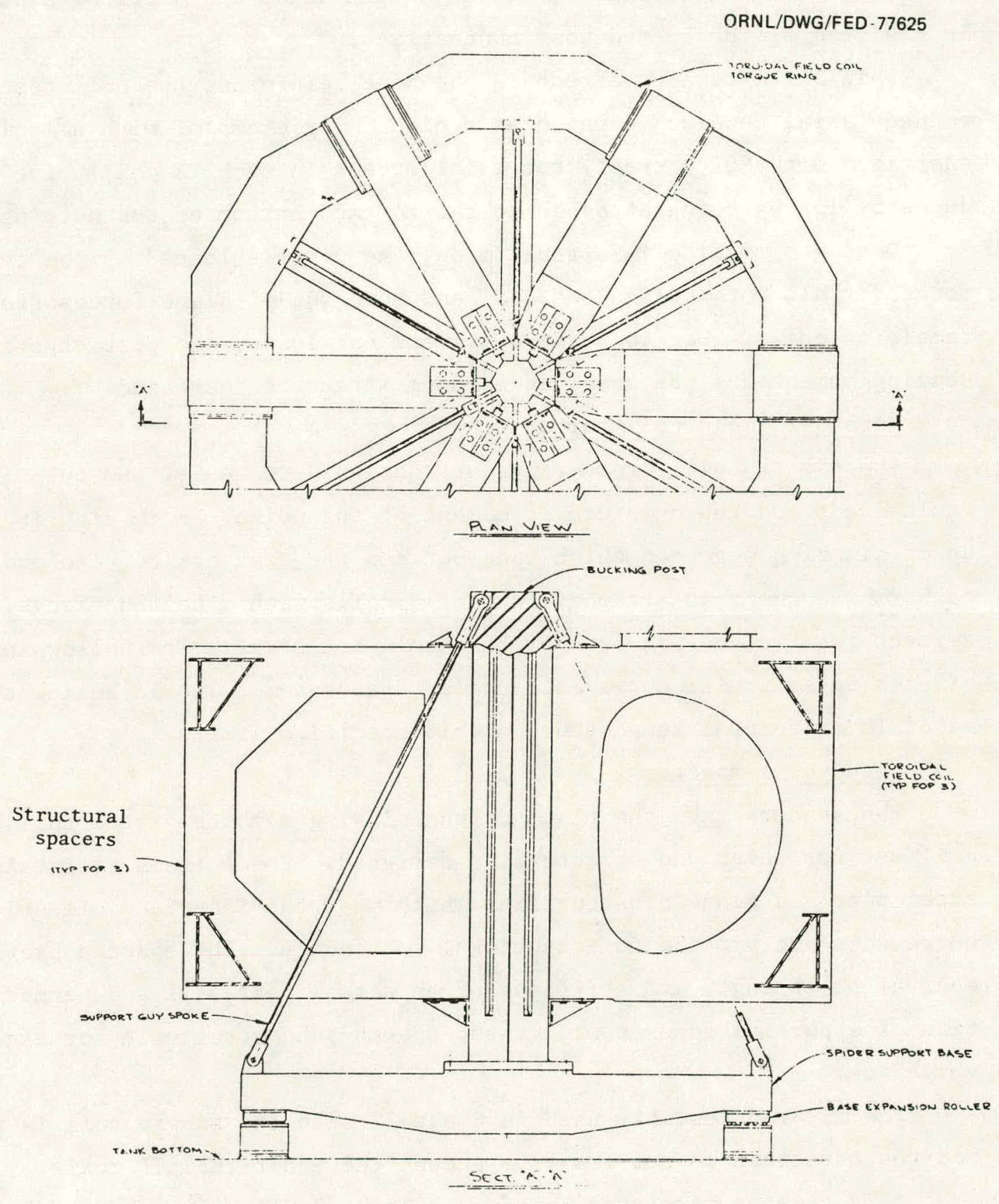

Fig. 3.24. Three-coil test stand. 
With all toroidal ficld coils equally energized, but without pulsed fields, the post is loaded by the radial centering forces of each coil and some out-of-plane forces due to operation in a cluster configuration. In addition, as each energized coil tends to expand, its vertical expansion is resisted by the bolted post connections.

This axial tension effect in the post reinforces the coil nose and reduces axial tension in the nose region. For example, with all six coils energized with $80 \%$ current, the axial stress in each TF coil noise is reduced by $15 \%$ by being attached to the top and bottom of the bucking post.

During operation in a fault mode, the post is loaded by the centering forces of all but the faulted coil and some out-of-plane forces from the remaining coils. Due to these unsymmetrical loads, the post experiences a bending moment and the combined maximum stress is increased.

Toroidal field coil torque rings

The two TF coil torque rings are designed to resist the out-of-plane fault loads and the overturning moment of the coils. Each ring is built up of six ring segments which span between the test coils. The end of each ring segment is attached to the TF coils with a bolted flange. Each segment is a welded box beam of 304 stainless steel. The hollow interior of each segment will serve as a coolant passage for liquid helium to maintain structural temperature within specified limits.

\section{Structural spacers}

The spacers take the place of the missing members of the full sixcoil set for which the structure is designed. These items are stainless steel pipe and plate constructions which meet the interface dimension requirements and provide for structural continuity. The spacers provide the equivalent strength and stiffness of an actual test coil and permit operation of a partial torus test without specialized structures for each variation.

The tie-rod assembly used in Stage II with the single coil is removed and the structure is now ready to accept the additional TF coils.

A TF coil or structural spacer is lowered into place by overhead crane and set on temporary jacks on the enclosure floor. These jacks will support and adjust the coil while it is being aligned. 
Each coil nose tongue is shimmed into the bucking post vertical groove to provide full bearing along the sides of the tongue and groove joint. Each coil is then rigidly attached to the bucking post with bolted angle brackets at the top and bottom of the post.

The torque ring sections are lowered into place between coils, shimmed snug, and bolted to each other through holes in the coils. The shims will provide a full bearing surface between the coil and torque ring and align the bolt holes.

\subsubsection{Electrical Power - Primary Distribution}

\section{Requirements}

The electrical loads for this stage of the LCTF will consist of special purpose dc power supplies and cryogenic pumps and compressors. The estimated loads are broken down in Table 3.7. A schematic of the proposed distribution system is given in Fig. 3.25.

Table 3.7 Facility electrical loads - Stage III

\begin{tabular}{lc}
\hline \multicolumn{1}{c}{ System } & $\begin{array}{c}\text { Connected } \\
\text { load (kVA) }\end{array}$ \\
\hline Helium refrigerator & 1000 \\
Cooling water & 500 \\
Toroidal field power supplies & $900^{\alpha}$ \\
Pulsed coil power supplies & 0 \\
Vacuum systems & 200 \\
Dump resistor ventilation (intermittent) & $150^{a}$ \\
HVAC & 100 \\
Clean power & 7 \\
Lighting and convenience receptacles & 150 \\
& 3007 \\
\hline
\end{tabular}

$a_{\text {Modified loads. }}$ 


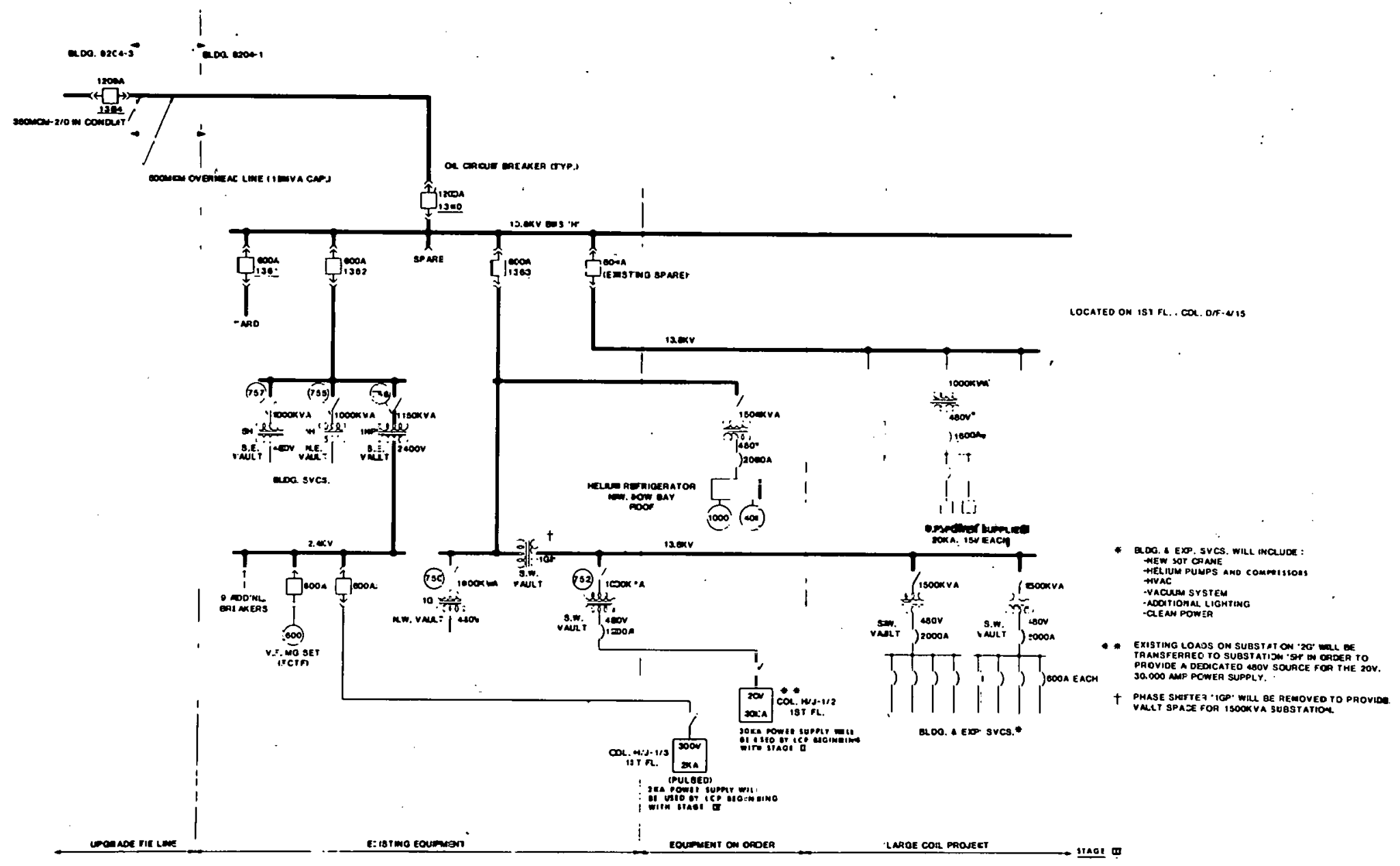

Fig. 3.25. Primary power cistributicn schematic - Stage III. 
New unit substation, building services

This stage of testing will require low voltage building and experiment power in excess of the transformer capacity provided in Stage II. A new 1500-kVA, 13.8-0.48-kV indoor unit substation will be installed in the southwest transformer vault to provide the additional power required. Floor space in the southwest vault for the new unit substation is available adjacent to the unit installed for Stage II.

New unit substation, dc power supplies

A new $1000-k V A, 13.8-0.48-\mathrm{kV}$ unit substation will be installed to provide power to the toroidal field dc power supplies. The unit substation will be installed on the first floor in an area bounded by columns 4/15-D/F. This area is currently used for equipment storage. Dry type transformers will be used so that the construction of a fireproof vault will not be required. New $15-\mathrm{kV}$, cross-1inked polyethylene cable in rigid conduit will be installed from the modified spare $13.8-\mathrm{kV}$ unit to the new unit substations. A roll-up door will be installed at column F-5/7 to provide access for removal and installation of the substation equipment. Secondary feeders to the dc power supplies will consist of either 600-V cable in rigid conduit or $600-\mathrm{V}$ feeder busway, and $5-\mathrm{kV}$, shielded, crosslinked polyethylene cable in rigid conduit.

\subsubsection{Electrical Power - Power Supplies and Secondary Distribution}

\section{Requirements}

It will be necessary to provide:

(1) independently controlled dc power to each test coil location and

(2) ac power for the operation of auxiliary equipment including liquid helium pumps and dump resistor ventilation fans.

An existing 30-kA, 20-V dc power supply will continue to be used to supply the coil power for testing one of the three coils in the vacuum. tank.

Each of the remaining TF coils in the main tank will be supplied from a separate 20-kA, $15-\mathrm{V}$ dc power supply. Six $1 / 2$ in. $x 6$ in. copper bars per leg will be installed from each power supply to a specified coil connection at the tank wall. A panel for each supply to control the output 
of the power supply will be installed in the LCTF control room. Remote operators will be installed on the $480-\mathrm{V}$ breakers which feed the power supplies, and the breakers will be operated from the control room. The power supply output current will be controlled manually from the control panel or by a computer.

Additional dump circuits, for emergency use, that limit the voltage to $1000 \mathrm{~V}$ and will discharge the coil in $50 \mathrm{sec}$ will be installed for each coil. A fan to cool each dump resistor to room temperature in one hour will also be supplied.

The 16 heaters in the coil will each be powered from a previously supplied 0-20-V, 50-A dc power supply. 'lhe heaters in each coil will be connected by a cable and a shell type MS plug to the switch panel and the panel connected to the power supplies. Interlocks will be arranged so that all the heaters to any single coil must be switched on before the power supplies can be energized. The power supplies will have remote panels in the LCTF control room and can be computer controlled.

Auxiliary systems. A motor control center sized to supply all existing equipment and with $20 \%$ spare units has been previously installed for Stage II testing. This center has the capacity to supply the helfum pump and any other additional auxiliary equipment. All of the equipment will be controlled from control stations located in the LCTF control room. The control circuits will be interlocked with the necessary instruments and valves to prevent a misoperation of the equipment. A 75-kVA, 3- $\phi$, 480-203/120-V. transformer and two 36-circuit panels will be installed to provide the necessary control power at the test site and in the control room.

The 2-kVA uninterruptible power supply will be modified to provide control power to the additional dump circuits and other selected instruments.

\subsubsection{Instrumentation}

\section{Requirements}

It will be necessary to provide:

(1) additional instrumentation and control of the facility services with primary emphasis on the cryogenic modifications, 
(2) data acquisition on the operating characteristics of the modified test stand and support structure, and

(3) additional coil diagnostic instrumentation to monitor the sensors inside and on each.test coil.

Description. Additional instrumentation and controls for the Stage III operation can be broken down into various subsystems to be modified. These include the liquid helium system, liquid nitrogen system, and the coil diagnostic system, each of which is discussed in greater detail below. In general the facility controls remain manually operated, while most facility and diagnostic variables are monitored by computer. However, fault detection and response are again automatic and redundant in critical areas.

Liquid helium system. The additions to the liquid helium transfer system will be monitored and controlled by a combination manual and automatic control system. The transfer of helium to the individual poolboiling or forced-flow coil manifolds will be controlled by an operator, but with the transfer monitored by the transducers necessary to ensure correct and orderly operation. In addition to the flow control loops provided for each coil path, each path will have temperature, pressure, and flow monitored by an instrumentation manifold whose outputs are linked to the facility digital computer. The details of the manifold are yet to be developed. The helium gas returned will have its flow. monitored and totalized to provide an indication of liquid helium usage.

Liquid nitrogen system. The $\mathrm{LN}_{2}$ distribution system will be manually operated. The flow and pressure will be monitored and alarmed in each liquid nitrogen line going to the coils. In addition to the $\mathrm{LN}_{2}$ flow to the coils, liquid nitrogen will agaln be utilized in the necessary heat exchangers. The pressure and temperature across each heat exchanger will be monttored and recorded to permit heat balance calculations across the exchangers.

Data acquisition. The modified support structures are to be instrumented with a variety of thermocouples, thermistors, and strain gages. These transducers will require a very low scanning rate and are external to the magnetic field. A digital data acquisition system has been proposed to $\log$ these data points and alarm if preset limits are exceeded. 
The system will basically be a low level, slow speed multiplexer, analogto-digital convertor, and PDP-8E digital computer. The computer will act as the system controller and provide the capability of Inearizing signals from thermistors and other cryogenic transducers.

Coil diagnostic instrumentation. The coil diagnostic instrumentation is identical to that described for Stage II and consists of the signal conditioning and analog-to-digital conversion equipment required to monitor the various types of sensors located inside and on each test coll.

The cooldown temperature signals are connected to the scanner and facility processor. These can then be displayed locally without having to go through the diagnostic computer. In addition to these signals, a num-. ber of other facility variables are monitored by the facility processor. Capabilities include not only display but also limit checking and some control functions.

\subsubsection{Liquid Helium System}

\section{$\underline{\text { Requirements }}$}

The specifications given to industrial suppliers of the large coils to be tested have given the cryogenic conditions to be used in the design. These conditions are therefore constraints on the facility design. An

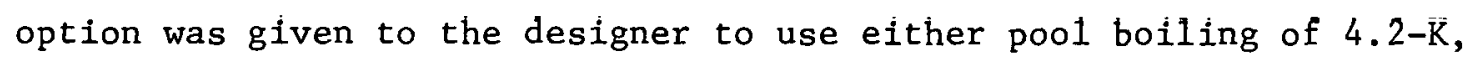
1-atm helium or torced convection-cooling using supercritical helium at 4-K minimum and 6-atm maximum pressure. The return fluid was to be no hotter than $6 \mathrm{~K}$ and at a minimum pressure of $2.5 \mathrm{~atm}$. The initial procurement of three coils includes two pool-boiling and one forced-flow design, so both forms of cooling must be provided in the facility design. Combinations were then postulated of the various arrangements that might be expected for three-coil tests to establish the range of cooling requirements to be provided. These are summarized in Table 3.8.

LHe test faclilty descriprion. A conceptual design has been made of the LHe portion of the test facility based on the requirements described above along with the constraints imposed by the refrigerator capabilities as described in Stage II. A schematic flow diagram of the system is shown in the accompanying drawing, Fig. 3.26. 
Table 3.8. LHe requirements - three-coil array

\begin{tabular}{|c|c|c|c|c|c|c|c|}
\hline Configuration & $\begin{array}{l}\text { Total } \\
\text { coils }\end{array}$ & $\begin{array}{c}\mathrm{PB} \\
\text { coils }\end{array}$ & $\begin{array}{c}\text { FC } \\
\text { coils }\end{array}$ & $\begin{array}{l}\text { Test } \\
\text { coil } \\
\text { type }\end{array}$ & (a ${ }^{W} .5 \mathrm{~K}$ & a $\quad \stackrel{W}{4.2 \mathrm{~K}}$ & $\begin{array}{l}\text { liters } / \mathrm{hr} \\
\text { for leads }\end{array}$ \\
\hline A & 3 & 2 & 1 & $\mathrm{FF}$ & 550 & 400 & 170 \\
\hline B & 3 & 2 & 1 & $\mathrm{~PB}$ & 100 & 600 & 170 \\
\hline
\end{tabular}

A substantial portion of the systems described below has been provided as part of Stage II with the exception of the pump loop. A fairly complete description is given to preserve continuity of this critical system, and reference to the flow schematic in Stage II will assist in identifying specific modifications.

Four basic subsystems exist and, along with the refrigerator, make up the helium system. The four are: (1) saturated liquid distribution and vapor return for pool boiling, (2) supercritical fluid coolant loop for forced convection cooling, (3) lead cooling, and (4) the cooldown loop.

Pool-boiling 1oop. In the pool-boiling loop, liquid helium from the refrigerator at $1.3 \mathrm{~atm}, 4.5 \mathrm{~K}$ is stored in a 5000-gal dewar. From herc it flows to the manifold for the pool-boiling-cooled test coils in the main test vessel. A feed tank will be supplied for each coil to provide a vapor disengaging space to help ensure that only liquid will be fed to the coil coolant passages. This feed tank will be at the top of the coil to provide sufficient static head for flow into the coil. Provision is made to supply this liquid either at the top or the bottom of the test coils.

Vapor generated in the boiling-cooling process will pass out of the top of the coil and flow to a compressor for return to the refrigerator. The compressor is provided with an expansion surge tank to help provide a smooth feed without significant pulsations. This return flow, essentially saturated vapor at $4.2 \mathrm{~K}$, will return to the refrigerator through its heat exchange system and hence represents a refrigeration load as opposed to a liquefaction load. 
ORNL/DWG/FED-77627

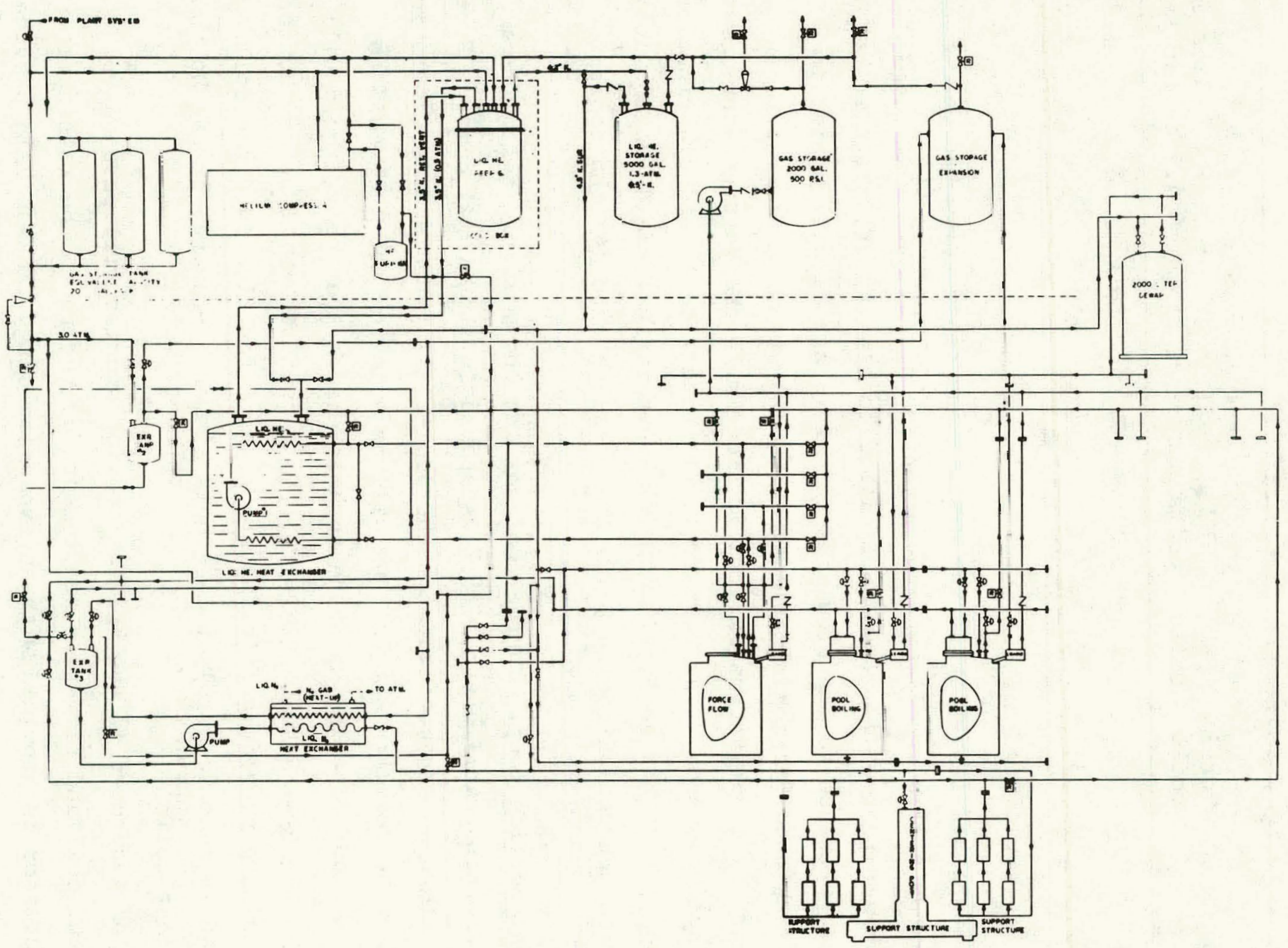

Fig. 3.26. Liquid helium Elow sheet - Stage III. 
Forced convection 1oop. The forced convection cooling loop requires a supply of $4-\mathrm{K}$ helium to circulate through the coil employing this mode of heat removal. A pressurized closed circuit is used for this purpose. Liquid helium from the refrigerator at $0.5 \mathrm{~atm}$ and $3.5 \mathrm{~K}$ is contained in a large dewar $(2.75 \mathrm{~m}$ in diameter and $2.75 \mathrm{~m} \mathrm{high})$. This helium is boiled to provide the heat sink for the $4-\mathrm{K}$ cooling loop. The circulating pumps and aftercooler heat exchangers will be submerged in the $3.5-\mathrm{K}$ helium. This is done not only to help ensure that the close approach temperature differential can be achieved but also to have the pump operate in a nearly isothermal condition to reduce the work input and concomitant heat removal required.

Return fluid from the coil is passed to the pump inlets with an expansion surge tank provided to accommodate density changes that can occur. Boiloff from the 3.5-K heat sink tank is returned directly to the refrigerator as an essentially saturated vapor. This again is represented as a refrigeration load during normal operation.

Power leads. The electrical leads supplying current to the various coils must have a temperature gradient as they pass from the coil interface at nominally $4 \mathrm{~K}$ to the power supply at room temperature. The cold end of the leads will be cooled with 4.2-K helium from a storage dewar separate from that supplying the pool-boiling feed for those coils. One 2000-1iter dewar will be provided for the two coils to provide redundancy and facilitate plumbing and operation with varying numbers of coils installed in the test vessel. These dewars will be filled from the 5000-gal dewar as required during periods between tests. A single dewar, supplied in Stage II, is retained for this stage with additional dewar costs deferred to Stage $V$, when a full complement of coils must be supplied. Trade-offs of reserve capacity and test time may change this philosophy and a second dewar may be supplied to support the three-coil array.

Cooldown 1oop. The fourth subsystem module is the equipment required to assist in cooling the entire test vessel and contents from room temperature down to operating conditions. The entire assembly represents a mass on the order of $3780 \mathrm{kN}$ requiring the removal of about $5.9 \times 10^{10} \mathrm{~J}$ to cool down to a nominal $4 \mathrm{~K}$. While, in theory, this could be done by 
operating the refrigerator and cooling systems just described, the time required for cooldown would be excessively long. For this reason as well as for energy conservation, it was decided to perform as much of the cooldown as possible using $\mathrm{LN}_{2}$ as the heat sink. Direct introduction of nitrogen into the various cooling passages is not desirable, however, since subsequent use of cryogenic helium could freeze traces of nitrogen which might still remain in the system and cause potential problems with flow maldistribution or even blockage. It was therefore decided to use helium as the heat transfer modium and seject the heat in an He- $\mathrm{LN}_{2}$ heat exchanger. Two parallel systems are to be used, one primarily for the coils and the other for associated support structure. This was done to permit more uniform control of the cuuldown, to minimize undesirable temperature gradients, and to use reasonable pipe sizes for the increased helium flow used during cooldown.

Gaseous helium at supercritical pressure will be pumped through the $\mathrm{LN}_{2}$ heat exchanger and then to the test assembly, i.e., coils and structure. When the temperature has becn brought duwil Lu near $\mathrm{LN}_{2}$ temperature, $80-90 \mathrm{~K}$, cooling will be switched to the helium refrigerator loops for the final conling.

\subsubsection{Liquid Nitrogen System}

\section{Requirements}

The $\mathrm{LN}_{2}$ system must satisfy the following additional requirements (flow schematic of this system is shown in Fig. 3.27):

(1) provide a low temperature environmental shield to reduce the added LHe system thermal loads and

(2) provide secondary cooling for GHe during cooldown of the test stand and coils from ambicnt to $35 \mathrm{~K}$.

Liquid nitrogen will be supplied to the coil support structure to reduce the thermal load on the liquid helium system. Common supply and return manifolds will deliver the liquid nitrogen to these areas. Remote shutoff valves will allow independent control of the flow to each diffusion pump baffle, coil lead assembly, the support structure, and the cold wall. The return manifold from these areas includes a relief valve sized to handle a loss of vacuum flow rate from the vacuum vessel system. 
ORNL/DWG/FED-77628

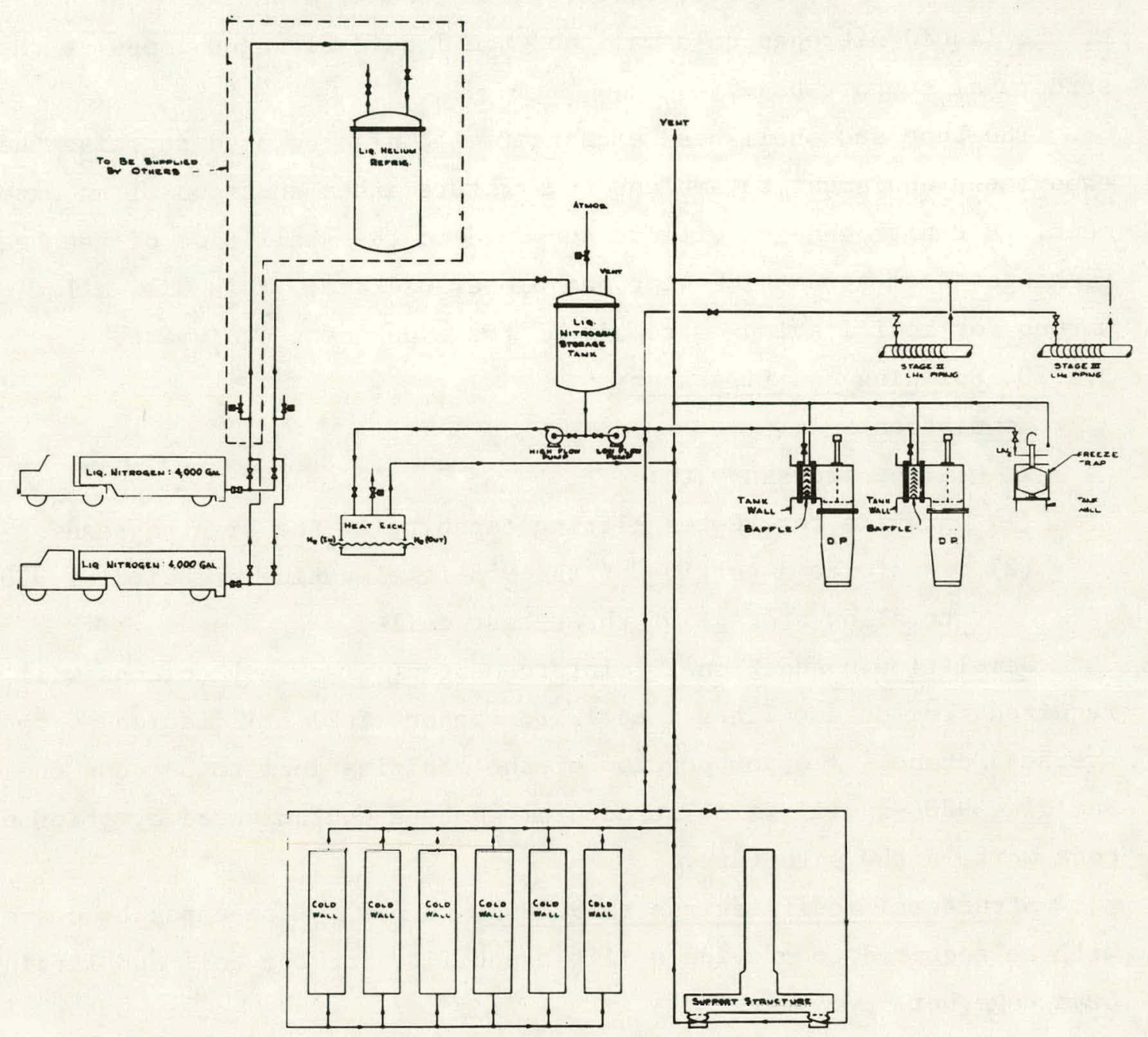

Fig. 3.27. Liquid nitrogen flow sheet - Stage III. 
Cooldown 1oop. A liquid nitrogen-to-gaseous helium tube and shell heat exchanger provides secondary cooling for the experiment during the cooldown from $300 \mathrm{~K}$ to $85 \mathrm{~K}$. The heat exchanger is sized to handle the full cooling load; however, some of this load will be taken out directly by the liquid nitrogen cold wall and the liquid nitrogen loops at the structural support base.

The tube and shell heat exchanger will also be used to raise the experiment equipment to ambient temperature after shutdown of all exper1ment. Hot nitrogen gas will be supplied to the shell side of the heat exchanger from a remote heater and blower package. This will allow quick warmup for modification or repair of the experiment equipment.

\subsubsection{Building Modifications}

Requirements

It will be necessary to:

(1) provide for 50-ton lifting capacity in the high bay and

(2) reinforce a portion of the 958-ft elevation of Building 9204-1 to allow storage of three test coils.

Demolition. Additional reinforcement of crane bay columns will be required from column lines 1 to 12 to support full utilization of the new overhead crane. A major portion of the modifications to be done in Building 9204-1 will be on structural members contaminated by prior process work in the structure.

Structural modifications to 9204-1. A new 50-ton-capacity crane will be required to provide a lift capability for the coil and lifting beam together.

l'ifty-Lull-capac1ty cranes are available to span 70 linear feet and meet the existing headroom requirements. Crane bay girders and columns between column lines 1 and 12 wi11 he rebuilt and reinforced tu alluw handling a 50-ton lift for the full width of the bay. This provides for greater flexibility in facility operation and better utilization of floor space. The full bay lifting capability allowed the location of a coil storage position in the southwest corner of the high bay area. Due to a $300 \mathrm{lb} / \mathrm{ft}^{2}$ limitation on the 958-ft level in 9204-1, this coil storage rack must be structurally supported all the way from bed rock. 
Transformer supports. New support pads will be required for the 1000-kVA primary power distribution transformers that will be located between column lines 4 to 15 and $E$ to $D$. These pads will be approximately $4.3 \mathrm{~m} \times 8.6 \mathrm{~m} \times 10 \mathrm{~cm}$.

\subsection{STAGE IV FACILITY}

The following sections present a detailed description of the systems or modifications to existing systems comprising the test facility to support testing in Stage IV of the program. A summary of the test facility hardware elements of this stage is presented in Table 3.9. The content of this section alone is insufficient to depict the full scope of the facilities provided. Review of preceding sections will provide the background required for full comprehension of the requirements and how these are being satisfied.

\subsubsection{Requirements}

The specific requirement considered in the conceptual design of this stage of the LCTF is to provide pulse field testing capability.

\subsubsection{Genera1 Description}

The facility will be modified for the conditions prevailing after Stages II and III to accommodate testing of a TF coil with imposition of pulse fields. Primary impacts are to incorporate a pulse coil system and its associated electrical power system. Details on these added items are presented in the following sections. Plan views showing the locations of the major items are presented in Figs. 3.28 and 3.29.

\subsubsection{Pulse Coil System}

\section{Requirements}

The TF coil support structure has been designed to withstand the magnetic loads resulting from operation with pulse coils. The reaction on the TF coils is an out-of-plane overturning moment. A corresponding moment acts on the coil generating the pulse field when the energized pulse coil attempts to align 1tself with the toroidal field.

Description. The TF coil structure again consists of a rigid central bucking post and two external torque rings. The bucking post resists the toroidal coil centering forces and also carries a portion of the out-ofplane luads. This is accomplished through a tongue and groove joint which 
Table 3.9. Large Cjil Test Facility Elements - Stage IV ${ }^{a}$

\begin{tabular}{|c|c|c|c|}
\hline \multirow{2}{*}{ System } & \multicolumn{3}{|c|}{ Hardware Inzorporated in Stage } \\
\hline & II - Single coll & III - Three ccil:s & IV $-3 /$ pulsed \\
\hline Vacuum & $\begin{array}{l}\text { - Vacuum tan } \kappa \\
\text { - Pumping system }\end{array}$ & & \\
\hline Liquid helium & $\begin{array}{l}\text { - Flow system for } \\
\text { single coil }\end{array}$ & $\begin{array}{l}\text { - Pump loop and systen } \\
\text { for two cdded coils }\end{array}$ & \\
\hline Liquid nitrogen & $\begin{array}{l}\text { - Flow systen for } \\
\text { single co } \_1 \\
\text { - Cold wall }\end{array}$ & $\begin{array}{l}\text { - Flow system for two } \\
\text { added coils }\end{array}$ & $\begin{array}{l}\text { - Frow system for } \\
\text { Eulse coil }\end{array}$ \\
\hline $\begin{array}{l}\text { Electrical } \\
\text { (experiment) }\end{array}$ & $\begin{array}{l}\text { - Install 30-kA } \\
\text { power bus } \\
\text { - Install heater power } \\
\text { - Single dumf c-rcuit } \\
\text { - Auxillary power } \\
\text { - Vapor-cooled lead }\end{array}$ & $\begin{array}{l}\text { - Add two } 2 \mathrm{C}-\mathrm{kA} \\
\text { power supplies } \\
\text { - Two added lump circuits } \\
\text { - Two added leads }\end{array}$ & $\begin{array}{l}\text { - Acid 2-kA, 300-V pulse } \\
\text { Eower supply }\end{array}$ \\
\hline Instrumenta:ion is control & $\begin{array}{l}\text { - Vacuum system and } \\
\text { utilities } \\
\text { - LHe - single coil } \\
\text { - } \mathrm{LN}_{2}-\text { single coil } \\
\text { - Coil diagnostics }\end{array}$ & $\begin{array}{l}\text { - LHe - two added coils } \\
\text { - } \mathrm{LN}_{2} \text { - two added coils } \\
\text { Diagnostics - two added coils }\end{array}$ & $\begin{array}{l}\text { - } \mathrm{LN}_{2} \text { - pulse coil } \\
\text { - Diagnostics - pulse coil }\end{array}$ \\
\hline $\begin{array}{l}\text { Structure } \\
\text { (test stanc) }\end{array}$ & $\begin{array}{l}\text { - Base supporz } \\
\text { - Bucking pos }= \\
\text { - Single-coil support } \\
\text { - Fixtures }\end{array}$ & $\begin{array}{l}\text { - Torque rings } \\
\text { - Structural spacers }\end{array}$ & $\begin{array}{l}\text { - Putse coit } \\
\text { - Pu'se coil supports }\end{array}$ \\
\hline Building modifications & $\begin{array}{l}\text { - Vacuum tank fo mndation } \\
\text { - Electric power and } \\
\text { utilities G\&A } \\
\text { - Fire protection } \\
\text { - Upgrade } 13 . \&-k V \text { tie line } \\
\text { - Install 1.5-MVA } \\
\text { substation } \\
\text { - Utilities }\end{array}$ & $\begin{array}{l}\text { - Instal1 } 50 \text {-ton crare } \\
\text { - Substation vault C\&A } \\
\text { - Install } 1.5 \text {-NVA } \\
\& 1.0 \text {-MVA substations }\end{array}$ & $\begin{array}{l}\text { - Install 1.0-MVA } \\
\text { substation }\end{array}$ \\
\hline
\end{tabular}

$a_{\text {New }}$ requirements are in talics. 


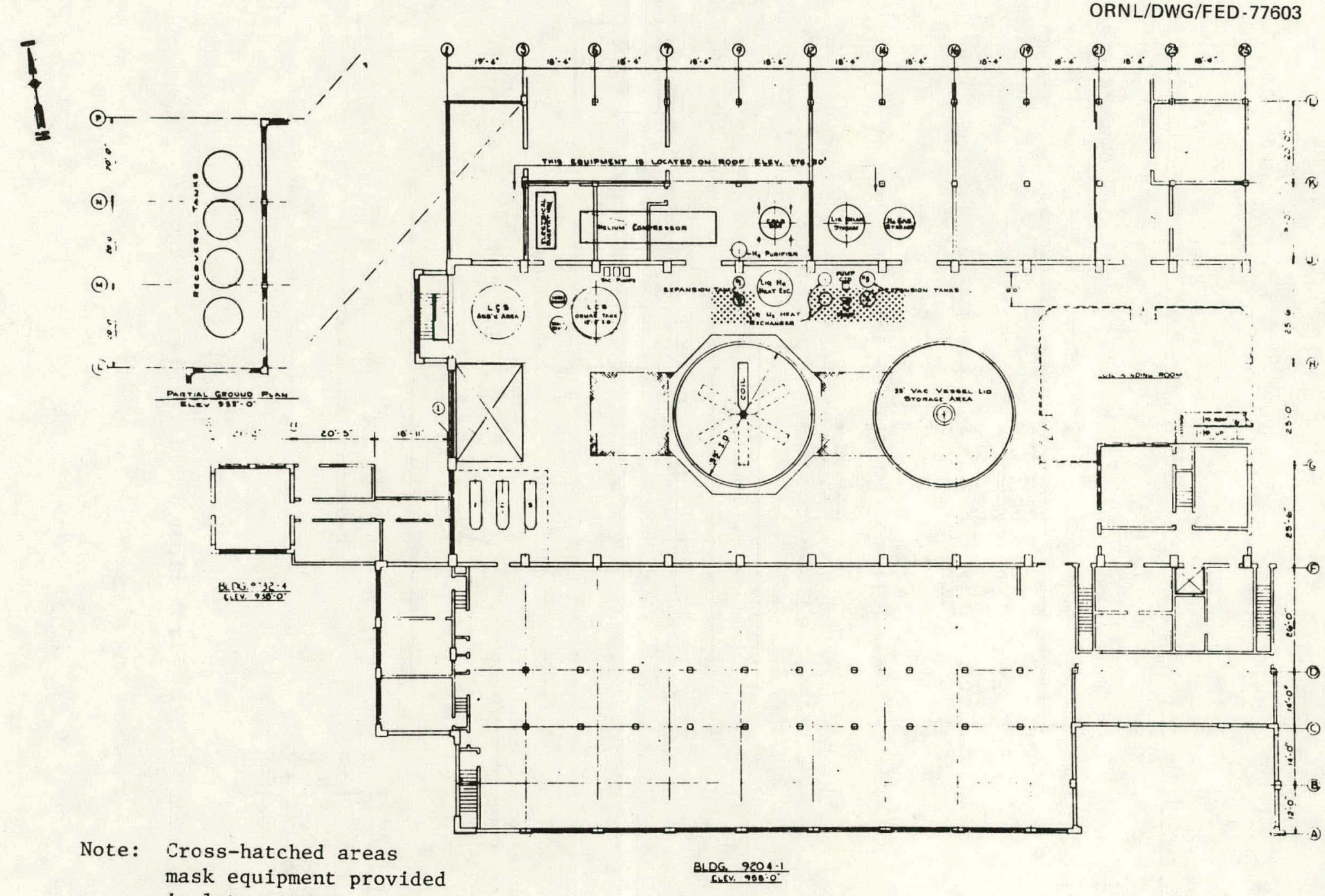

Fig. 3.28. Second floor facility plan - Stage IV. 


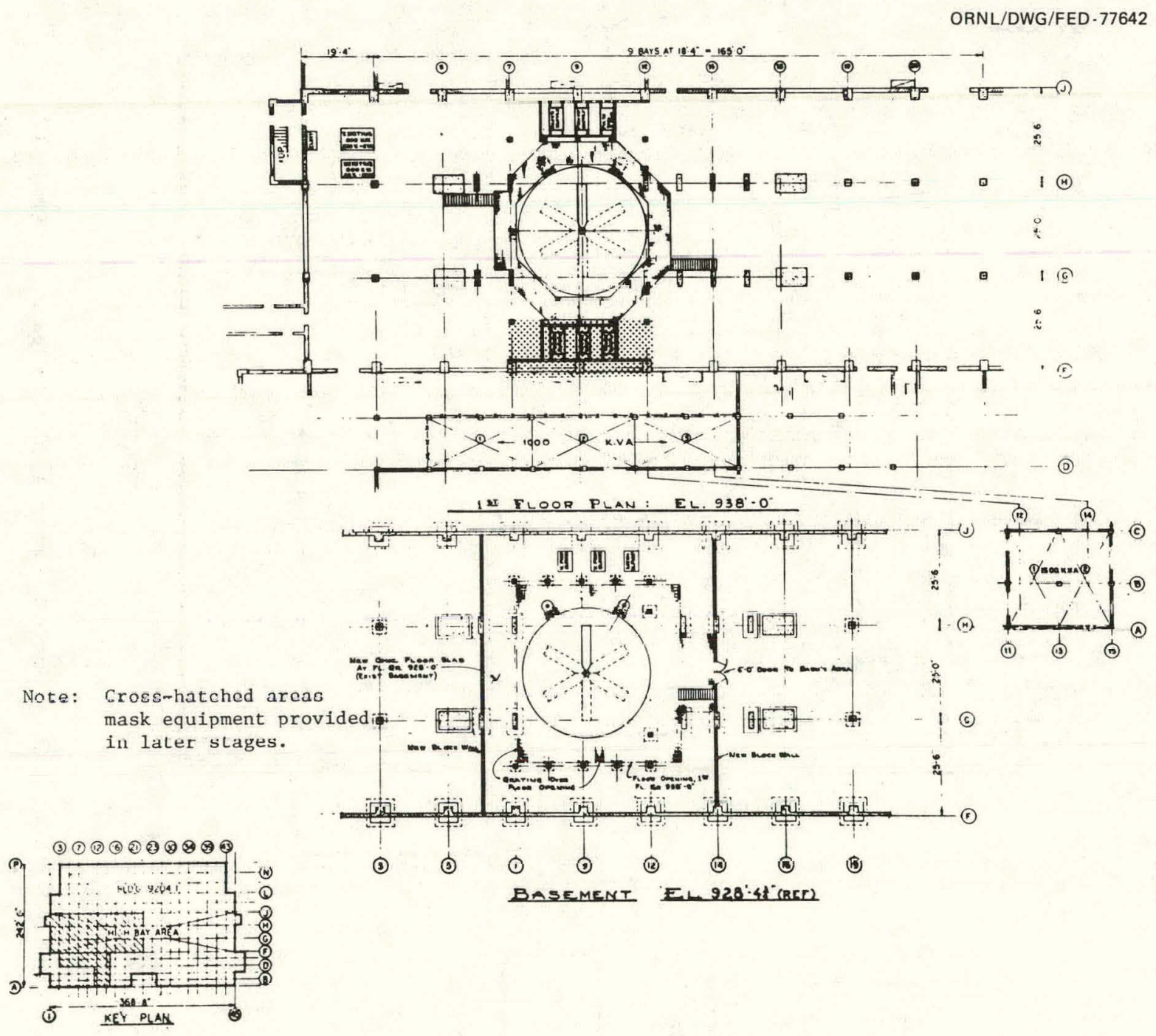

Fig. 3.29. First floor facility plan - Stage IV. 
connects the coil to the post and runs the full length of the post. The torque rings resist the out-of-plane forces and overturning moments at the outside of the torus.

The pulse coil structure consists of a torque ring which runs through the bore of the TF coils. This ring in turn is supported by spokes from the top and bottom of the bucking post. A concept drawing of this arrangement is presented in Fig. 3.30.

All structural components are designed for off-site fabrication and are within the 50-ton weight limitation of the facility handling equipment.

The pulse coil support spokes and end fittings will be $21-6-9$ stainless steel. This higher strength steel was chosen to allow for a small cross section in the spokes to reduce heat conduction to the $4 \mathrm{~K}$ bucking post.

A pulse coil is included in the LCTF test stand to simulate the pulsed field environment of the toroidal coils in a tokamak reactor. Since TNS will be the first tokamak to require the technology developed in LCTF, it was chosen to define the magnetic criteria for the pulse coils. These criteria include the magnitude, distribution, and rate of change of pulsed fields in the toroidal coil windings.

After a study of the TNS poloidal currents and resulting fields (Ref. 5), the requirements for the LCTF pulse fields were chosen. The peak magnitude and distribution of fields in the test coil will approximate the envelope shown in Fig. 3.31. This corresponds to the fields in the toroidal coils of TNS two seconds into its operating cycle. The operating cycle is shown in Figs. 3.32 and 3.33. The peak rates of change of field would then be as severe as those of TNS.

In addition to the magnetic requirements, there are facility-related considerations such as versatility of design, ease of fabrication, and cost of operation. Versatility of design includes the ability to pulse the test coils selectively, modify the field distribution, and remove or replace the test coils easily. Ease of fabrication means that the pulse coils should not be more difficult or expensive to build than the toroidal coils, nor should they require new technology. Finally, the cost of operation, primarily the refrigeration loads on the nitrogen and helium systems, should be as small as possible. 


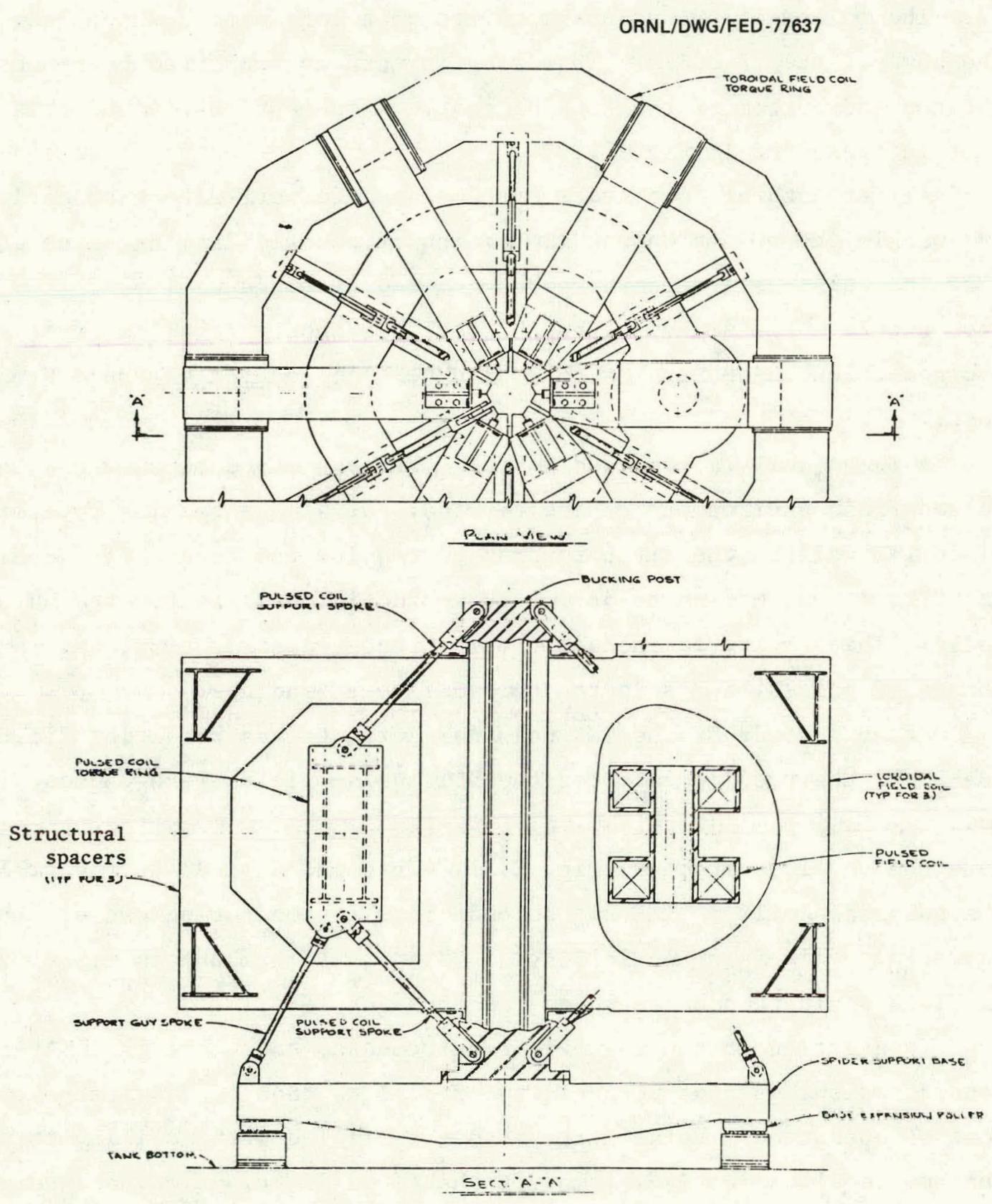

Fig. 3.30. Three-coil test stand with pulse coil. 

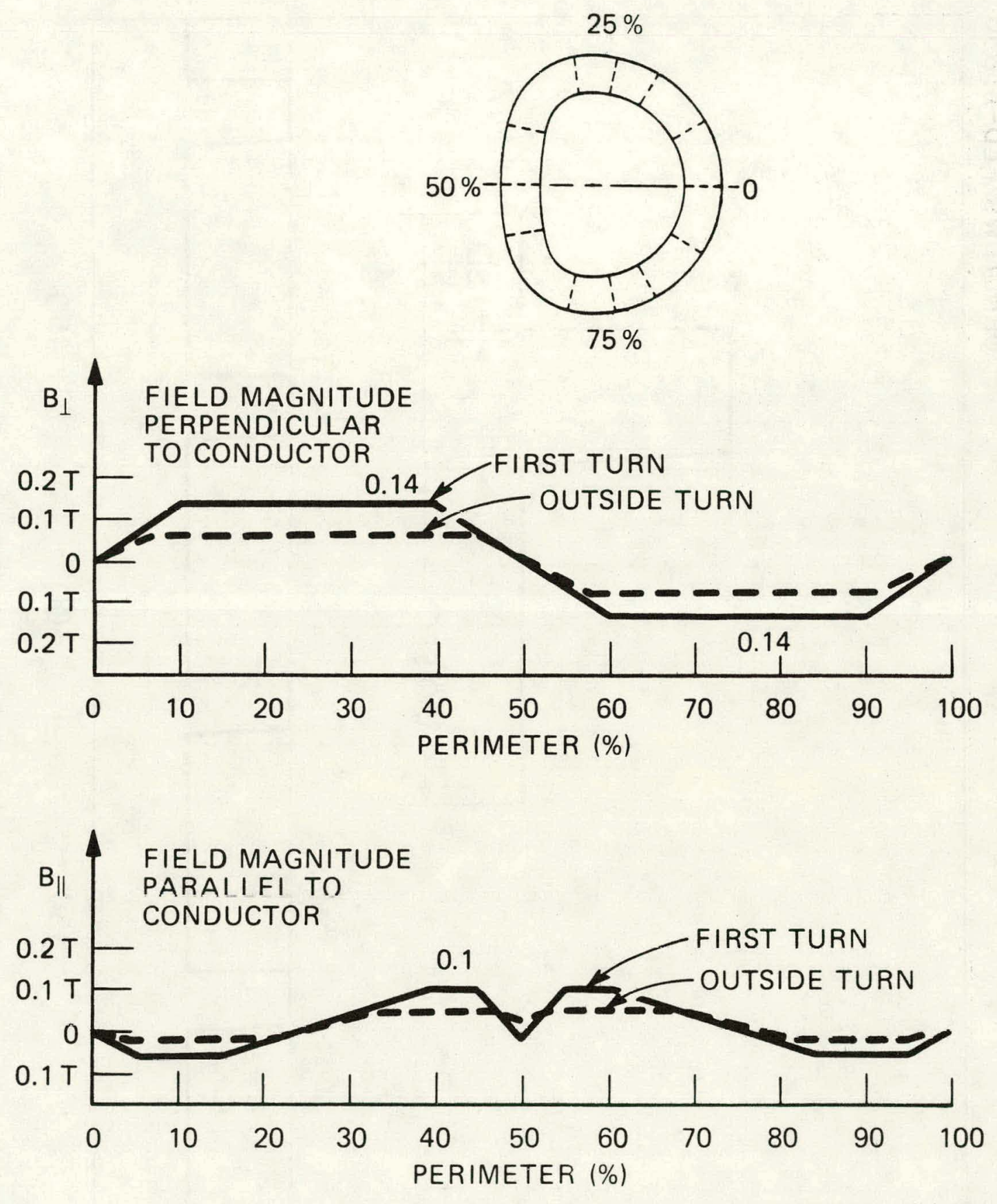

Fig. 3.31. Magnitude of pulse field. 
JRNL/DWG/FED-77630

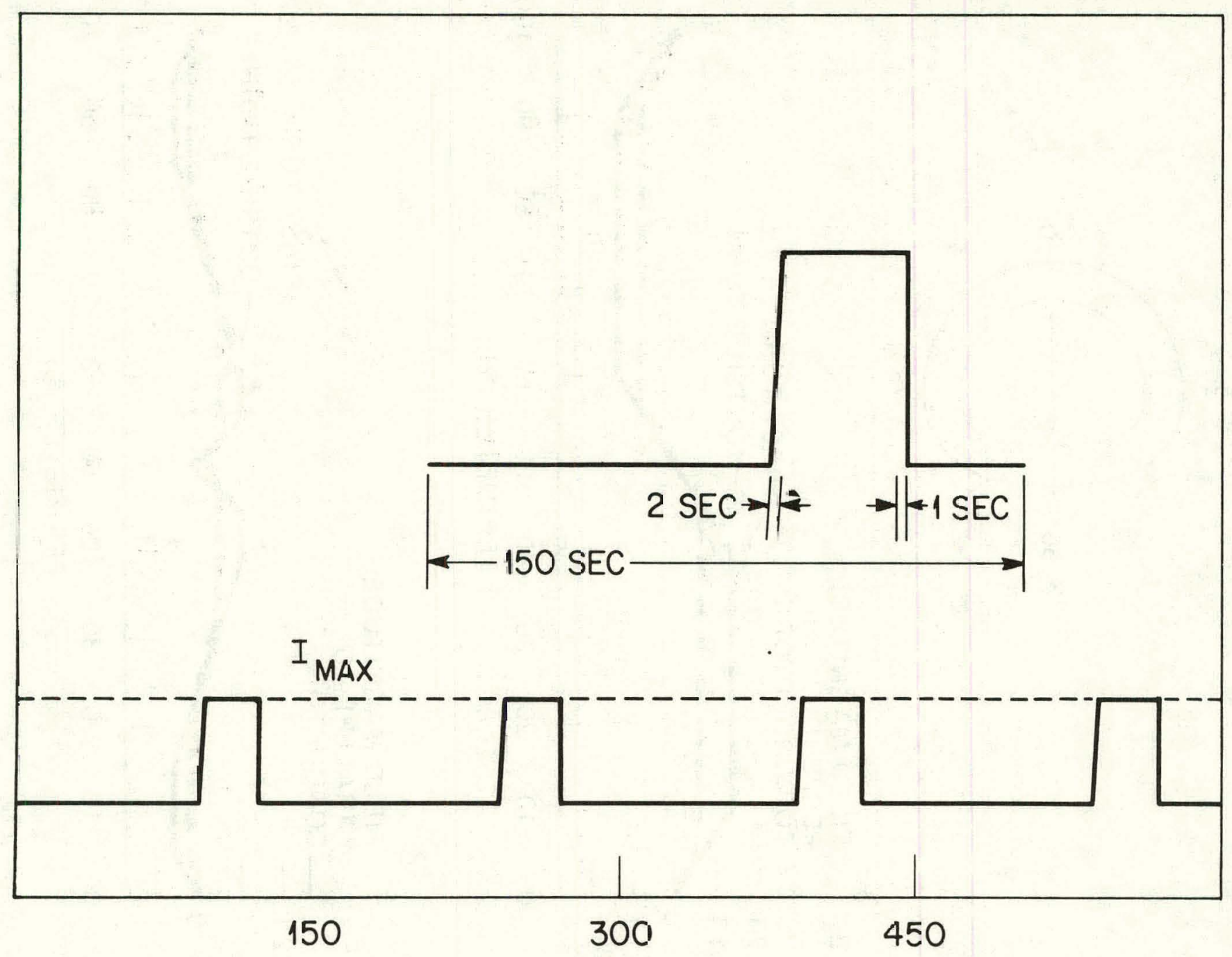

Fig. 3.32. Pulse coil current cycle. 


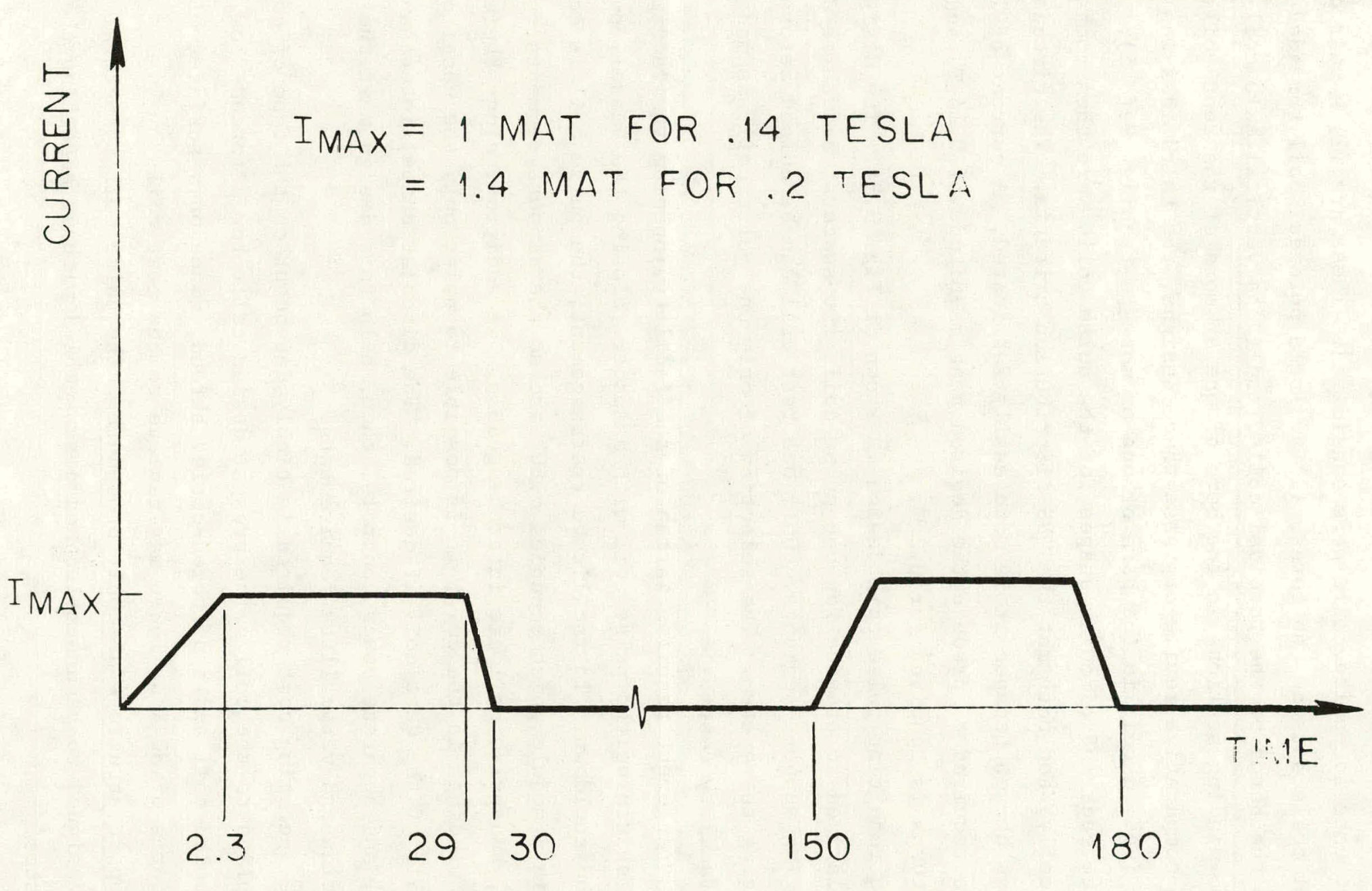

Fig. 3.33. Pulse coil current waveform. 
To meet the magnetic and facility requirements outlined above, three basic schemes for pulse coils were considered. These are (1) a pair of poloidal coils outside the torus, (2) a single poloidal coil threaded through the bores of the toroidal coils, and (3) a vertical axis coil with two winding sections in the bore of one or more of the test coils. After a comparative review of these three designs, the third idea was chosen, i.e., a coil in the bore of one or more test coils (Ref. 5).

Racetrack and circular shapes for the pulse coils were then compared magnetically, and both met the TNS distributinn rriteria. The circular shape was chosen because it is more easily fabricated. A current of $1 \mathrm{MA}$ turns is required to produce the desired peak magnitnie of $0.14 \mathrm{~T}$, and 1. 1 MA turns is required for $0.2 \mathrm{~T}$.

The resulting pulse coil design is shown in Fig. 3.34. The design is modularized to provide for one pulse coil, twn spacers, and threc torque ring support segments. Only one test coil can be pulsed before rearranging the system. The selection of only one pulse coil was made to reduce facility costs.

Rearrangement requires warmup of the facility, opening the vacuum vesse1, switching the pular coil with a spacer, closing the vesse1, pumpdown, and cooldown. To facilitate rearrangement, the pulse coil is conLained in a module which occupies a $60^{\circ}$ arc so the support segments, spacers, and pulse coil are interchangeable. In addition, since there are two windings in the coil, it is possible to pulse only the upper or lower half of the test coil if desired. The circular shape, interchangeability, and separate power controls, then, help this design meet the fabrication and versatility requirements.

The operating cost required is highly dependent on the type of cooling supplied to the coil. The present design calls for a forced-flow, water-cooled coil and a nftrogen-cooled shroud, since only surfaces with temperatures of $80 \mathrm{~K}$ or lower may radiate to the test coil.

Support structure assembly procedure. The pulse coil structural system is designed to be assembled and disassembled without affecting the TF coil system. 
ORNL/DWG/FED-77632

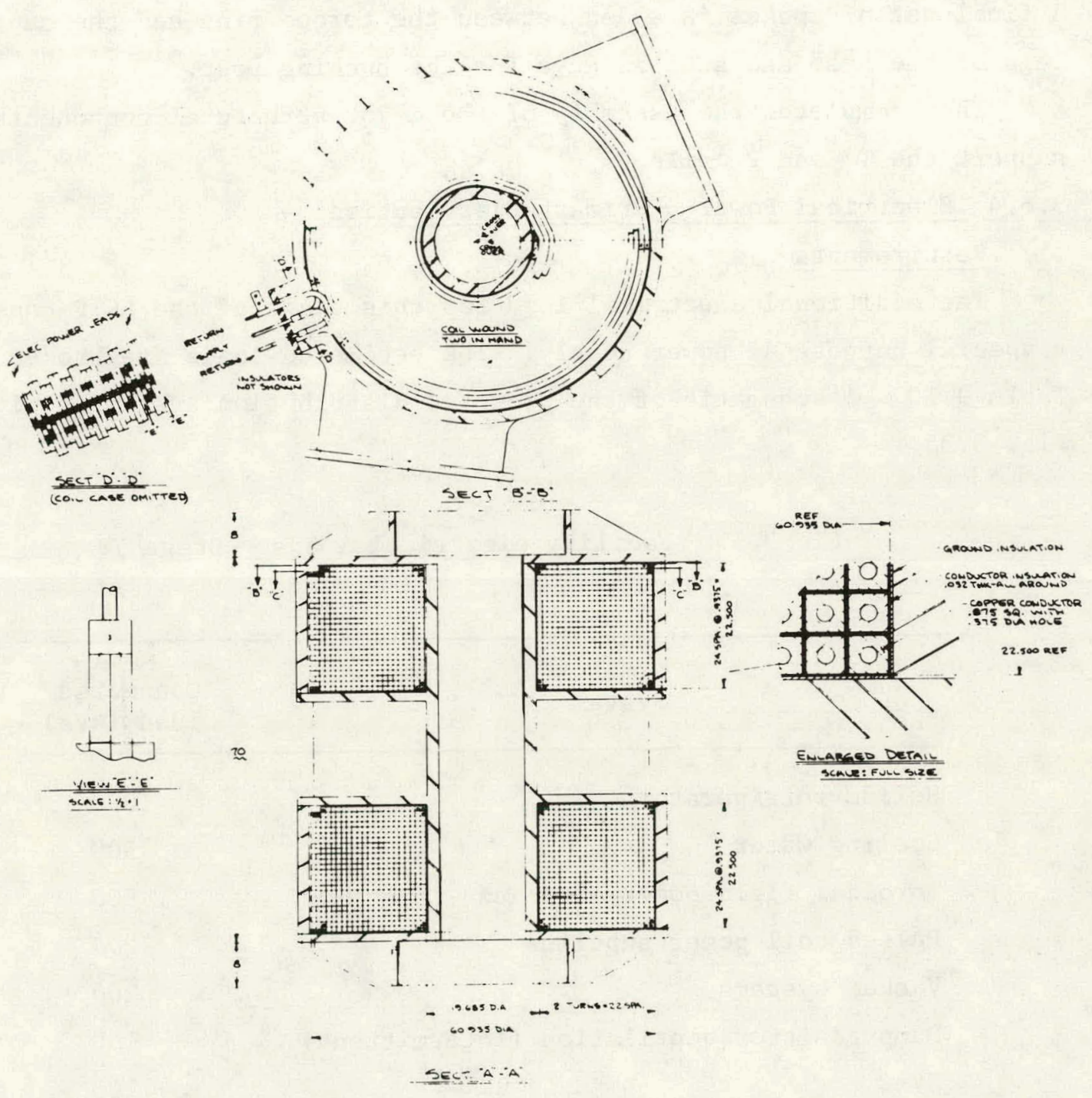

Fig. 3.34. Pulse coil assembly. 
The pulse coil ( $\mathrm{P}$ coil) is set into the bore of the TF coils and secured to temporary support columns. The $\mathrm{P}$ coil torque ring sections are set in place, shimmed snug, and bolted to the $P$ coil.

The $P$ coil support spokes are attached with pin and clevis joints between the $P$ coil torque ring and the top and bottom of the bucking post. A final set of spokes is added between the torque ring and the support legs of the base and acts as guys for the bucking post.

This completes the assembly of the major structural components to support the TF and $\mathrm{P}$ coils.

\subsubsection{Electrical Power - Primary Distribution}

\section{Requirements}

The additional electrical luad for this stage of the LC'I'F consists of a special purpose dc power supply. The estimated loads are broken down in Table 3.10. A schematic of the proposed distribution system is given in Fig. 3.35.

Table 3.10. Facility electrical loads - Stage TV

\begin{tabular}{lc}
\hline \multicolumn{1}{c}{ System } & $\begin{array}{c}\text { Connected } \\
\text { load (kVA) }\end{array}$ \\
\hline Helium refrigerator & 1000 \\
Cooling water & 500 \\
l'oroida field power supplies & 900 \\
Pulsed coil power supplies & $1200^{a}$ \\
Vacuum systems & 200 \\
Dump resistor ventilation (intermittent) & 150 \\
HVAC & 100 \\
Clean power & 7 \\
Lighting and convenience receptacles & 150 \\
& $\frac{4207^{a}}{}$ \\
\hline Modified load. &
\end{tabular}


ORNL/DWG/FED-77633

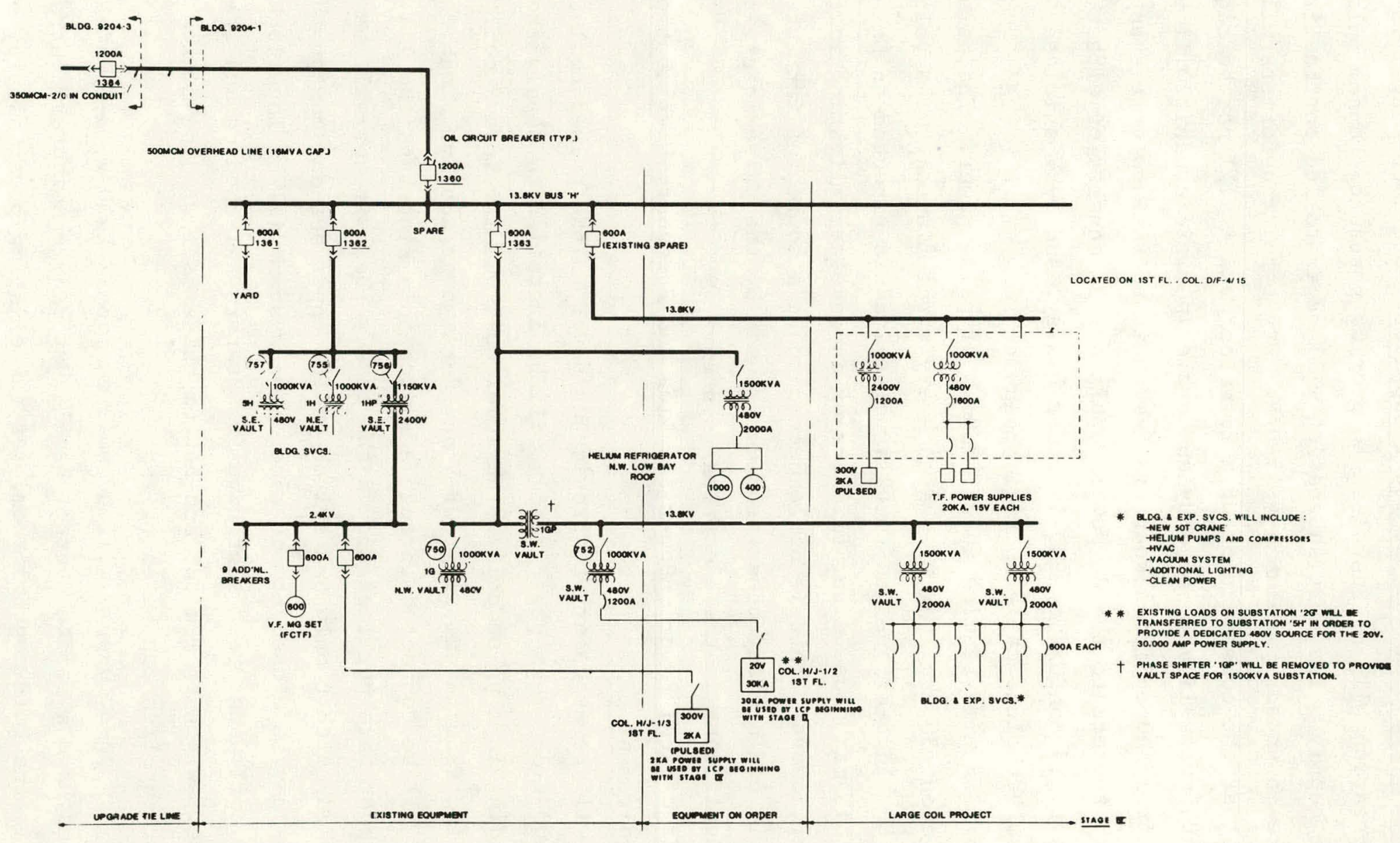

Fig. 3.35. Primary power distribution schematic - Stage IV. 
New unit substations, dc power supplies. One 1000-kVA, 13.8-2.4-kV unit substation will be installed to provide power to the new pulse coil dc power supply. The unit substation will be installed on the first floor in an area bounded by columns 4/15-D/F. Dry type transformers will be used so that the construction of a fireproof vault will not be required. New 15-kV, cross-linked polyethylene cable in rigid conduit will be installed from the modified spare $13.8-\mathrm{kV}$ unit to the new unit substation. Secondary feeders to the dc power supplies will consist of either $600-V$ cable in rigid conduit or $600-\mathrm{V}$ feeder busway, and $5-\mathrm{k} V$ shielded, crooclinked polyethelene cable in rigid conduit.

The LCTF will require about $1200 \mathrm{~kW}$ of pulse power. The pulses will be about $30 \mathrm{sec}$ long, repeated every three minutes. The voltage drop on the $13.8-\mathrm{kV}$ bus due to this pulse load is expected to be about $0.9 \%$. This may cause minor flickers of incandescent 1ighting in the building; however, this is not expected to be a source of irritation to personnel, nor are any other problems caused by the pulse load expected to be significant in the electrical system.

\subsubsection{Electrical Power - Power Supplies and Secondary Distribution}

\section{Requirement.}

It will be necessary to provide de power to the pulsed coils.

A 300-V dc, 2-kA power supply will be installed to supply the upper coil winding in a pulse coil. The lower coil winding in a $\mathrm{P}$ coil will be supplied from an existing 300-V dc, 2-kA power supply. Each P coil winding will be connected through a switch to a ring bus (two $1 / 4$ in. $x$ 4-in. copper bars per leg) around the tank. The switches will be key interlocked so that only one switch on the upper bus and one on the lower bus may be closed at one time. The system will be interlocked so that the coil under test must have its heaters switched on and the disconnect switch to its top and bottom pulse coil winding closed before the power supplies can be energized.

The new power supply will be powered from a $2400-\mathrm{V}, 3-\phi, 60-\mathrm{Hz}$ power source and have a remote control panel that can be computer-controlled located in the LCTF control room. At the existing power supply, switches will be installed in the existing output bus run so the power can be 
switched between its present site and the new LCTF test tank. These switches will be remotely controlled from a panel near the power supply. A new control panel for the existing power supply, complete with interconnecting cables, will be purchased and installed in the LCTF control room.

The bus runs of the two power supplies will be arranged so that sections of the bus can be changed and give a 600-V, 2-kA supply for the pulse coils.

\subsubsection{Instrumentation}

Requirement

It will be necessary to provide additional data acquisition on the operating characteristics of the test stand, support structure, and vacuum vessel cold walls.

Description. Instrumentation and controls for this stage of the LCTF include the additions to the liquid nitrogen system and the diagnostic system to account for pulsed fields. In general, the facility remains essentially as described previously.

\subsubsection{Liquid Nitrogen System}

Requirement

The $\mathrm{LN}_{2}$ system must satisfy the requirement to provide cooling of the pulse coil thermal shroud.

Description. The pulse coil is enclosed in a nitrogen-cooled thermal shroud to control the thermal radiation load from the water-cooled pulse coil to the 4-K TF coils and structure. This requires a simple plumbing system addition to existing liquid nitrogen system hardware. 'l'he modifications required are shown schematically in Fig. 3.36.

\subsection{STAGE V FACILITY}

The following sections present a detailed description of the systems or modifications to existing systems comprising the test facility required to support testing in Stage $V$ of the program. A summary of the test facility hardware elements of this stage is presented in Table 3.11. The content of this section alone is insufficient to depict the full scope of 
Table 3.11. Large Coil Test Facility Elements - Stage $\mathrm{v}^{a}$

\begin{tabular}{|c|c|c|c|c|}
\hline \multirow{2}{*}{ System } & \multicolumn{4}{|c|}{ Hardware incorporated in stage } \\
\hline & II - Single coil & III - Three coils & IV $-3 /$ pulsed & $v-$ Six coils \\
\hline Vacuum & $\begin{array}{l}\text { - Vacuum tank } \\
\text { - Pumping system }\end{array}$ & & & \\
\hline Liquid helium & $\begin{array}{l}\text { - Flow system for } \\
\text { single coil }\end{array}$ & $\begin{array}{l}\text { - Pump loop and system } \\
\text { for two added coils }\end{array}$ & & $\begin{array}{l}\text { - Flow system for } \\
\text { three adäed coils }\end{array}$ \\
\hline Liquid nitrogen & $\begin{array}{l}\text { - Flow system for } \\
\text { single coill } \\
\text { - Cold wall }\end{array}$ & $\begin{array}{l}\text { - Flow system for } \\
\text { two added coils }\end{array}$ & $\begin{array}{l}\text { - Flow system for } \\
\text { pulse coil shield }\end{array}$ & $\begin{array}{l}\text { - Flow system for } \\
\text { three adäed coils:- }\end{array}$ \\
\hline Electrical & $\begin{array}{l}\text { - Install } 30-\mathrm{kA} \\
\text { power bus } \\
\text { - Install heater } \\
\text { power } \\
\text { - Single dump circuit } \\
\text { - Aux-1iary power } \\
\text { - Vapor-cooled lead }\end{array}$ & $\begin{array}{l}\text { - Add two } 20-\mathrm{kA} \\
\text { power supplies } \\
\text { - Two added dump circuits } \\
\text { - Two added leads }\end{array}$ & $\begin{array}{l}\text { - Add } 2-k A, 300-V \\
\text { pulse power supply }\end{array}$ & $\begin{array}{l}\text { - Add three 20-kA } \\
\text { power supplies } \\
\text { - Three added dump } \\
\text { circuits } \\
\text { - Three added leads }\end{array}$ \\
\hline $\begin{array}{l}\text { Instrumentation \& } \\
\text { control }\end{array}$ & $\begin{array}{l}\text { - Vacuum system and } \\
\text { utilities } \\
\text { - LHe - single coil } \\
\text { - } \mathrm{LN}_{2}-\text { single coil } \\
\text { - Coi- diagnostics }\end{array}$ & $\begin{array}{l}\text { - LHe - two added coils } \\
\text { - } \mathrm{LN}_{2} \text { - two added coils } \\
\text { - Diagnostics - two } \\
\text { added coils }\end{array}$ & $\begin{array}{l}\text { - } \mathrm{LN}_{2}-\text { pulse coil } \\
\text { Diagnostics - pulse } \\
\text { coil }\end{array}$ & $\begin{array}{l}\text { - LHe - three added } \\
\text { coils } \\
\text { - } \mathrm{LN}_{2} \text { - three added } \\
\text { coils } \\
\text { - Diagnostics - } \\
\text { three added coils }\end{array}$ \\
\hline Structure & $\begin{array}{l}\text { - Base support } \\
\text { - Bucking post } \\
\text { - Single coil support } \\
\text { - Fix=ures }\end{array}$ & $\begin{array}{l}\text { - Torque rings } \\
\text { - Structural spacers }\end{array}$ & $\begin{array}{l}\text { - Pulse coll } \\
\text { - P coil supports }\end{array}$ & \\
\hline $\begin{array}{l}\text { Building } \\
\text { modifications }\end{array}$ & $\begin{array}{l}\text { - Vacuum tank } \\
\text { foundation } \\
\text { - Electric power and } \\
\text { utilities C\&A } \\
\text { - Firz protection } \\
\text { - Upgrade 13.8-kV } \\
\text { tiz line } \\
\text { - Install 1.5-MVA } \\
\text { sujstation } \\
\text { - Utilities }\end{array}$ & $\begin{array}{l}\text { - Instal1 50-ton crane } \\
\text { - Substation vault C\&A } \\
\text { - Insta11 } 1.5-M V A \text { and } \\
\text { 1.0-MVA substation }\end{array}$ & $\begin{array}{l}\text { - Install } 1.0-\mathrm{MVA} \\
\text { substation }\end{array}$ & $\begin{array}{l}\text { - InstalZ } 1.0-M V A \\
\text { substation }\end{array}$ \\
\hline
\end{tabular}

$a_{\text {New requirements are in italics. }}$ 
the facilities provided. Review of preceding sections will provide the background required for full comprehension of the total requirements and how these are being satisfied.

\subsubsection{Requirements}

The specific requirement to be considered in this stage is the addition of three more TF coils to provide a full six-coil test array. Cryogenic, electrical, structural, and diagnostic capability must be provided to allow testing a six-coil array of combined forced-flow and pool-boilingcooled coils with each capable of selection as the test cnil.

\subsubsection{General Description}

The facility will be modified to accommodate three additional coils to complete the six-coil torus. Primary impacts are in the arcas of cryogenic systems and electrical power supplies. Details on the added systems or modifications to established items are presented in the following sections. Plan views showing the locations of the major items added are presented in Figs. 3.37 and 3.38 .

\subsubsection{Structure}

The test stand structure provided for Stage IV, which included structural elements for the pulse coils and structural spacers for the three missing members, is to be used in this stage. The only change required is to remove the spacers and install the three new test coils in their place. A conceptual drawing of this total assembly is shown in Fig. 3.39.

Additional coolant manifolding to appropriate ports on the coils is also required. This is assumed to be a corresponding mix of forced-flow and pool-boiling designs which results in the final six-coil array being comprised of two forced-flow and four pool-boiling cooled coils.

Each additional coil will require a set of vapor-cooled electrical leads.

Spccific operating characteristics and structural behavior under all operating modes can be found in Ref. 4 relating to structural analysis and concept selection.

Assembly of the three new coils into the torus will require removal of the pulse coil and its support structure and the structural spacers. Reassembly will follow procedures established in previous discussions. 


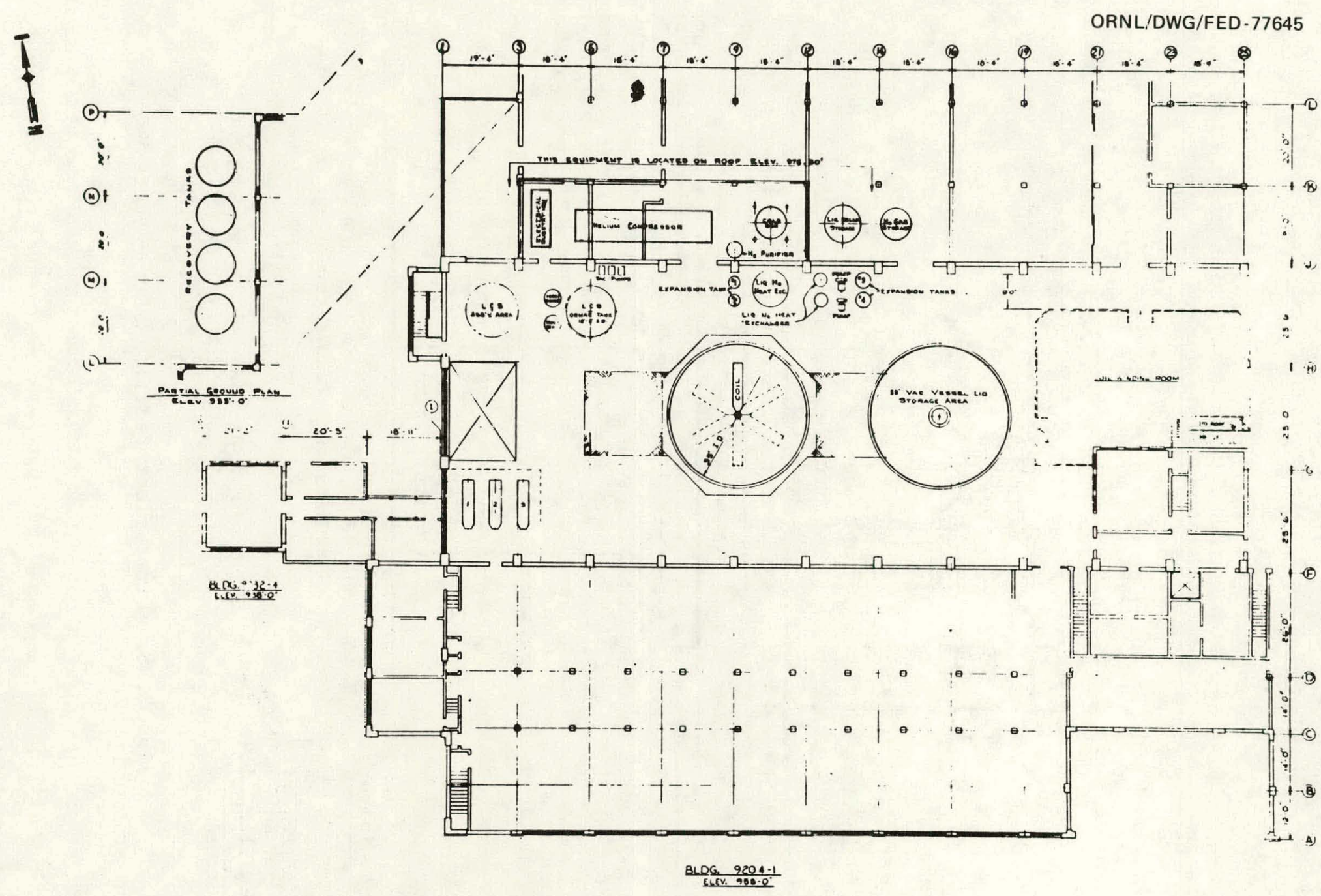

Fig. 3.37. Second floor facility plan - Stage V. 
ORNL/DWG/FED -77643

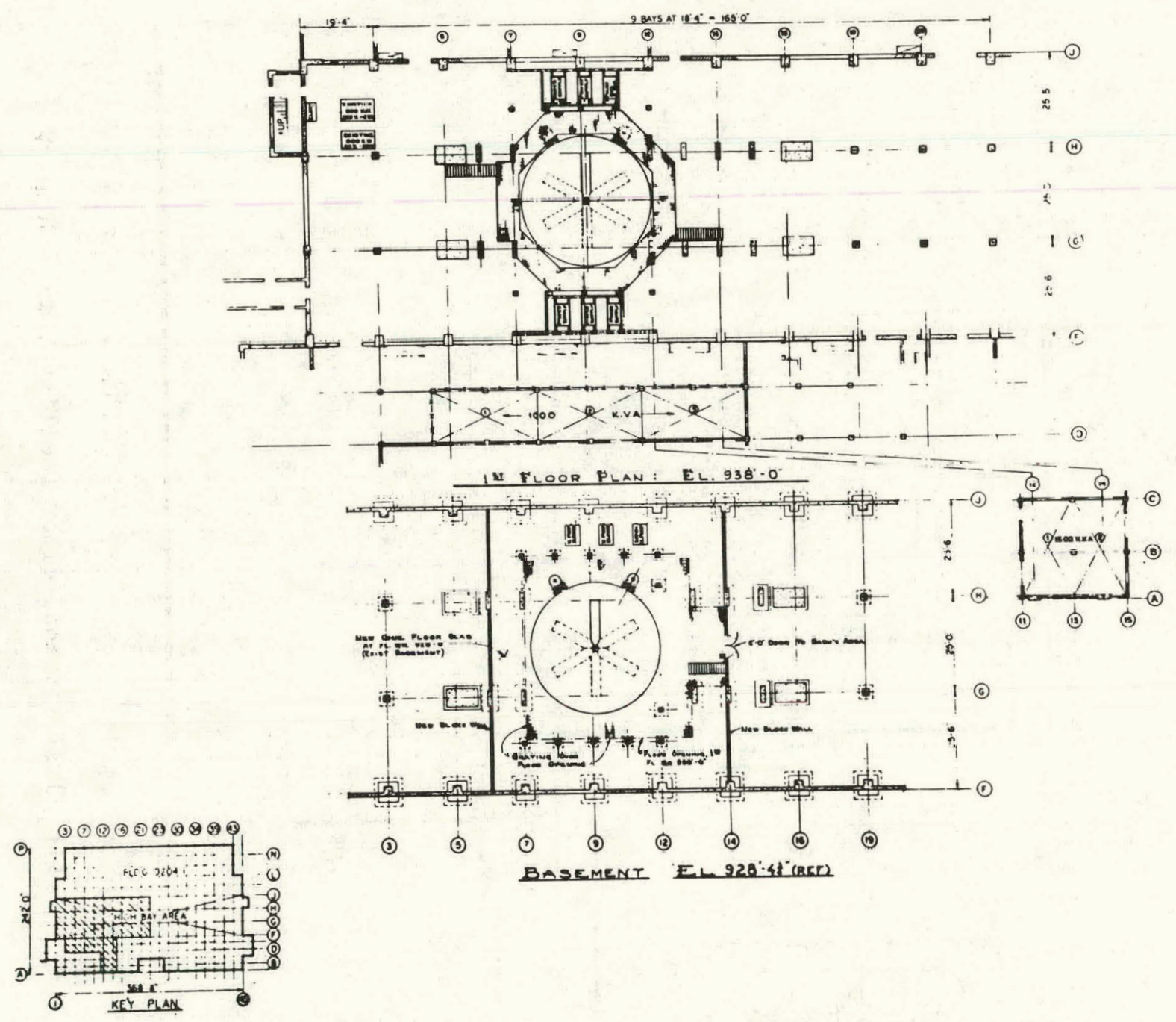

Fig. 3.38. First floor facility plan - Stage V. 

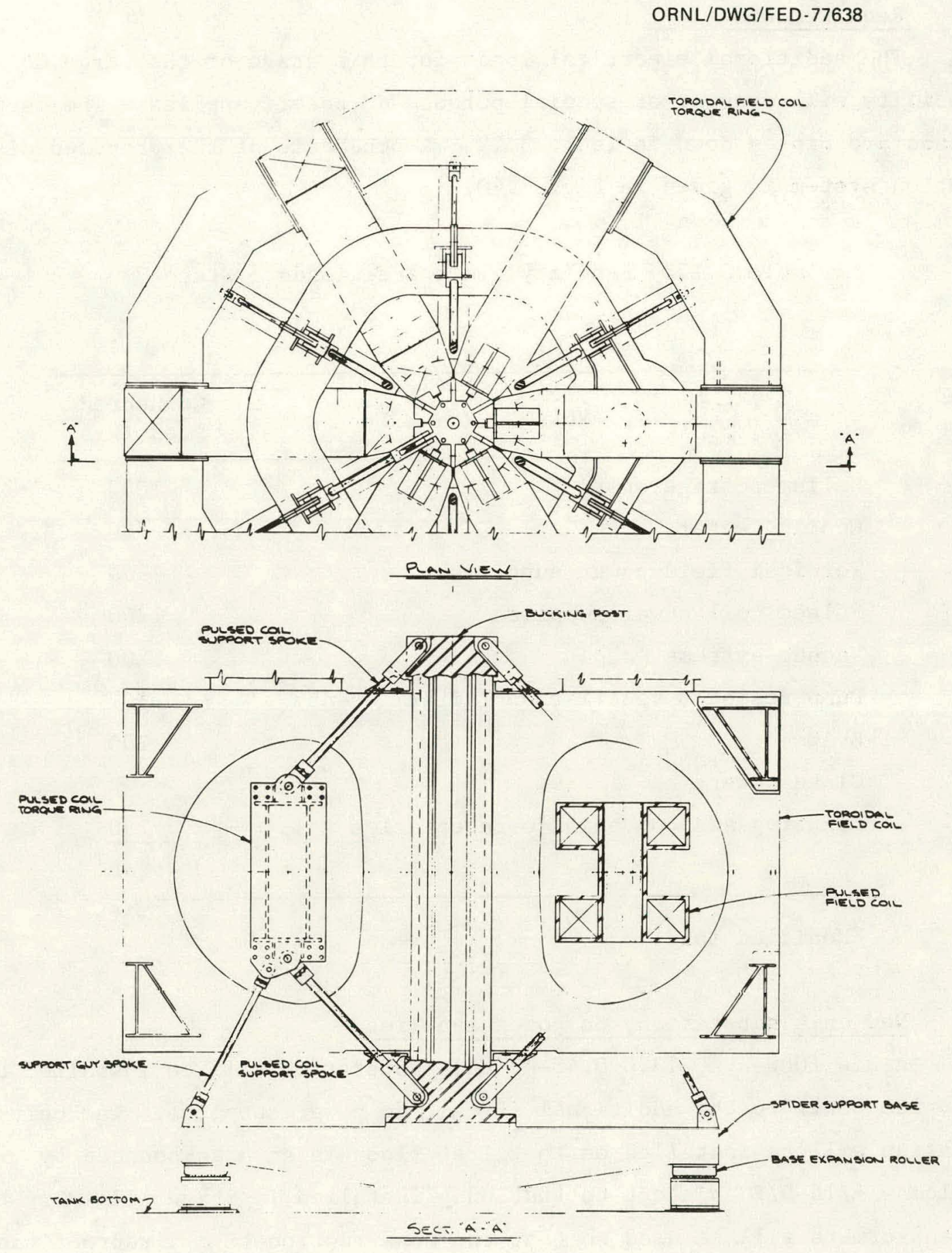

Fig. 3.39. Six-coil test stand with pulse coil. 


\subsubsection{Electrica1 Power - Primary Distribution}

\section{Requirements}

The additional electrical loads for this stage of the Large Coil Test Facility will consist of special purpose dc power supplies. The estimated loads are broken down in Table 3.12. A schematic of the proposed distribution system is given in Fig. 3.40 .

Table 3.12. Facility electrical loads - Stage V

\begin{tabular}{lc}
\hline \multicolumn{1}{c}{ System } & $\begin{array}{c}\text { Connected } \\
\text { load (kVA) }\end{array}$ \\
\hline Helium refrigerator & 1000 \\
Cooling water & 500 \\
Toroidal field power supplies & $1800^{\alpha}$ \\
Pulsed coil power supplies & 1200 \\
Vacuum systems & 200 \\
Dump resistor ventilation (intermittent) & $300^{\alpha}$ \\
HVAC & 100 \\
Clean power & 7 \\
Lighting and convenience receptacles & 150 \\
\end{tabular}

Modified load.

New unit substaliun, de power supplies

A new $1000-\mathrm{kVA}, 13.80 .48-\mathrm{kV}$ unit substaliun will be Installed to provide power to the additional TF coil dc power supplies. The unit substation will be installed on the first floor in an area bounded by columns 4/15-D/F adjacent to that unit installed in Stage III. Dry type transformers will be used so that the construction of a fireproof vault will not be required. New $15-\mathrm{kV}$, cross-linked polyethelene cable in rigid conduit will be installed from the modified spare $13.8-\mathrm{kV}$ unit to the new unit substation. Secondary feeders to the dc power supply will consist 


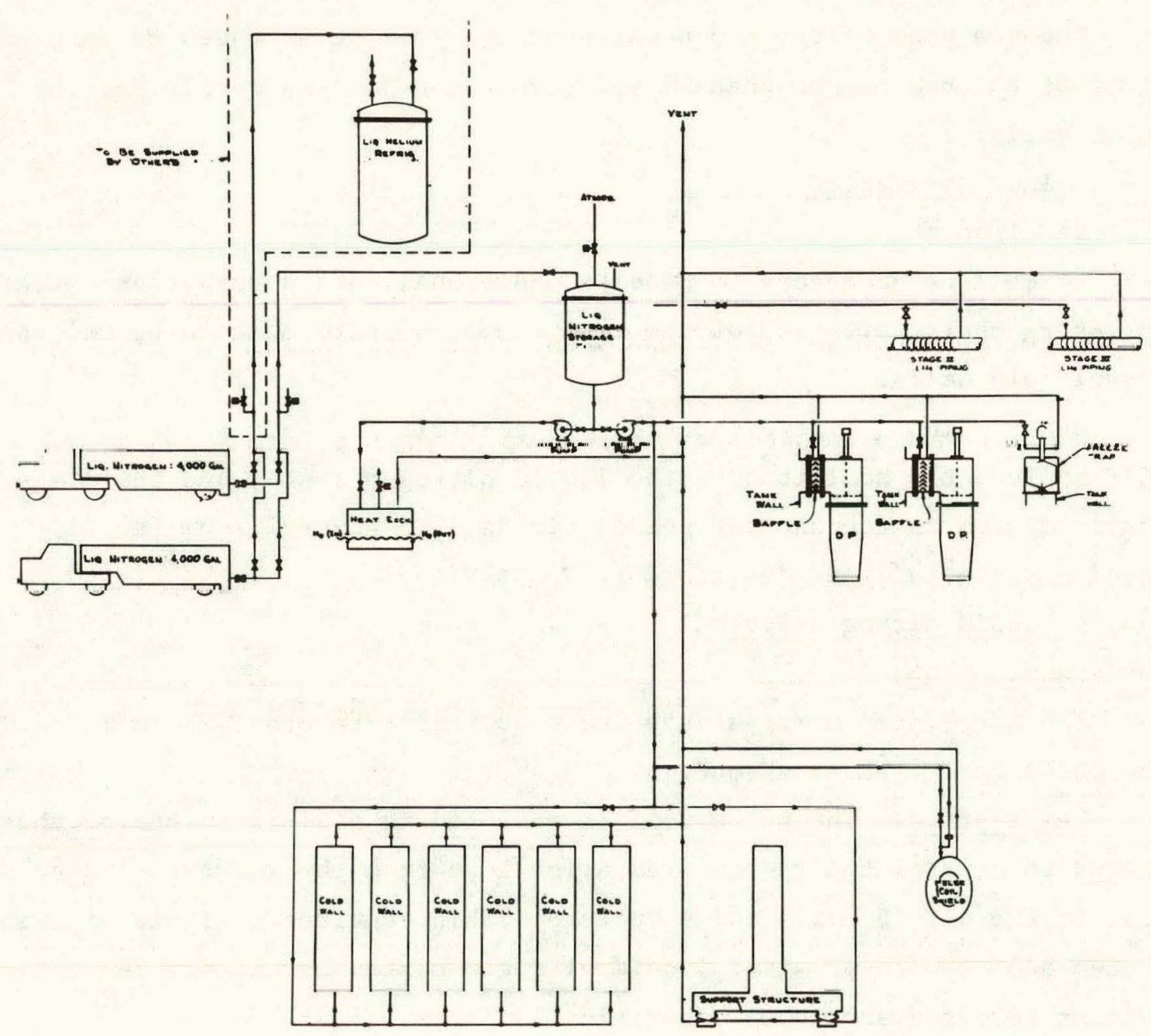

Fig. 3.36. Llquid nitrogen flow sheet - Stage IV. 


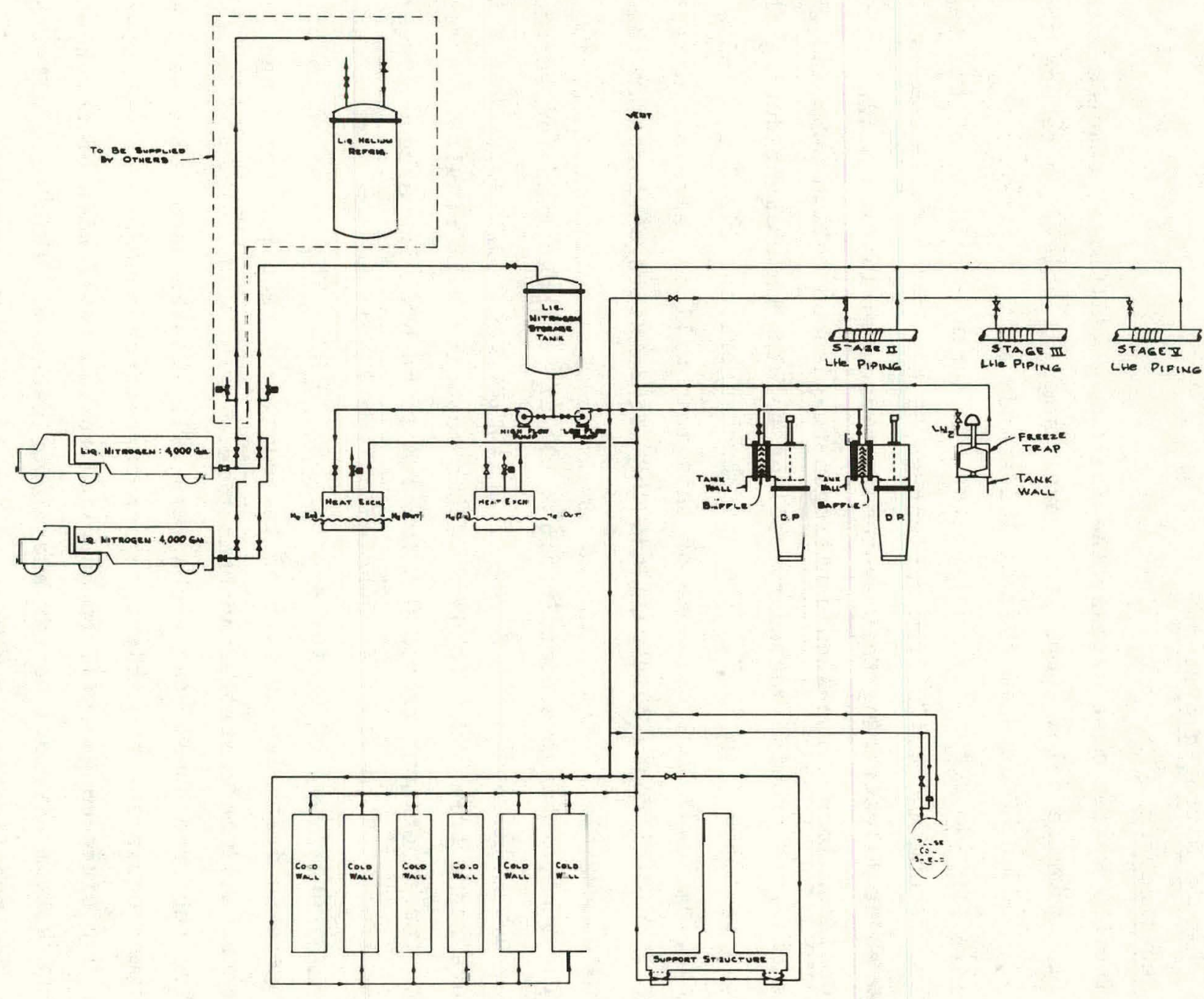

Fig. 3. L2. Liquid n-trogen Elow sheet - Staze $V$. 
ORNL/DWG/FED- 77635

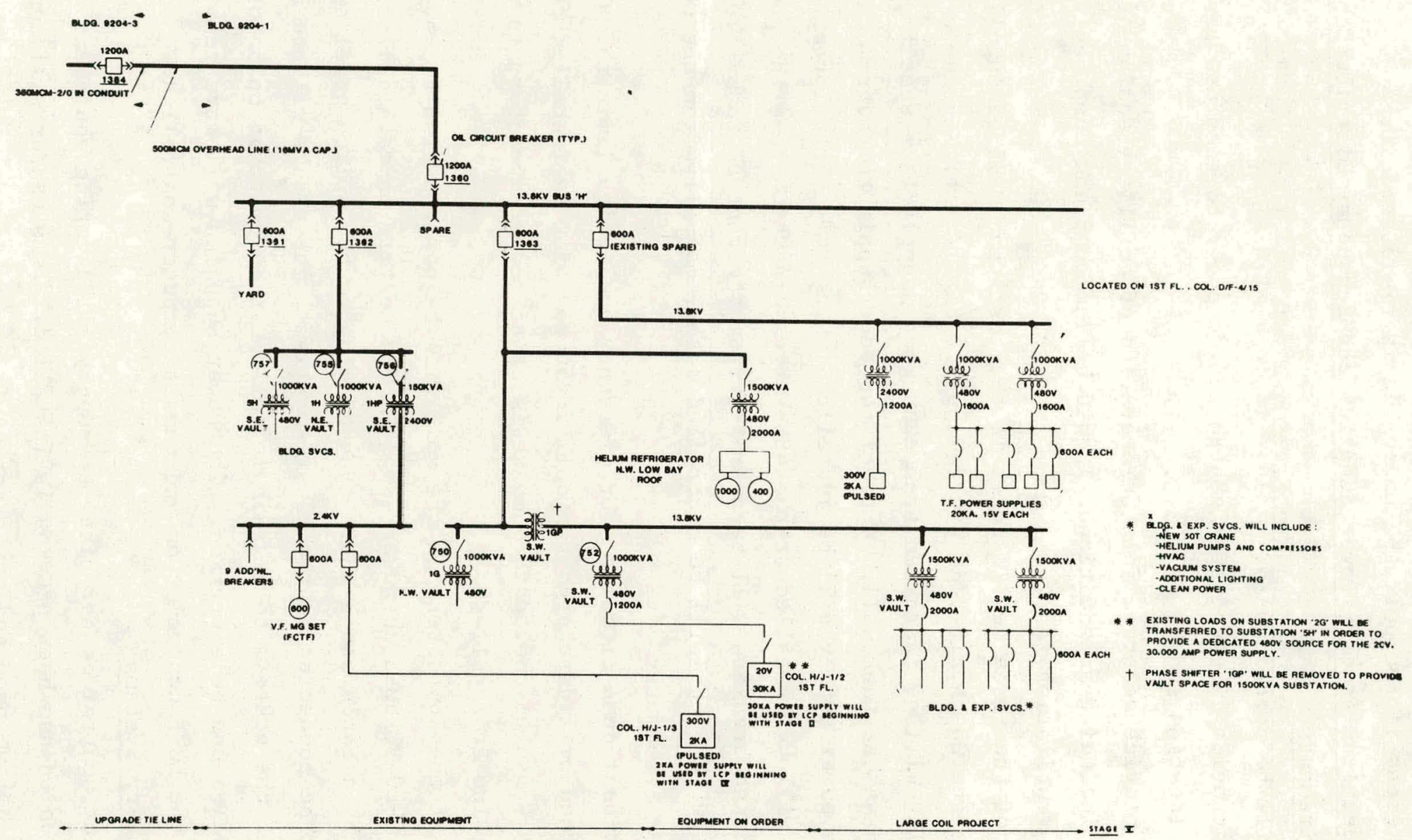

Fig. 3.40. Primary power distribution schematic - Stage V. 
of either $600-\mathrm{V}$ cable in rigid conduit or $600-\mathrm{V}$ feeder busway, and $5-\mathrm{kV}$, shielded, cross-linked polyethelene cable in rigid conduit.

\subsubsection{Electrical Power - Power Supplies and Secondary Distribution}

\section{Requirements}

It will be necessary to:

(1) provide independently controlled dc power to each new test coil location and

(2) provide ac power for the operation of auxiliary equipment, including an additional liquid helium pump and dump resistor ventilation fans.

Each of the three new TF coils in the test tank wil1 he supplied from a new separate $20-k A, 15-V$ dc power supply. Six $1 / 2$ in. $x \quad 6$ in. copper bars per leg will be installed from each power supply to a specified coil connection at the tank wall. A panel for each supply to control the output of the power supply will be installed in the LCTF control room. Remote operators will be installed on the $480-\mathrm{V}$ breakers which feed the power supplies, and the breakers will be operated from the control room. The power supply output current will be controlled either manually from the control panel or by a computer.

Additional dump circuits (for emergency use) which limit the voltage to $1000 \mathrm{~V}$ and will discharge the coil in $50 \mathrm{sec}$ will be installed for each new coil. A fan to cool each dump resistor to room temperature in one hour will also be supplied.

Each of the 16 heaters in the coil will be powered from a previously installed 0-20-V, 50-A dc power supply. The heaters in each coil will be connected by a cable and a shell type MS plug to the switch panel and the panel will be connected to the power supplies. Interlocks will be arranged so that all the heaters to any single coil must be switched on before the power supplies can be energized. The power supplies will have remote panels in the LCTF control room and can be computer-controlled.

Auxiliary Systems

A motor control center sized to supply all exlsting equipment and with $20 \%$ spare units has been previously installed. This center will supply the additional helium pump and any other auxiliary equipment. All of the 
equipment will be controlled from control stations located in the LCTF control room. The control circuits will be interlocked with the necessary instruments and valves to prevent a misoperation of the equipment. A 75-kVA, 3- $\phi$, 480-203/120-V transformer and two 36-circuit panels have been installed to provide the necessary control power at the test site and in the control room.

The 2-kVA uninterruptible power supply will be modified to provide control power to the additional dump circuits and other selected instruments.

\subsubsection{Instrumentation}

\section{Requirements}

It will be necessary to provide:

(1) additional instrumentation and control of the facility services with primary emphasis on the cryogenic modifications,

(2) data acquisition on the operating characteristics of the modified test stand and support structure, and

(3) additional coil diagnostic instrumentation to monitor the sensors inside and on each test coil.

Description. Additional instrumentation and controls for Stage $\mathrm{V}$ operation can be broken down into the various subsystems to be modified. These include the liquid helium system, the liquid nitrogen system, and the coil diagnostic system. Each of these areas is discussed in greater detail below. In general, the facility controls remain manually operated, while most facility and diagnostic variables are monitored by computer. However, fault detection and response are again automatic and redundant in critical areas.

Liquid helium system. The additional liquid helium transfer system will be monitored and controlled by a combination manual and automatic control system. The transfer of helium to the individual pool-boiling or forced-flow coil manifolds will be controlled by an operator, but with the transfer monitored by the transducers necessary to ensure correct and orderly operation. In addition to the flow control loops provided for each coil path, each path will have temperature, pressure, and flow monitored by an instrumentation manifold whose outputs are linked to the 
facility digital computer. The helium gas returned will have its flow monitored and totalized to provide an indication of liquid helium usage.

Liquid nitrogen system. The $\mathrm{LN}_{2}$ system additions will be monitored and controlled by the same type of process controls as the liquid helium. The transducers involved will be for liquid nitrogen temperatures, but the controls will be configured similar to those defined for the LHe. The valving to each item included in the $\mathrm{LN}_{2}$ distribution system will be manually operated. The flow and pressure will be monitored and alarmed in each liquid nitrogen 1 ine going to the coils. In addition Lu the $T_{1} N_{2}$ flow to the coils, liquid nitrogen will be utilized in the neressary heat exchangers. The pressure and temperature across each heat exchanger will be monitored and recorded to permit heat balance calculations across the exchangers.

Data acquisition. The support structures have previnus1y heen instrumented with a variety of thermocouples, thermistors, and strain gages, and this system remains essentially the same as described for previous stages. Coil diagnostic instrumentation. The coil diagnostic instrumentation is increased to handle the added coils and consists of the signal conditioning and analog-to-digital conversion equipment required to monitor the various types of sensors located inside and on each test coil.

\subsubsection{Liquid Helium System}

\section{$\underline{\text { Requirements }}$}

A summary of coolant conditions derived from the specifications given to industrial suppliers of the large coils to be tested has given the cryogenic conditions to be used in the design. The initial procurement of three coils included at least one of each type, so both forms of cooling were provided in the facility design. Subsequent procurement of an additional three coils to provide a simulated full torus configuration also provides a mixture of cuulant modes. Combinations were postulated of the various arrangements that might be expected for both three-coil and six-coil tests to establish the range of cooling requirements to be provided. These are summarized in Table 3.13 . 
Table 3.13. LHe requirements - six-coil array

\begin{tabular}{|c|c|c|c|c|c|c|c|}
\hline Configuration & $\begin{array}{l}\text { Total } \\
\text { coils }\end{array}$ & $\begin{array}{l}\mathrm{PB} \\
\text { coils }\end{array}$ & $\begin{array}{l}\mathrm{FC} \\
\text { coils }\end{array}$ & $\begin{array}{l}\text { Test } \\
\text { coil } \\
\text { type }\end{array}$ & (c) 3.5 & $\mathrm{~K} @ \stackrel{\mathrm{W}}{4.2} \mathrm{~K}^{\mathrm{N}}$ & $\begin{array}{l}\text { liters/hr } \\
\text { for leads }\end{array}$ \\
\hline A & 3 & 2 & 1 & FF & 550 & 400 & 170 \\
\hline B & 3 & 2 & 1 & $\mathrm{~PB}$ & 100 & 600 & 170 \\
\hline $\mathrm{C}$ & 3 & 1 & 2 & FF & 650 & 350 & 170 \\
\hline D & 3 & 1 & 2 & $\mathrm{~PB}$ & 200 & 550 & 170 \\
\hline $\mathrm{E}$ & 6 & 2 & 4 & $\mathrm{FF}$ & 250 & 400 & 330 \\
\hline F & 6 & 2 & 4 & $\mathrm{~PB}$ & 400 & 600 & 330 \\
\hline G & 6 & 4 & 2 & $\mathrm{~PB}$ & 200 & 700 & 330 \\
\hline $\mathrm{H}$ & 6 & 4 & 2 & $\mathrm{FF}$ & 650 & 500 & 330 \\
\hline
\end{tabular}

\section{LHe test facility description}

A conceptual design has been made of the LHe portion of the test facility, based on the requirements described above along with the constraints imposed by the refrigerator capabilities discussed with regard to Stage II. A schematic flow diagram of the system is shown in the accompanying drawing, Fig. 3.41.

A substantial portion of the systems described below has been provided as part of Stages II, III, and IV; however, a fairly complete description is provided in this section to preserve continuity of this critical system. Reference to previous flow schematics will assist in identifying specific modifications and additions incorporated in this stage.

Four basic subsystems exist and, along with the refrigerator, make up the helium system: (1) saturated liquid distribution and vapor return for pool boiling, (2) supercritical fluid coolant loop for forced convection cooling, (3) lead cooling, and (4) the cooldown loop.

Pool-boiling loop. In the pool-boiling loop, liquid helium from the refrigerator at $1.3 \mathrm{~atm}, 4.5 \mathrm{~K}$ is stored in a 5000-gal dewar. From here it flows to the manifold for the pool-boiling-cooled test coils in the main test vessel. A feed tank will be supplied for each coil to provide 
ORNL/DWG/FED - 77604

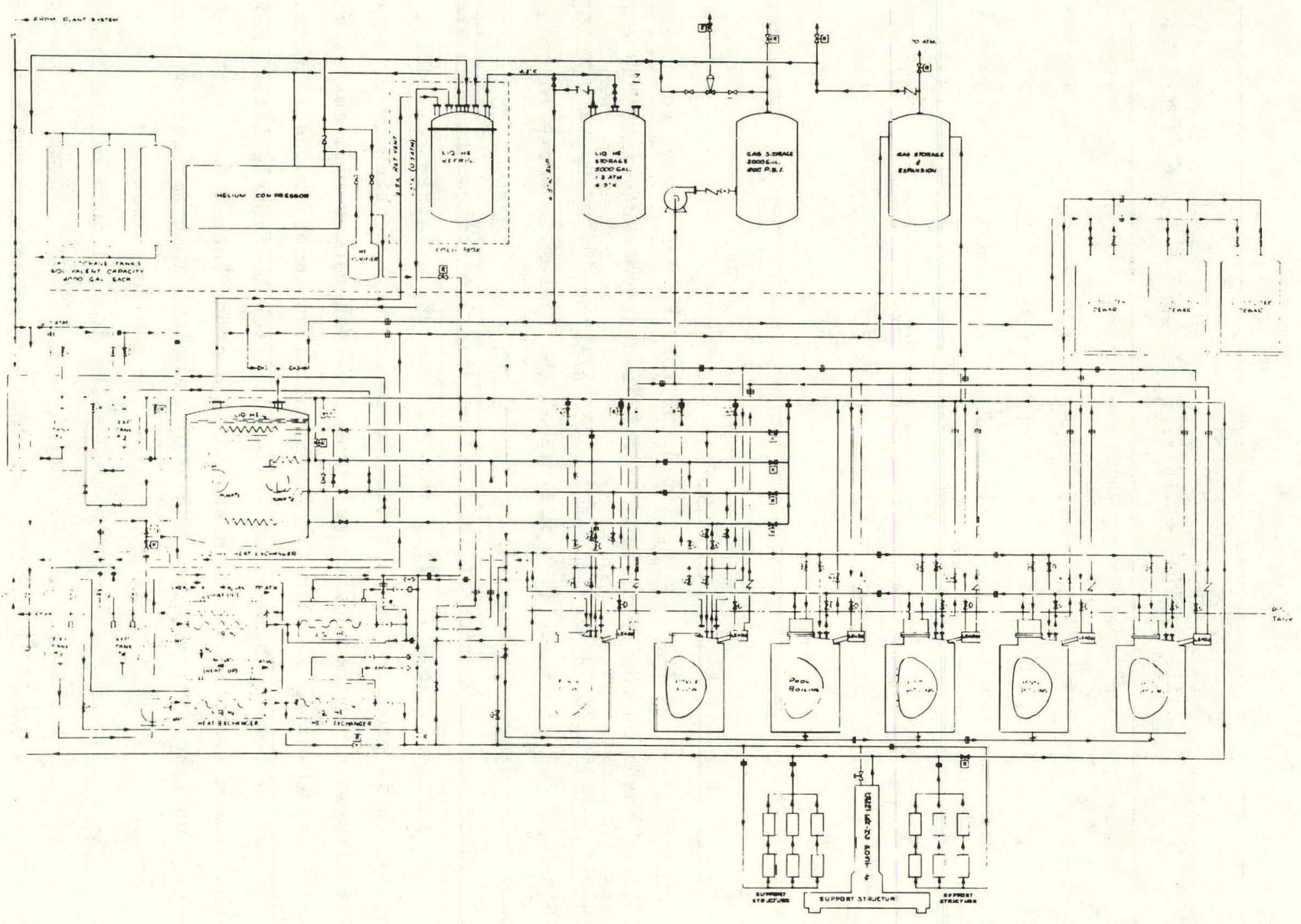

Fi 
a vapor disengaging space to help ensure that only liquid will be fed to the coil coolant passages. This feed tank will be at the top of the coil to provide sufficient static heat for flow into the coil. Provision is made to supply this liquid at either the top or the bottom of the coils.

Vapor generated in the boiling-cooling process will pass out from the top of the coil and will flow to a compressor for return to the refrigerator. The compressor has an expansion surge tank to help provide a smooth feed without significant pulsations. This return flow, essentially saturated vapor at $4.2 \mathrm{~K}$, will return to the refrigerator through its heat exchange system and hence represents a refrigeration load as opposed to a liquefaction load.

Forced-convection 1oop. The forced-convection cooling loop requires a supply of $4.0-\mathrm{K}$ helium to circulate through the coils employing this mode of heat removal. A pressurized closed circuit is used for this purpose. Liquid helium from the refrigerator at $0.5 \mathrm{~atm}$ and $3.5 \mathrm{~K}$ is contained in a large dewar, $2.75 \mathrm{~m}$ in diameter and $2.75 \mathrm{~m}$ high. This helium is boiled to provide the heat sink for the 4-K cooling loop. The circulating pumps and aftercooler heat exchangers will be submerged in the 3.5-K helium. This is done not only to help ensure that the close approach temperature differential can be achieved but also to have the pumps operate in a nearly isothermal condition to reduce the work input and concomitant heat removal required.

During the coil testing, one of the coils will be selected as the primary test coil with the others operating at reduced conditions to supply the background magnetic tield. 'lhe primary test coil will be subjected to higher current loading, simulated nuclear heating, etc., thus imposing a significantly higher cooling requirement. For this reason, two separate pump loops are provided - one to supply the test coil alone when it is of forced-cooled type, the other for the remaining forced-convectioncooled background coils. This will provide a degree of redundancy as well as better control of the cooling of the test coil. The first of these loops was installed in Stage III; the second will be incorporated at this time. Provision has been made in the design for manifolding so that any selected coil can be the test coil. 
Return fluid from the coils is passed to the respective pump inlets; an expansion surge tank is provided for each to accommodate density changes that can occur. Boiloff from the 3.5-K heat sink tank is returned directly to the refrigerator as an essentially saturated vapor. This again is represented as a refrigeration load during normal operation.

Power leads. The electrical leads supplying current to the various coils must have a temperature gradient because they pass from the coil interface at nominally $4 \mathrm{~K}$ to the power supply at room temperature. The cold end of the leads will be cooled with 4.2-K helium from storage dewars separate from that supplying the pool-boiling feed for those coils. One 2000-1iter dewar will be provided for each two coils to provide redundancy and facilitate plumbing and operation with varying numbers of coils installed in the test vessel. These dewars will be filled from the 5000-gal dewars as required during periods between tests.

Cooldown loop. The fourth subsystem module is the equipment required to assist in cooling the entire test vessel and contents from room temperature down to operating conditions. The entire assemhly represents a maso on the order of $3780 \mathrm{kN}$ requiring the removal of about $4.9 \times 10^{10} \mathrm{~J}$ to cool down to a nominal $4 \mathrm{~K}$. While, in theory, this could be done by operating the refrigerator and cooling systems just described, the time required for cooldown would be excessively long. For this reason as well as for energy conservation, it was decided to perform as much of the cooldown as possible using $\mathrm{LN}_{2}$ as the heat sink. Direct intrnduction of nitrogen into the various cooling passages is not desirable, however, since subsequent use of cryogenic helium could freeze traces of nitrogen which might still remain in the system and cause potential problems with flow maldistribution or even blockage. It was therefore decided to use helium as the heat transfer medium and reject the heat in a He- $\mathrm{LN}_{2}$ heat exchanger. Two paral1el systeme arc to bc used - vile primarfly for the coils and the other for associated support structure. This was done to permit more uniform control of the cooldown, minimize undesirable temperature gradients, and to allow the use of reasnnable pipe sizes for the increased helium flow used during cooldown.

Gaseous helium at supercritical pressure will be pumped through the $\mathrm{LN}_{2}$ heat exchanger and then to the test assembly, i.e., coils and structure. 
When the temperature has been brought down to near $\mathrm{LN}_{2}$ temperature, $80-90 \mathrm{~K}$, cooling will be switched to the helium refrigerator loops for the final cooling.

\subsubsection{Liquid Nitrogen System}

\section{Requirements}

The $\mathrm{LN}_{2}$ system must satisfy the following additional requirements:

(1) provide a low temperature environmental shield to reduce the added LHe system thermal loads and

(2) provide secondary cooling for GHe during cooldown of the test stand and coils from ambient to $85 \mathrm{~K}$.

A flow sheet illustrating this system is presented in Fig. 3.42.

Cooldown loop. Two liquid nitrogen-to-gaseous helium tube and shell heat exchangers provide secondary cooling for the experiment during the cooldown from $300 \mathrm{~K}$ to $85 \mathrm{~K}$. The heat exchangers are sized to handle the full cooling load; however, some of this load will be taken out directly by the liquid nitrogen cold wall and the liquid nitrogen loops at the structural support base.

The heat exchangers contain $5.6 \times 10^{6} \mathrm{~cm}^{2}$ of heat transfer surface area. They will handle $200 \mathrm{~g} / \mathrm{sec}$ of helium at 5-atm pressure over a temperature range from $300 \mathrm{~K}$ to $85 \mathrm{~K}$. This capacity will result in a cooldown of the experiment from $300 \mathrm{~K}$ to $85 \mathrm{~K}$ in $60 \mathrm{hr}$. The second stage cooling from $85 \mathrm{~K}$ to $4.5 \mathrm{~K}$ is handled on the liquid helium system and requires an additional $60 \mathrm{hr}$ for a total of $120 \mathrm{hr}$. The first of these heat exchangers is installed as part of the equipment required for Stage II; the second will be installed at this time.

The tube and shell heat exchangers will also be used to raise the experiment equipment to ambient temperature after shutdown of an experiment. Hot nitrogen gas will be supplied to the shell side of the heat exchangers from a remote heater and blower package. This will allow quick warmup for modification or repair of the experiment equipment. 


\section{SITE}

The site planned for LCTF is Building 9204-1, a concrete and masonry building in the south-central part of the Oak Ridge Y-12 Plant. This building has a total floor area of about $220,000 \mathrm{ft}^{2}$ on two floors; some limited mezzanine and basement area also exists. It was constructed in 1944 to house electromagnetic isotope separation systems but was withdrawn from this use in 1947. In 1954 the electromagnetic separation equipment was removed to provide space for ORNL research and reactor component testing facilities. No major additions have been made to the building, but extensive modifications and equipment installations have been made over the years.

Because of current adjustments in ORNL operations plans, it has become feasible to convert approximately the western half of the building to Fusion Energy Division (FED) uses. A part of this space, contiguous with the proposed LCTF location, has been designated as a laboratory for superconducting magnet development and testing (part of the DMFE program for development of superconducting toroidal magnets that is being conducted by ORNL). The physical characteristics of the building and the arrangement of its site well adapt it to magnet development and LCTF use. The location is in a high crane bay.

Building 9204-1 is included in the unclassified eastern area of the plant. This eastern area is physically controlled (access by badge or pass only); however, $Q$ clearance is not required, and aliens may be admitted so that the LCTF would be accessible to visiting scientists. Vehicular access to Building $9204-1$ is via a paved road (Third Street) south of the building, by which route the building is about one-fourth mile from the main ORNL FED facility in Building 9201-2. Pedestrian access from the central part of the Y-12 Plant, that is the cafeteria, the medical center, etc., is via an elevated enclosed walkway spanning a road connecting security exclusion areas. 
5. SAFETY, FIRE, AND HEALTH CONSIDERATIONS

The LCTF design, construction, and operation must comply with DOE regulations and other applicable codes and standards pertaining to health, safety, and fire protection.

\subsection{SAFETY}

\subsubsection{Safety Programs}

Activilles al Lhe LCTF sile (Building 9204-1, Y-12 Flant) will come under the safety programs of the ORNL Fusion Energy Division. The FED, being located in the $\mathrm{Y}-12$ area, comes under the $\mathrm{Y}-12$ safety program, whose general policy. statement 1 s as follows.

It is the policy of the Y-12 Plant to establish an effective accident prevention program and to maintain the nécéssàry statit, serivicè and advisory groups to assist line supervision who are responsible for the safety of employees and equipment. Whenever our safety objective conflicts with other objectives, safety shall be our first consideration.

Program management is implemented by the Plant Superintendent through monthly mectings of a Central Eafcty Committce consioting of plant and division superintendents. Safety committees at four levels meet regularly to assist in instruction of personnel and analysis of safety problems. A Safety Department is responsible for formulation and direction of the program, analysis, auditing and evaluations, and recommendations to line supervision. A Radiation Safety Department, responsible for all personnel and environmental monitoring, provides technical assistance to line supervision.

Through a permanent, qualified Division Safety Officer who provides liaison and ensures compliance, the F'ED safety program implements the Y-12 program with procedures specific to FED experiments.

\section{1 .2 DOE requirements}

All phases of the project will be done in accordance with ERUA 0550, "Operational Safety Standards." 


\subsubsection{Industrial Safety}

Equipment will be fitted with safety devices and protective guards to prevent operator injury. Electrical work, piping, and pressure vessels will conform to applicable codes and standards.

Operations involving liquid helium and liquid nitrogen will utilize procedures, protective clothing, and equipment normally used in handling cryogenic liquids.

\section{1 .4 Radiological Safety}

There are no radiological hazards associated with LCTF.

\subsubsection{Seismic Considerations}

The new portions of the facility will be designed in accordance with the seismic design criteria for DOE facilities.

\subsection{FIRE PROTECTION}

Building $9204-1$ is equipped with automatic sprinkler systems for protection of the building and equipment. (The high bay area is presently excepted, but sprinklers will be added there as required to protect LCTF equipment.) Fire alarm boxes and sprinkler annunciator alarms are connected through the Y-12 Plant fire alarm system to the fire and guard headquarters and to the plant emergency control center. The plant emergency control center is manned at all times.

In addition to the fire alarm system, all fire doors and alarms associated with the water distribution system are monitored by the plant monitoring system that provides information on exact location of an alarm, and planned procedures can be initiated in a matter of seconds.

The Y-12 Plant Emergency Squad responds to all alarms with a pumper, a fully equipped emergency truck, and an ambulance. Another pumper and a $\mathrm{CO}_{2}$ truck serve as backup. Other personnel and equipment from other Oak Ridge plants and the city of Oak Ridge respond to larger emergencies under mutual aid agreements.

\subsection{MEDICAL SERVICES}

Medical services for the LCTF staff will be available from both the Y-12 Health Center and the ORNL Health Division. The latter provides 
periodic examinations as well as consultation on health problems for ORNL staff members. I'he Y-12 Health Center has on-site availability and will provide treatment for illness or injury affecting an LCTF employee while at work or that arises out of or in the course of his or her employment. In addition, the Y-12 Health Center is responsible for defining and maintaining a healthful work environment and is available for monitoring health hazards. 


\section{ENVIRONMENTAL ASSESSMENT}

The LCTF will impact the environment primarily through its requirements for electrical power generation and distribution and the discharge of waste heat at the site. Construction and operation of the LCTF will not have a significant impact on supplies of any material. Being located within a large plant (mostly inside an existing building) and constituting only a very small fraction of the plant's activities, LCTF has little other environmental impact. Benefits to the nation's fusion power program are very large compared with the environmental costs.

\subsection{DESCRIPTION}

\section{1 .1 Facility}

General descriptions of LCTF and its site are given in Sects. 3 and 4. Features germane to the assessment of environmental impact are as follows.

Visual impact will be very minor, since the facility lies entirely within the Y-12 plant. The facility itself and most of the supporting systems are located within a large existing building. Some of the supporting equipment (helium refrigerator) is located on the roof but is out of sight of any place open to the public. Storage and run tanks for gases and liquefied gases are located near the building and will also be screened from public view by intervening, existing structures.

In the recommended design, approximately 19 tons of niobium, 7 tons of tin, 3 tons of titanium, 91 tons of copper, 410 tons of stainless steel, and 50 tons of carbon steel will be employed. Practically all of these materials will be recoverable at the conclusion of several years of operation. Helium consumption is expected to amount to less than $275,000 \mathrm{scf} / \mathrm{yr}$. No other material of strategic importance will be used.

\subsubsection{Characterization of Existing Environment}

The site is within the Oak Ridge Y-12 Plant, which is located within the corporate limits of the city of Oak Ridge. The Y-12 Plant occupies a 500-acre tract lying in the valley between Pine Ridge and Chestnut Ridge, which rise 200-300 ft above the valley floor. A road open to the public 
runs along the valley, skirting the north edge of the plant. The building housing the LCTF is near the south edge of the plant. A small stream, the East Fork of Poplar Creek, which originates about one mile west of the LCTF site, flows eastwardly through a rip-rapped channel about $40 \mathrm{ft}$ south of the building. The ridges and the valley outside the plant are government property (part of the 37,000 acres still owned by DOE in the Oak Ridge area). The environs of the Y-12 Plant are generally wooded and are unused (except for DOE-controlled forestry). The nearest residence is about 1-1/2 miles from the eite, across Pine Ridge; ligh-density population of the city of Oak Ridge begins about 2 miles away in the same direction.

The site lies in a seismic area classified by the Uniform Building Code as "Zone 2 - Moderate Damage." Seismic activity in East Tennessee has been mild to moderate, with 11 earthquakes of $V$ and VT. intensity of the modified Mercalli scale in the last 100 years. One quake with intensities of VII occurred in the Knoxville area in 1913.

\subsection{EVALUATION OF THE ENVIRONMENTAL IMPACT}

\subsubsection{Unavoidable Adverse Effects}

The possible adverse environmental impacts of the proposed project include the following areas: disruption of land usage, requirements for electric power, hear dissipation, and disposal of sanitary wastes.

The total disturbed area at the site is less than one acre, due to installation of the liquid nitrogen supply tanks and gaseous helium storage tanks and connecting lines.

The proposed project will require a peak of about 5.3 MW of power for a few seconds and a base of about 4.1 MW during operation. Annual consumption will amount to about $12,600,000 \mathrm{kWh}$. No additional power generating capacity will be required. Since the peak powcr to the projecl w11l be interruptible, the project will have no significant effect on power generating reserves in the area.

The amount of heat to be dissipated from the proposed project during the day is roughly equivalent to $1.3-M W$, steady-state load. 
The LCTF staff will be comprised of about 15 people. Thus the presence of this facility will have negligible effects on the sewage output from the Y-12 Plant, which has a working population of 6,100 .

6.2.2 Cumulative and Long-term Environmental Effects

The long-term environmental effects are expected to be limited to the minor disturbance of the land at the site.

6.3 KNOWN OR POTENTIAL CONFLICTS WITH STATE OR LOCAL PROGRAMS

No conflict with any state or local program is foreseen. 


\section{REFERENCES}

1. P. N. Haubenreich, W. C. Anderson, J. N. Luton, and P. B. Thompson, "Plan for the Large Coil Program, "ORNL/TM-5824, (February 1977).

2. P. B. Thompson, J. N. Luton, and P. N. Haubenreich, "Specifications for Superconducting Toroidal Field Coil for Large Coil Program," to be issued as ORNL/TM-6172.

3. J. R. Moore, "Methods of Testing 12 Tesla LCP Coils and Prototype TNG Coils in the Large Coil Test Facility," to be issued as ORNL/TM-6196.

4. P. S. Litherland, "Conceptual Design of the LC̣P Coid Support Structure," to be issued as ORNL/TM-619.5.

5. B. E. Nelson, P. B. Burn, and P. B. Thompson, "Evaluation of Pulse Coil Alternatives for the Large Coil Program," to be issued as ORINL/TM-6197. 
ORNL/TM-6032

UC-20, b

INTERNAL DISTRIBUTION

1. J. K. Ballou

2. W. Recraft

3. M. Bender

4. L. A. Berry

5. R. L. Brown

6. E. H. Bryant

7. P. B. Burn

8. J. D. Callen

9. D. D. Cannon

10. K. D. Cook

11. R. A. Dandl

12. L. Dresner

13. R. S. Edwards

14. W. A. Fietz

15. W. M. Fletcher

16. J. S. Goddard

17. H. H. Haselton

18. P. N. Haubenreich

19. R. E. Hill

20. R. M. Hill

21. G. Jasney

22. R. P. Jernigan

23. T. C. Jernigan

24. G. G. Kelley

25. J. P. Kois

26. C. G. Lawson

27. P. S. Litherland

28. M. S. Lube11

29. J. W. Lue

30. J. N. Luton

31-35. T. L. Mann

36. W. E. Manrod

37. J. B. Marsha11
38. J. R. May

39. H. C. McCurdy

40. J. R. McGuffey

41. 0. B. Morgan

42. J. R. Moore

43. D. R. Norris

44-48. L. W. Nelms

49. B. E. Nelson

50. M. Roberts

51. M. W. Rosenthal

52. T. L. Ryan

53. R. E. Schwall

54. J. L. Scott

55. T. E. Shannon

56. J. Sheffield

57. S. S. Shen

58. S. J. Sosnowski

59. R. E. Stamps

60. R. C. Stewart

61. D. Steiner

62. W. C. T. Stoddart

63-67. P: B. Thompson

68. P. L. Walstrom

69. R. S. Ware

70. J. L. Waters

71. E. R. Wells

72. ORNL Patent Office

73-74. Central Research Library

75. Y-12 Document Reference Section

76-78. Laboratory Records Department

79. Laboratory Records ORNL-RC

80. Fusion Energy Division Library 
EXTERNAL DISTRIBUTION

81. Donald S. Beard, DMFE, DOE, Washington D. C. 20545

82. R. W. Conn, Dept. of Nuclear Engineering, University of Wisconsin, Madison, WI 53706

83. J. File, Princeton Plasma Physics Laboratory, P. O. Box 451, Princeton, NJ 08540

84. Harold K. Forsen, Vice President, General Manager, Laser Enrichment Department, Exxon Nuclear Company, Inc., 777-106th Ave., NE, C-00777, Bellevue, WA 98009

85. Harold P. Furth, Co-Head Experimental Division, Plasma Physirs Laboratory, Princeton University, P. 0. Box 451, Princeton, NJ 08540

86. Roy W. Gould, California Institute of Technology, Mai.1. Stop 1.16-81, Pasadena, CA 91125

87. Robert L. Hirsch, Deputy Manager, Science and Technology Division, Exxon Corporation, 1251 Avenue of the Americas, New York NY 10020

88. Ray Huse, Chairman, EPRI Fusion Program Committee, Public Service Electric and Gas co., 80 Park Place, Newark, NJ 07101

89. Robert B. Jacobs, 1942 Broadway, Suite 207, Boulder, CO 80302

90. J. A. Lenhard, ORO, Oak Ridge, TN 37830

91. J. O. Neff, DMFE, DOE, Washington D. C. 20545

92. J. W. Nehls, DOE-ORO, Oak Ridge, TN 37830

93. David J. Rose, Department of Nuclear Engineering, Room 24-210, Massachusetts Institute of Technology, Cambridge, MA 02139

94. Suoan Waddlc, Ono, Oak Ridgé, TN 37830

95. Herbert H. Woodson, Chairman, Department of Electrical Engineer1ng, The University of Texas at Austin, Austin, TX 78712

96. J. L. Young, Westinghouse Electric Corporation, Research and Development C'enter, Churchill Boro, Pittsburgh, PA 15235

97. E. J. Ziurys, DMFE, DOE, Washington D. C. 20545

98. Research and Technical Support Division, DOE-ORO, Oak Ridge, TN 37830

99-249. Given distribution as shown in TID-4500, Controlled Thermonuclear Processes (Distribution Category UC-20,h) 